\title{
Development and Characterization for the Automated Surface Mount Assembly
}

Federal Manufacturing \& Technologies

S. S. Yerganian and

J. V. Grice

KCP-613-5781

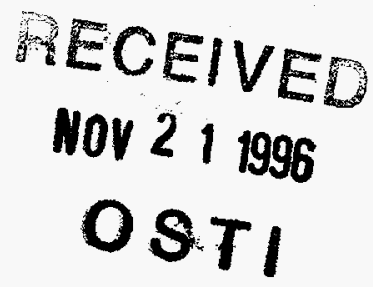

Published November 1996

Final Report

Approved for public release; distribution is unlimited.

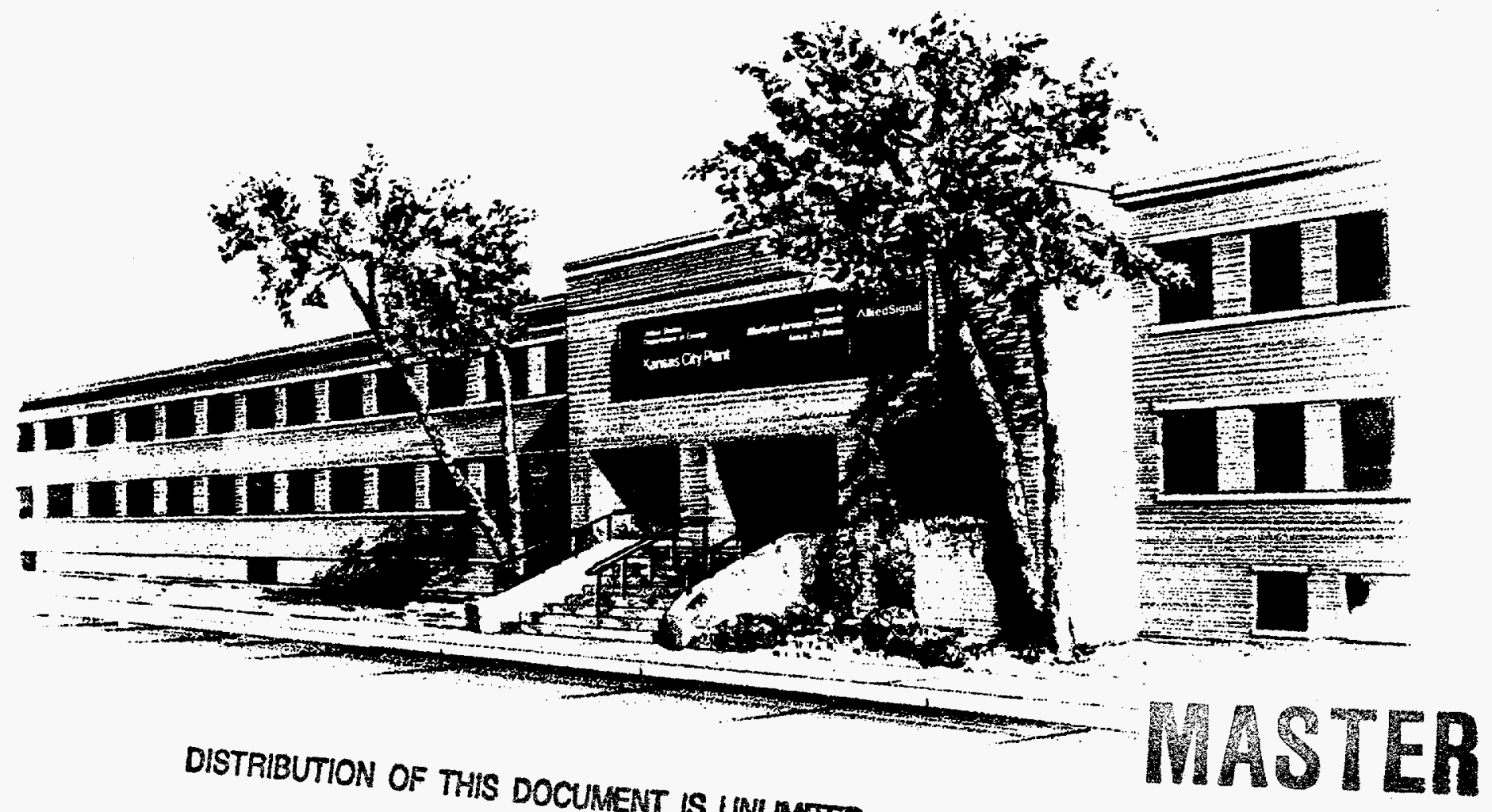

Prepared Under Contract Number DE-AC04-76-DP00613 for the United States Department of Energy

AlliedSignal

A E R O S P A C E 
KCP-613-5781

Distribution Category UC-706

Approved for public release; distribution is unlimited.

DEVELOPMENT AND CHARACTERIZATION

FOR THE AUTOMATED SURFACE MOUNT ASSEMBLY

S. S. Yerganian and

J. V. Grice

Published November 1996

Final Report 


\section{DISCLAIMER}

Portions of this document may be illegible in electronic image products. Images are produced from the best available original document. 


\section{Contents}

Section

Page

Abstract ............................................................................. 5

Summary ............................................................................ 5

Discussion .......................................................................... 7

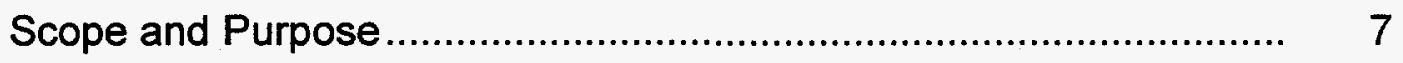

Activity ....................................................................... 7

Preparation for Methods of Measurement .......................... 7

Measurements of Accuracy and Repeatability Using Dial Indicator.

Work to Develop Improved Accuracy and Repeatability of Placement and Measurement of Results Using Precision Glass Gauge

Stress Analysis of Components Due to Centering Jaw Loading and Placement.

Accomplishments

Future Work

Reference

Appendices
A. Pick and Place Data Precision and Accuracy Analysis
59
B. Second Analysis
79
C. Drawings 



\section{Illustrations}

Figure

Page

1 Positional System .................................................................. 8

2 Chuck Assembly ........................................................................ 10

3 Pickup by Chuck ....................................................................... 11

4 Placement by Chuck.................................................................... 11

5 Coordinate System ................................................................... 12

6 Glass Slide .......................................................................... 15

7 Precision Blocks ........................................................................... 16

8 Chuck With Rubber Band on Spindle ............................................... 18

9 Chuck Against Dial Indicator ........................................................ 20

10 Layout for $x, y, z$ Positioning Experiment ....................................... 21

11 System Over Calibration Target .................................................... 23

12 System Over Calibration Target With Target on Monitor.................... 24

13 Changes to Chuck ................................................................... 27

14 Testing Jaw Rotating and Interfering With Non-Testing Jaws ............ 28

15 Alignment Tools ..................................................................... 29

16 New Versus Old Vacuum Tips.................................................... 30

17 3-Degree Angle Centering Jaws Versus Flat Centering Jaws on Alignment Tool...

18 Chuck With Shortened Versus Long Leaf Springs ........................... 31

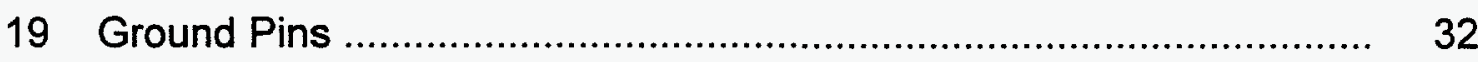


21 Jaws on Centering Tool............................................................ 35

22 Small Parts on Glass .............................................................. 39

235100 Size Parts on Glass ......................................................... 40

24 Small and Large Parts on Glass ............................................ 41

25 Compressive Stresses Contacting Solder, Compressive Stresses Yielding Solder, Buckling Load and Deflection, Bending Stresses Due to Eccentric Axial Loads.

26 Component Placed on Substrate, Shear and Moment From Component Placed on Substrate.

27 Free-Body Diagram of Chuck .................................................. 48

28 Magazine Go and No-Go Plugs.................................................... 52

\section{Table}

Number

Page

1 Measurements of the Placement Error 


\begin{abstract}
Development of the ability to automatically assemble surface mount devices on circuits is described, including the characterization of the assembly process and improvements made to the system to increase the accuracy and repeatability of this process. The accuracy and repeatability of the system were characterized by measurements of the individual system components as well as the actual placement of components on a specially designed gauge. The forces and stresses experienced by the components when handled by the system were analyzed. The ability to deliver surface mount components to the system was developed by the design and development of stick magazines, vibratory feeders, a feeder control system, and an automatic stick magazine loader.
\end{abstract}

\title{
Summary
}

The ability of the machine to accurately and repeatedly place components on an electrical circuit was investigated. The accuracy of the machine was defined as its ability to place a component on a desired spot and in the desired orientation specified to it by a computer program. The repeatability of the machine was defined as its ability to place a component in the same location and orientation regardless of whether or not the location is the desired spot specified by the program. The factors affecting repeatability and accuracy were characterized and modifications were made to the system where possible to improve the machine accuracy and repeatability. These modifications included the development of a tool to align the centering jaws, design changes of the chuck assembly and centering jaws, change in the speed with which the machine goes through the homing routine, a change in the mounting system for the vision camera, and the development of a system using a fixed vision target to calibrate the vision camera. Three methods of measurement were used for designing experiments used to characterize the system. These experiments made use of a dial indicator, placing components on a precision pattern photo etched on glass, and the fixed target developed to calibrate the vision system. Based on these experiments, significant variations in the positional repeatability of the machine were found to be caused by the homing routine and whether or not the system had a sufficient warm-up period. The effects of changing the homing speed of the system were found to be insignificant. A half-hour warm-up period was found to be sufficient to eliminate errors due to warm-up. In practical use, the system will have a half-hour minimum warm-up. During the running of a placement program, any errors in the repeatability of the homing routine are compensated for by the vision system and do not affect the accuracy or repeatability of the component placements. Errors in the placement accuracy and repeatability due to errors in homing may occur if the system runs through the homing routine during the assembly of the circuit. This occurs whenever the system is unable to pick up a component after three attempts or if the head crashes. If the added inaccuracy and unrepeatability due to homing is unacceptable, the program may need to be started again at the beginning to perform the vision correction and then returned to the previous step in the program. A replacement of the through beam sensor with a more precise sensor or sensing method could be used to eliminate any error due to homing. Without homing error, the positional repeatability of the system over 
its entire table area was determined to be plus or minus $0.0008^{\prime \prime}$ in the $x$ direction and 0.0009 " in the $y$ direction. With homing error, the repeatability was found to be plus or minus $0.0015^{\prime \prime}$ in the $x$ direction and $0.0016^{\prime \prime}$ in the $y$ direction. The accuracy of the system without homing error was found to be plus or minus $0.0038^{\prime \prime}$ in the $x$ direction and $0.0035^{\prime \prime}$ in the y direction. With homing error included, the accuracy was found to be plus or minus $0.0045^{\prime \prime}$ in the $x$ direction and $0.0059^{\prime \prime}$ in the $y$ direction.

The ability to feed high-reliability components to the pick and place system was developed. This included the characterization and development of vibratory feeding with the ability to automatically load the components into the stick magazine carriers used to feed them. A study was also conducted to determine the amount of wear experienced by component solder terminations due to vibratory feeding, and a control system was developed to turn off the vibration of the feeders except for the few seconds needed to feed each part into position. As part of the characterization of the centering jaws, the forces applied to the component during centering and placement were investigated and a stress analysis was performed using classical strength of materials. The analysis proved that the component stresses, due to handling by the machine, were low. 


\section{Discussion}

\section{Scope and Purpose}

This purpose of this project was to develop and characterize the ability to automatically assemble surface mount components onto either printed wiring boards or hybrid microcircuits. The project focused on the automation of this process from the handling of the components received to the assembly area in bulk to the placement of these components onto the assembly. An analysis was performed to determine the stresses created within the components due to the handling of the assembly system and the wear experienced by the components due to the automated handing.

\section{Activity}

\section{Preparation for Methods of Measurement}

Three methods of measurement were used for designing experiments used to characterize the system. These experiments made use of a dial indicator, placing components on a precision pattern photo etched on glass, and a fixed target developed to calibrate the vision system. The factors investigated which contribute to the repeatability and accuracy of the machine and the method used to characterize them were as follows.

\section{Factors Affecting Repeatability}

- Repeatability of the $x, y, z$ positional system (dial indicator)

- Repeatability of homing (dial indicator)

- Repeatability of component centering (placement on precision glass)

\section{Factors Affecting Accuracy}

- Accuracy of the $x, y, z$ positional system (placement on precision glass)

- Accuracy of component centering (placement on precision glass)

- Rotational accuracy (dial indicator)

- Perpendicularity of spindle (dial indicator)

- Accuracy of vision system (placement on precision glass)

\section{Positional System}

The positional system is a four-degree-of-freedom, closed-loop system using lead screws and stepper motors. The four degrees of freedom are along three orthogonal axes with one rotational degree of freedom about the vertical axis (see Figure 1). To characterize the system, designed experiments were run using a dial indicator. The manufacturer's specification claims the positional repeatability of the machine to be plus or minus 0.001 " and the positional accuracy to be plus or minus $0.002 "$. The machine bases all distances from the "home" 


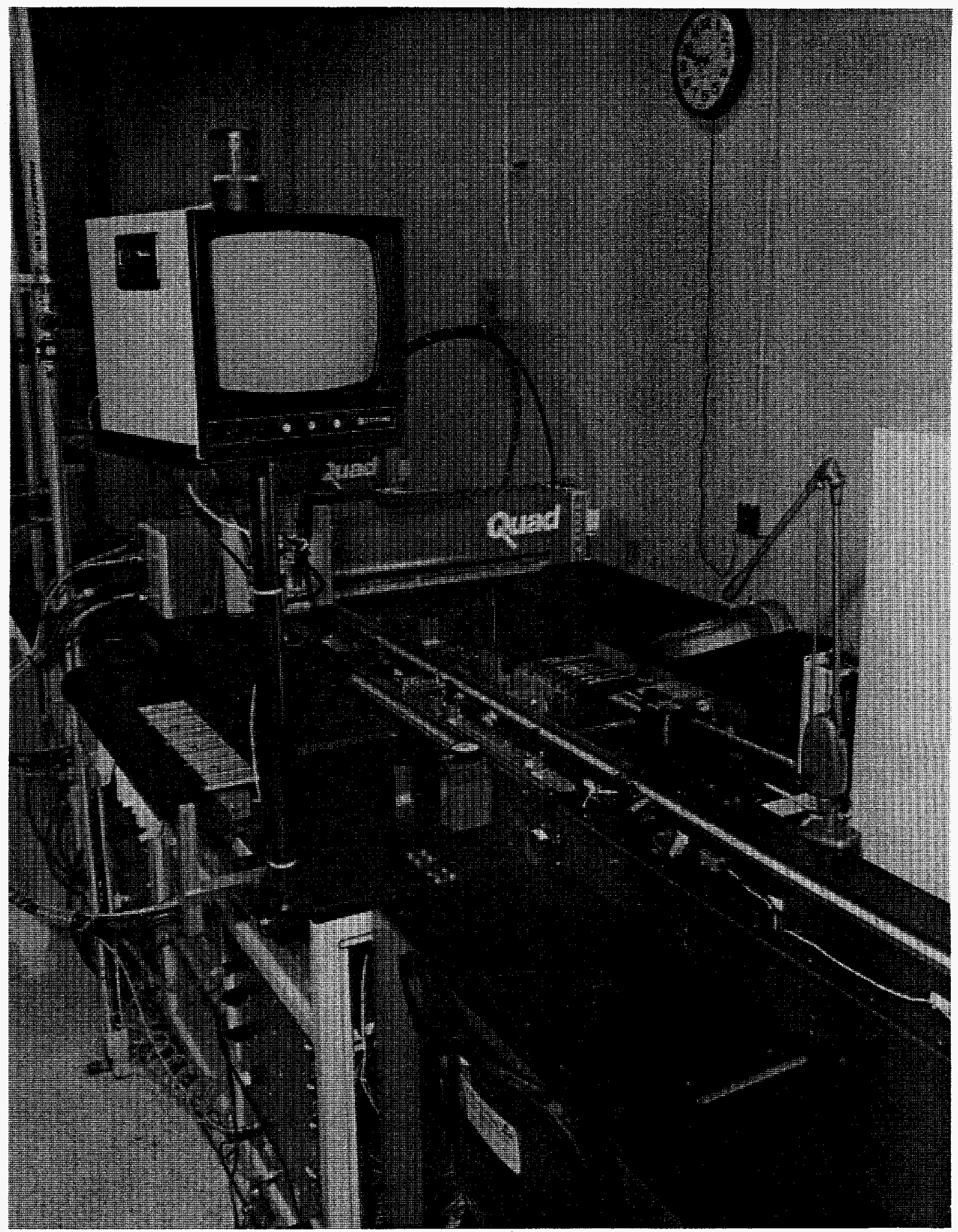

Figure 1. Positional System 
position. The home position is established when either the power to the machine is turned on, the reset button is pressed, or the home button on the hand-held controller is pressed twice.

During the homing routine, the machine moves along one axis at a time until a through beam sensor on that axis or a through beam sensor for the rotation about the vertical axis is activated. This position is called the "hard home" for that axis by the manufacturer. The machine then moves out along the axis by a pre-set number of steps of the stepper motor so that the sensor will no longer be activated. This position, called "soft home" by the manufacturer, serves as the home location established as the zero for that axis. The machine moves the head into the placement position by driving the stepper motor a certain number of steps along each axis pertaining to the distance it was programmed to move. As the head reaches this position, the feedback control system drives the head forward or backward to compensate for errors of the stepper motors. The feedback system measures the distance traveled from the home position by using a sensor to count the number of marks etched linearly along a piece of glass. The parameters characterized relating to the repeatability of the positional system were the repeatability of the head movement in the $x, y$, and $z$ directions and the ability of the machine to find a repeatable home position. A parameter characterized relating to the accuracy of the positional system was the perpendicularity of the spindle. Another parameter characterized relating to the accuracy of the positional system and the chuck was the rotational trueness of the spindle with the chuck attached.

\section{Chuck Assemblies}

The vacuum chucks used on the machine consist of the chuck body, vacuum nozzle, and centering jaws as shown in Figure 2. Some chuck assemblies include centering jaws used for electrical verification testing of the component. The vacuum chuck body is held on the outside diameter of the spindle shaft by a 3/8" inside diameter bronze bushing which has been press fit inside the top of the chuck body. This bronze bushing forms a slip fit with the spindle shaft. A spring-loaded polymer bushing mounted on the spindle shaft seats against the top face of the bronze bushing, forming a vacuum seal. A stainless steel nozzle assembly is threaded into a tapped hole at the bottom of the aluminum chuck body. A vacuum tip made of white delrin is pressed into the nozzle assembly for the chucks used for small components. The component is picked up by vacuum and held on the end of the delrin tip. As the spindle and vacuum chuck are lowered to pick up a component, the centering jaws open and rise up away from the vacuum tip. As the spindle and vacuum chuck are raised, the centering jaws are lowered and begin to close on the component on all four sides, centering it on the vacuum tip.

The centering mechanism consists of four aluminum levers named "fingers" by the manufacturer which attach to a stainless steel bracket named by the manufacturer as the "knuckle." The knuckle is machined to provide four clevis-type joints for the fingers to rotate within. The fingers contain small rollers which contact the two flat plates attached to the linear ball slides on the head assembly. As the spindle and chuck are lowered to pick up a 


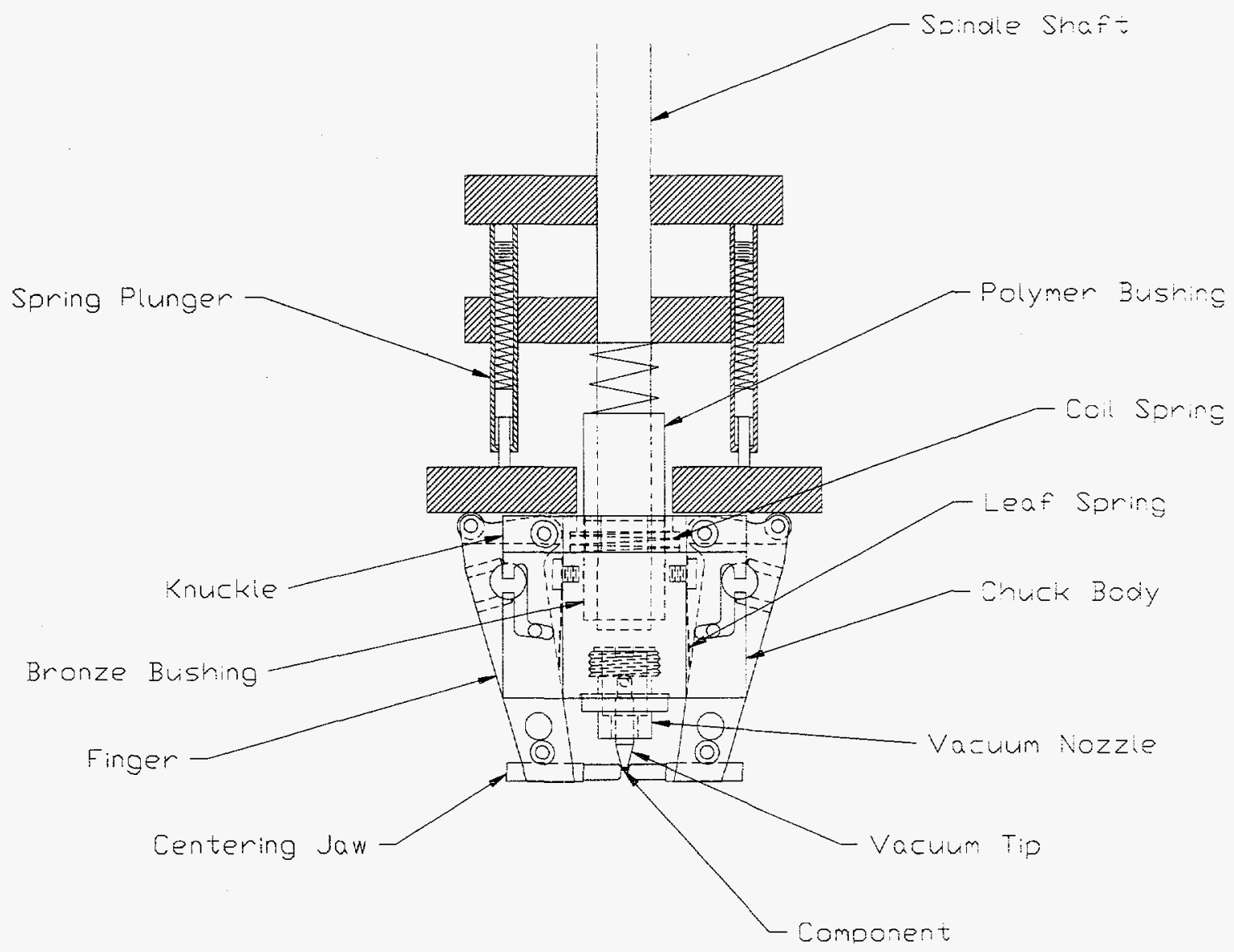

Figure 2. Chuck Assembly

component, the compression in the spring plungers which push against the flat plate is released. This relaxes the force on the rollers that close the centering jaws. As the clamping force on the jaws is released, the leaf springs begin to push the jaws open, and the coil spring between the chuck body and knuckle raises the fingers and centering jaws up and out of the way of the vacuum tip. This process is reversed when the chuck is raised after the component has been picked up by the vacuum. As the spindle and chuck move upward, the centering jaws force in the plungers close the jaws by overriding the weaker coil spring and leaf springs (see Figure 3). As the component is placed on the circuit, the lowering of the chuck again opens and raises the centering jaws away from the component (see Figure 4). 

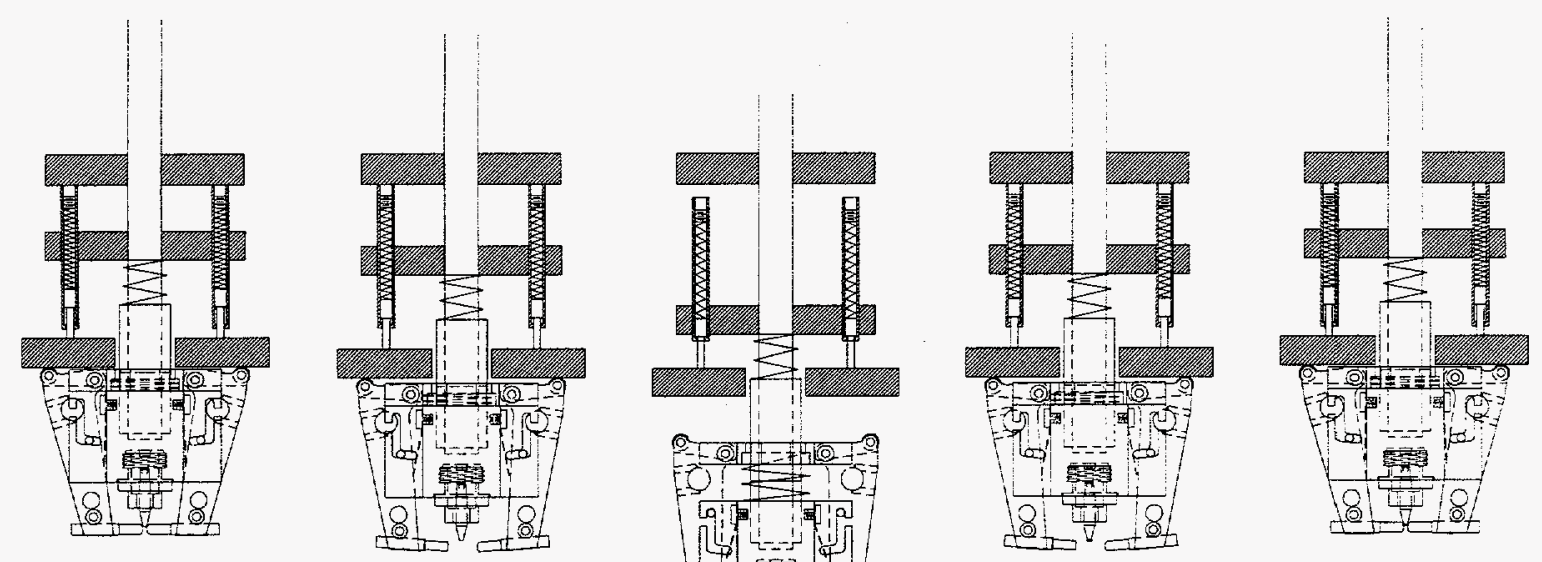

Figure 3. Pickup by Chuck
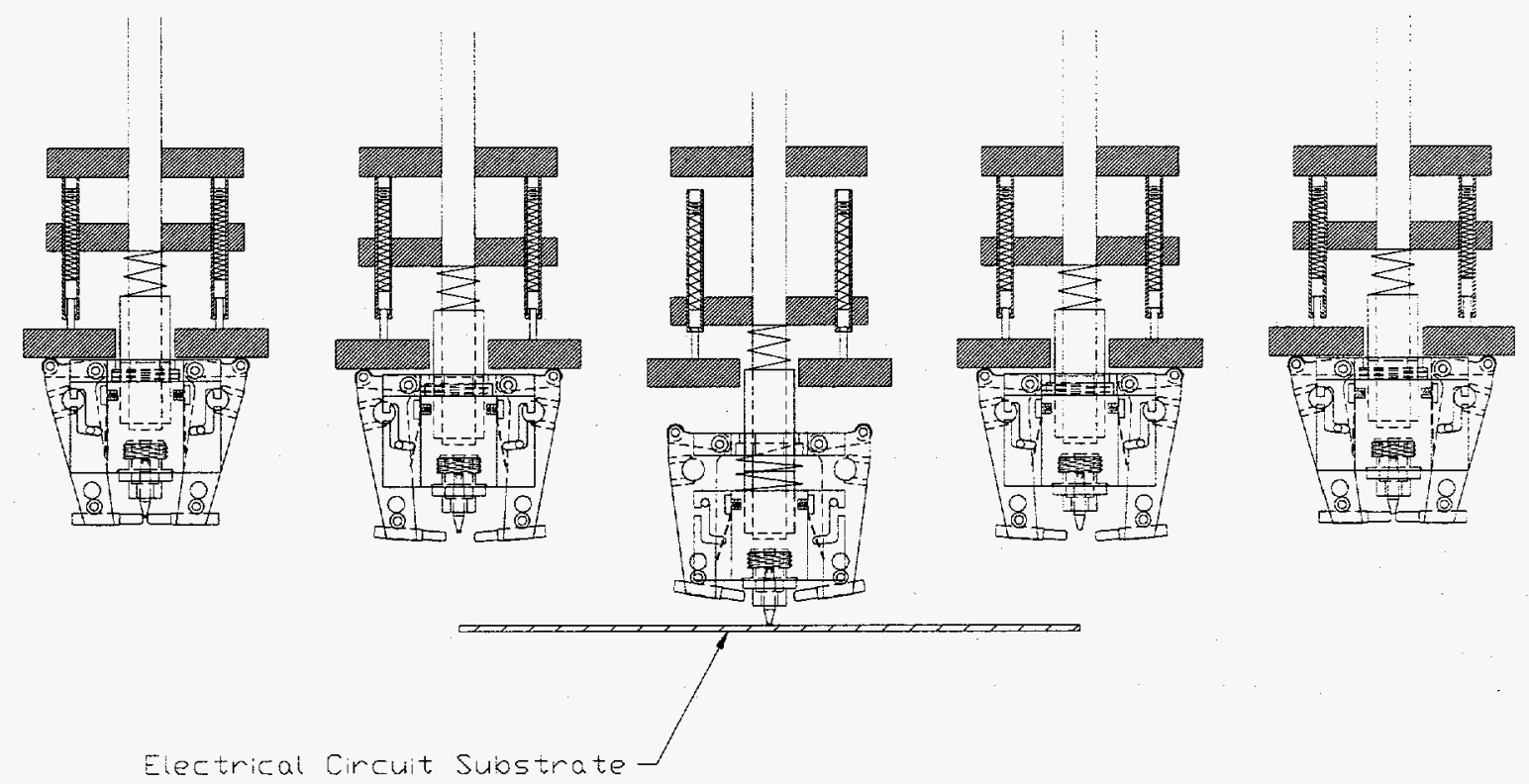

Figure 4. Placement by Chuck 


\section{Coordinate System and Development of Placement Program}

The coordinate system of the machine is shown in Figure 5. Positions on the machine used for the placement program may be "taught" by moving the vacuum nozzle over the position using the hand-held controller and entering that position into the placement program. This method is used to teach the pickup positions for the components to be placed by the machine and may be used to teach the placement positions. This method is very time consuming for a densely populated circuit and is limited in accuracy by the ability of the one doing the teaching. A faster and more accurate method generates the placement program using the $x$ and $y$ coordinates from the computer-aided design (CAD) data of the circuit design. In order to incorporate the CAD coordinate data into the placement program, the $x$ and $y$ axes may need to be switched, and the positive or negative sign of some data values may need to be reversed. The values for the coordinates of the center of each component placement position generated from the CAD data may be referenced from any arbitrary origin. Usually, to save the need to alter the coordinates, the same origin used for the CAD data is used in the machine program. To tie the coordinate data of the circuit together with the machine positional system, the offset distance between the origin chosen for the circuit and the home position of the machine needs to be determined. The offset from machine home needs to be found for the circuit in the position it occupies during assembly and is entered into the placement program. The placement program automatically adds this offset together with the CAD data coordinates and generates the actual machine data used to drive the positional system for each placement position.

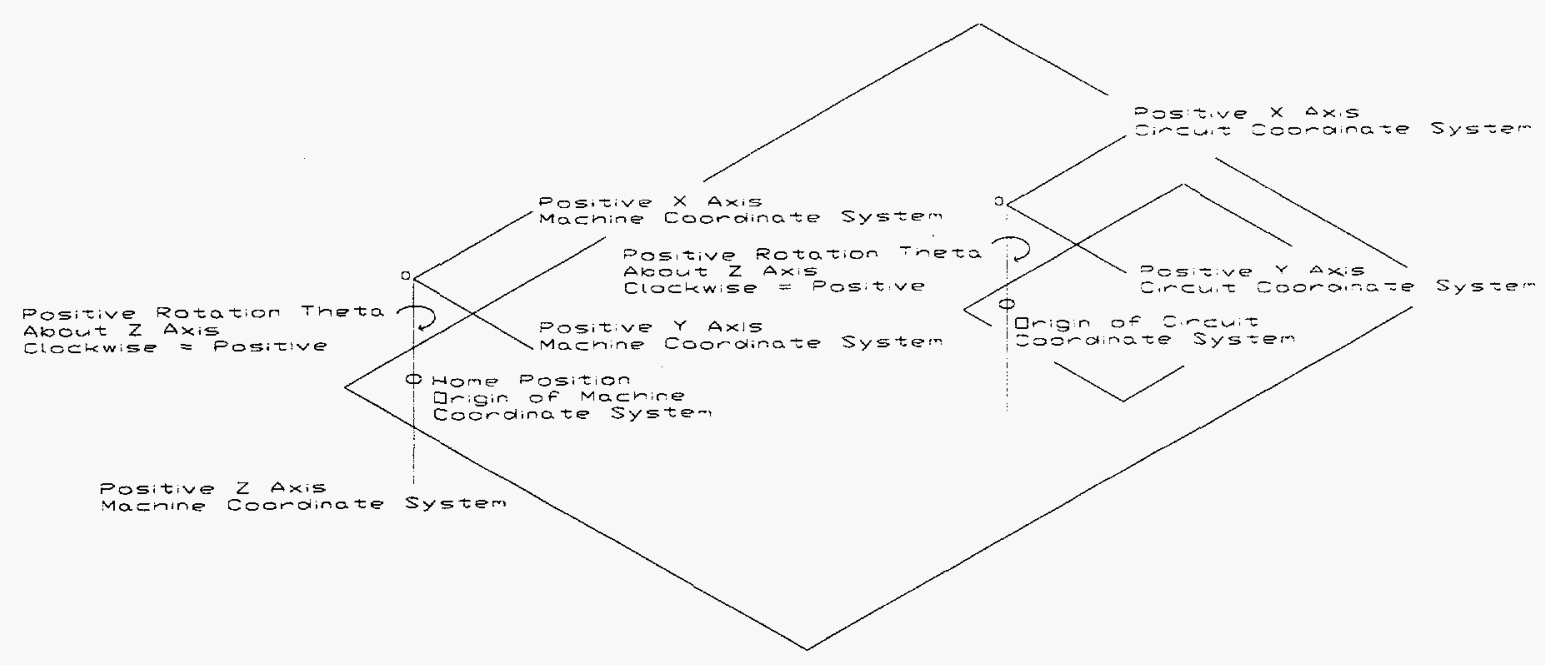

Figure 5. Coordinate System

\section{Vision System and Calibration Target}

The vision system corrects for errors in the repeatability in the positioning of the circuit for assembly. It will also correct for errors perceived in the positioning of the circuit due to errors in the repeatability of the homing sequence. It uses a video camera to determine the actual location and rotational orientation of the circuit by finding two fiducial marks on the circuit before assembly and compensates for the errors by altering the placement coordinates. The 
vision system may also allow for easier development of the placement program by not requiring the offset from machine home to be exact and allowing positions on the machine to be programmed using the camera. The camera is offset from the center of the spindle and chuck assembly. The value for the camera offset is stored in a configuration file on the hard disk of the personal computer which controls the system. Since the head of the machine is driven by $x$ and $y$ distances from the machine home to the center of the spindle, the fiducial coordinates are recognized by the machine as the spindle positions which cause the center of the camera to be positioned over the center of a fiducial mark. At the beginning of the program, the machine moves to each fiducial coordinate and finds the actual location of each fiducial mark within the field of view of the camera. The correction in the position and angular rotation of the placement coordinates is calculated based on the distances found between the camera center and actual fiducial locations. As with the placement positions, the fiducial mark coordinates may be taught using the hand-held control or entered from the CAD data of the circuit design. The threshold value for the imaging system, size of fiducial, and size of search area still need to be taught using the hand-held control for each fiducial mark regardless of whether the position of the mark is defined with CAD data or taught using the hand-held control. Although the actual use of the vision system at the beginning of the placement program is the same, the method by which the vision coordinates are programmed determines the factors which affect the placement accuracy. The factors relating to placement accuracy due to the method used for programming the fiducial coordinates are discussed below:

- Fiducials Entered From CAD Data - Fiducial coordinates entered into the program from CAD data are referenced from the circuit origin. Since the location of the circuit origin is defined by the offset from machine home, the system derives the fiducial coordinates used for the positioning system by adding the CAD fiducial coordinates to the value of the offset from machine home and then compensating for the camera offset by subtracting the distance between the camera and spindle. The vision system will compensate for an error in the value of the offset from machine home since it is related to the fiducial mark locations by the CAD data. When CAD data is used to define the fiducial marks, the offset from machine home need only be defined accurately enough to create fiducial coordinates that will position the field of view of the camera over the fiducial marks. As long as the system is able to determine the actual fiducial mark locations, it will correct the placement program to compensate for the total error between the actual fiducial positions and the fiducial coordinates that were defined mathematically regardless of whether the error is caused by a movement of the circuit or errors in the offset from machine home value. When the fiducial coordinates are programmed from CAD data, the value for the camera offset needs to be as accurate as possible. An error in this value will cause a separate error in the fiducial coordinates positioning the camera incorrectly over the fiducial marks by an amount unrelated to the location of the circuit origin. This creates an error in the vision system correction of the placement program.

- Fiducials Taught Using Hand-Held Control - When the hand-held control is used to teach the fiducial coordinates, the fiducial coordinates are established by the spindle positions taught and are not defined relative to the circuit. The system only corrects the placement program to compensate for the difference between the actual fiducial locations and the fiducial locations taught. Without mathematically defined fiducial coordinates based on the circuit origin, the system has no reference other than the fiducial locations 
taught, and will not compensate for placement inaccuracies due to errors during the program development. This requires that at the time the fiducial marks are taught, the rotational orientation of the circuit be as true with the machine axes as possible and the value for the offset from machine home be known as well as possible. Since the fiducial coordinates are not defined mathematically when taught using the hand-held control, the accuracy of the value for the camera offset has no effect on the vision system.

The vision system has an operating mode for teaching coordinate positions (such as pickup or placement locations) by using the crosshairs of the video camera. As long as the offset value from camera to spindle is accurate, the system compensates for this offset and calculates the positional system coordinates to the location taught. The system displays the coordinates on the hand-held terminal and the personal computer screen when the enter button on the handheld terminal is pressed.

\section{Precision Glass Placement Accuracy Gauge and Precision Blocks}

The precision glass gauge used to measure the accuracy and repeatability of placement of the machine was the Surface Mount Component Placement Accuracy Gauge (United States patent number $4,776,088$ ) as shown in Figure 6 . It provides a convenient method for directly measuring the actual placement accuracy and repeatability of the placement machine by its placement of components within the gridlines on the gauge. The gauge contains fiducial marks and a grid system for checking the accuracy and repeatability of placements requiring no rotation of the component or rotations of an angle which is a multiple of 90 degrees and a circular grid area for checking placements rotated at angles other than a multiple of 90 degrees. Precision steel blocks cut from a stainless steel sheet with a wire EDM machine were developed to be placed on the gauge to eliminate placement errors due to the shape and size of the components. The blocks were made to fit within the gridlines of the gauge and were as shown in Figure 7. The glass gauge and steel blocks were used to evaluate the actual placement accuracy of the machine with the vision system using all improvements developed for the machine.

\section{Measurements of Accuracy and Repeatability Using Dial Indicator}

\section{Setup of Dial Indicator for Accuracy and Repeatability Measurements}

The indicator was rigidly mounted on the machine. Most measurements were made with the cylindrical shape of the centering jaw alignment tool or spindle contacting the flat tip used on the stem of the indicator. For the measurements of the rotation angle of the chuck assembly at zero rotation, the spherical tip was used on the stem of the indicator to contact the flat surface of the chuck assembly. The use of the line contact of a cylindrical surface or the point contact of a spherical surface with a flat surface prevented errors of movement of one axis from influencing the other. A placement position was taught using the hand-held control to cause the machine surface to be measured to come in contact with the dial indicator. The placement position was taught and the dial was zeroed after moving the head forward to drive the indicator inward one full revolution of the dial $(0.008 ")$. This allowed the indicator to detect changes along both its positive and negative directions. To check that the indicator axis was 


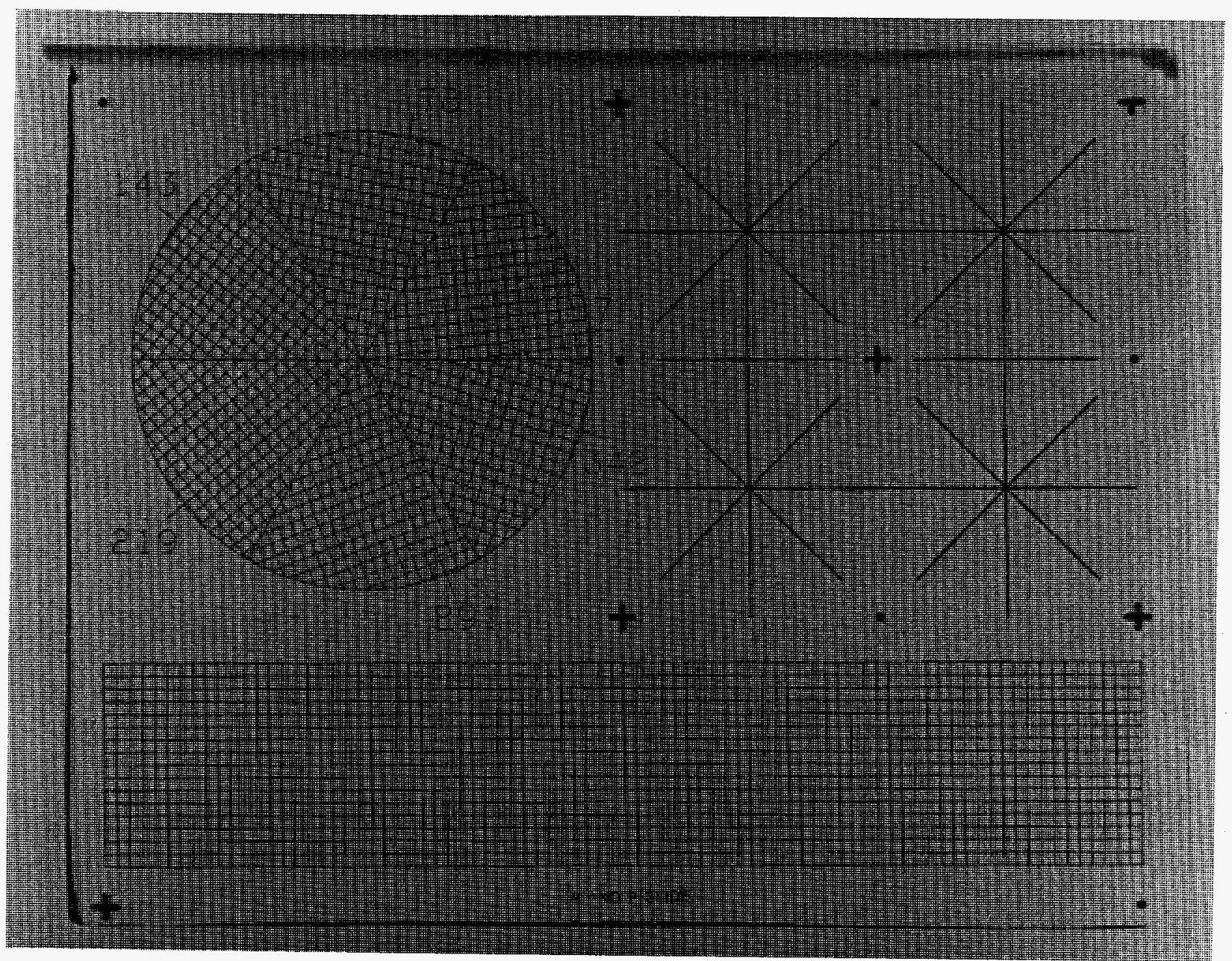

Figure 6. Glass Slide

parallel to the machine axis being measured, the head was moved laterally with respect to the measured axis. If a lateral movement in both directions of about 0.004 " or $0.005^{\prime \prime}$ resulted in a change in the dial position of less than $0.0001 "$ ", the indicator axis was considered parallel with the machine axis.

\section{Measurement of Centering Jaw Alignment Tool}

In order to measure the rotational trueness of the spindle and chuck combination with a dial indicator, the centering jaw alignment tool was used. It was measured in order to determine how much error it would contribute to the rotational trueness measurements and how accurately it would serve as a tool for aligning the centering jaws. The measurements proved it would serve as a good measurement aid and centering tool, since the $0.350^{\prime \prime}$ diameter of the second step of the alignment tool used for the rotational trueness measurements and the center pin used for aligning the centering jaws lie along the same centerline within 0.0002 " or $0.0003^{\prime \prime}$. The centering pin of the tool was found to be within $0.0002 "$ of the center line of the second step of the alignment tool in the testing jaw direction and within $0.0003^{\prime \prime}$ in the non- testing jaw direction by measurements under a Zeiss measuring microscope in the precision 


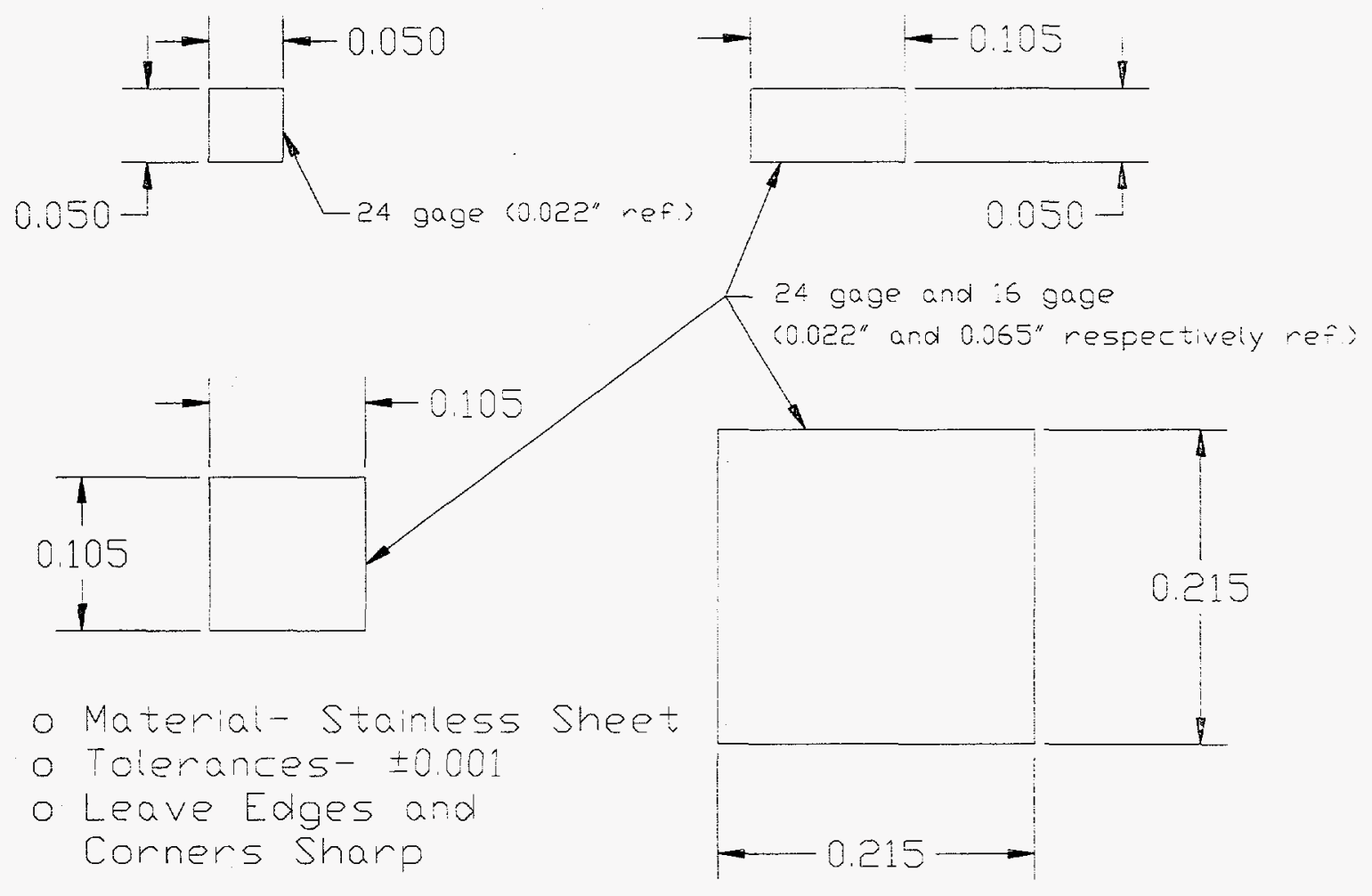

Figure 7. Precision Blocks

measurement department. The second steps of the alignment tool and the centering pin were found to be extremely straight and perpendicular to each other with no noticeable variation found between their edges and the etched lines of the measuring microscope.

\section{Rotational Trueness of Spindle With Chuck}

To characterize how well the chuck and vacuum nozzle lie along the axis of rotation of the spindle, measurements with the dial indicator were made as the spindle and chuck assembly were rotated. The centering jaw alignment tool was used in place of the nozzle for the dial indicator measurements. The precision of the centering jaw alignment tool was established by the measurements made on the Zeiss optic measuring microscope. The centering tool was threaded into the first head chuck used for the smallest components in place of the vacuum nozzle, and the second step of the tool was brought against the indicator which was mounted on the machine. The flat tip was used on the stem of the indicator. To allow the indicator to detect changes along both its positive and negative directions, the position was taught with the centering tool rotating the needle one revolution of the dial $(0.008$ ") and the indicator was zeroed at a head rotation of zero degrees. The head was then rotated from zero degrees to 360 degrees with indicator readings taken at angles in 45-degree increments. These readings are shown in the data below. Care was taken when making these measurements to keep the 
blue plastic cover which encloses the head assembly from contacting and moving the top of the $z$ axis lead screw. Before securing the cover so that it could not contact the lead screw, variations as large as $0.0105^{\prime \prime}$ were noticed as an inconsistency in indicator measurements. The cover was secured to prevent this from causing errors in placement during machine operation.

\begin{tabular}{|c|c|}
\hline $\begin{array}{c}\text { Rotation Angle } \\
\text { (degrees) }\end{array}$ & $\begin{array}{c}\text { Measurement } \\
\text { (thousandths inch) }\end{array}$ \\
\hline 0 & zeroed \\
\hline 45 & +0.7 \\
\hline 90 & +0.4 \\
\hline 135 & -0.4 \\
\hline 180 & -0.8 \\
\hline 225 & -1.4 \\
\hline 270 & -0.5 \\
\hline 315 & +0.5 \\
\hline 0 & +0.0 (back to \\
zero)
\end{tabular}

\section{Perpendicularity of Spindle}

If the spindle is truly perpendicular, only inaccuracies caused by the $x$ and $y$ positioning system and the chuck assembly will occur during placement with no additional errors as the spindle moves the placement head downward to place a component on the circuit. If the spindle is not truly perpendicular to the $x$ and $y$ plane of the machine, movements of the spindle along the vertical $z$ axis will cause movements along the $x$ and $y$ axes. To measure the perpendicularity of the spindle through its movement along the vertical axis, the dial indicator was mounted on the machine. The bushing and spring that operate on the spindle were pushed up out of the way and held by wrapping a rubber band around the spindle (see Figure 8 ). The rubber band was placed as far up the spindle as possible. This gave a length of about $0.620^{\prime \prime}$ along the spindle for measurements. A flat tip was used on the stem of the indicator for contacting the spindle. A placement position was taught by bringing the top area of the spindle (just under the rubber band) against the indicator tip and then moving the head forward to rotate the indicator needle one full revolution. The indicator was zeroed and the head was rotated 360 degrees in 45-degree increments. At each angle, the indicator was zeroed toward the top of the spindle and then the head was moved up such that the reading could be taken at the bottom of the spindle. This reading represents the difference used as an indication of how perpendicular the spindle is in its movement. The results of this test showed the spindle to run along a very true $z$ axis within about $0.0004 "$ and are as shown below. 


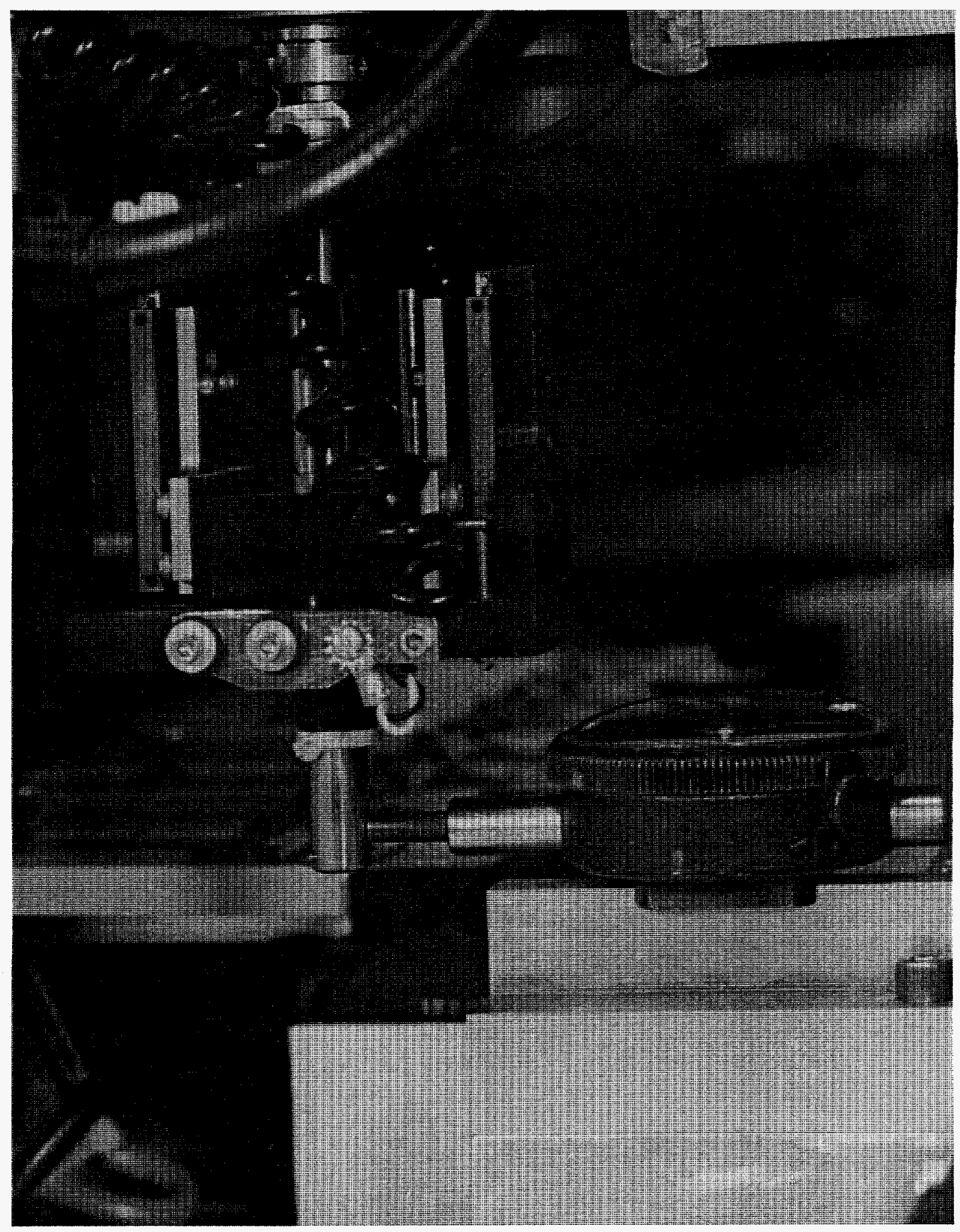

Figure 8. Chuck With Rubber Band on Spindle 


\begin{tabular}{|c|c|}
\hline $\begin{array}{c}\text { Rotation Angle } \\
\text { (degrees) }\end{array}$ & $\begin{array}{c}\text { Total Variation Along } \\
\text { Full Travel of Spindle } \\
\text { (thousandths inch) }\end{array}$ \\
\hline 0 & +0.4 \\
\hline 45 & +0.1 \\
\hline 90 & -0.3 \\
\hline 135 & -0.2 \\
\hline 180 & -0.2 \\
\hline 225 & -0.2 \\
\hline 270 & -0.1 \\
\hline 315 & -0.2 \\
\hline
\end{tabular}

\section{Repeatability of Head Movement in x, y, z}

To determine how repeatably the system could return to a taught position, data was collected in the $x$ and $y$ directions with a dial indicator in five locations on the machine. The machine was not reset during these measurements (eliminating homing error). The locations corresponded to the center and four corners of the square table top area. Ten measurements were made in both the $x$ and $y$ directions at each location. Two measurements were made in the $z$ direction at the center location. These measurements determined the repeatability of the positional system excluding any errors due to the variability in the machine home position. The measurements in the $\mathrm{z}$ direction were more difficult to make due to the manner in which the machine is programmed. The two measurements of the $z$ repeatability were made by measuring how far a vacuum tip was pressed into the nozzle assembly before and after the two placements. These measurements showed a $z$ position variation of about 0.002 inch. The accuracy and repeatability needed by the machine for movement in the $z$ direction is much less than the other two directions. The actual $z$ depth used for placing the components includes an additional 0.020 -inch overdrive. The nozzle assembly is compliant and free to float upwards as necessary. The positions for $x$ and $y$ measurements were taught using a chuck containing the centering alignment tool. A flat tip was used on the stem of the indicator to come in contact with the cylindrical shape of the alignment tool, preventing errors of movement of one axis from influencing the other. The placement position was taught by bringing the alignment tool in contact with the tip and then moving the head forward to drive the indicator inward one full revolution of the dial ( $0.008 ")$. To check that the indicator axis was parallel with the machine axis being measured, the head was moved laterally with respect to the measured axis. If a lateral movement in both directions of about 0.004 " or 0.005 " resulted in a change in the dial position of less than $0.0001 "$ ", the indicator axis was considered parallel with the machine axis. The indicator was then zeroed and measurements taken as shown in Figure 9. The layout of the dial indicator positions of the machine for this experiment was as shown in Figure 10. 


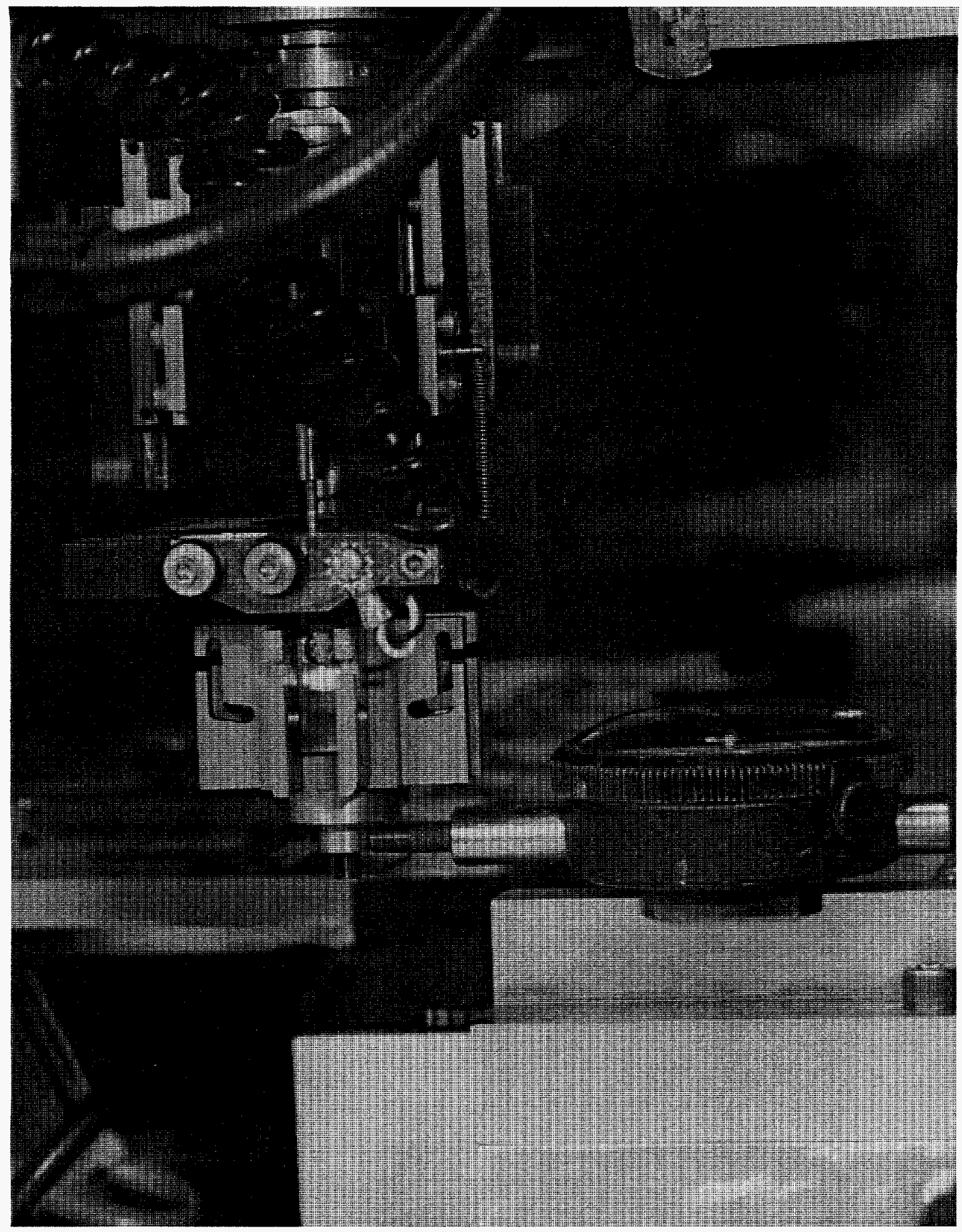

Figure 9. Chuck Against Dial Indicator 


\section{$\mathrm{X}$ - DIRECTION}

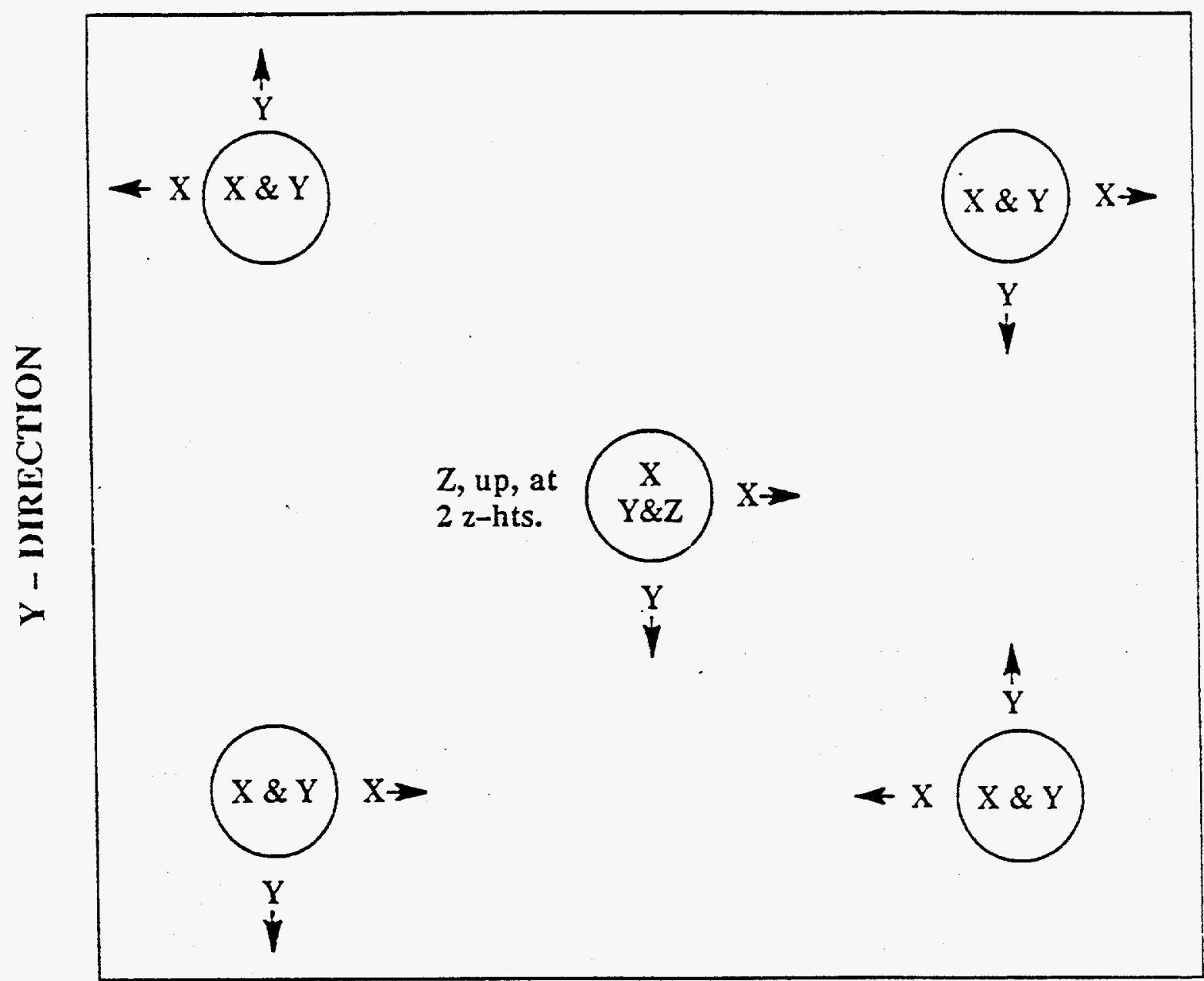

Figure 10. Layout for $x, y, z$ Positioning Experiment

The results of the $x$ and $y$ measurements were a standard deviation in the $x$ direction for the machine over its entire table area of 0.0003935 inch. The y direction standard deviation over the entire table area was 0.000427 inch. The "Two Sigma" variation was used to estimate the practical repeatability of the machine. Based on this method, the machine positional repeatability was found to be plus or minus 0.0008 inch in the $x$ direction and plus or minus 0.0009 inch in the $y$ direction. An explanation of the tests and all of the data are in the appendices.

\section{Total Repeatability of the $x, y, z$ Positional System Including Homing Error}

The ability of the machine to find the same home position is important to its repeatability since all distances (including the measurements of the feedback system) are based on the home position. If the system is reset during the running of its program, it goes through its homing routine and additional errors are created based on how repeatably it is able to find the same home position. To characterize the effect of the repeatability of the home position on the 
placement repeatability, data was collected in the $x$ and $y$ directions with a dial indicator in two locations on the machine. Three sets of data were collected over a three-day period and included variations due to the warm-up time of the system and variations due to the programmable speed with which the system goes through its homing routine. For each set of data, the machine was reset seven times, and two measurements were made each time the machine was reset. The speed at which the machine moves into the home position was found by the manufacturer to influence its repeatability, and the manufacturer suggested changing the values of the programmable numbers which influence this speed. After changing the speed of homing as suggested by the manufacturer, the same measurements as before were made.

Based on these experiments, significant variations in the positional repeatability of the machine were found to be caused by resetting the system and whether or not the system had a sufficient warm-up period. The effects of changing the homing speed of the system were found to be insignificant.

A half-hour warm-up period was found to be sufficient to eliminate errors due to warm-up. In practical use, the system will have a half-hour minimum warm-up and will be reset during the running of an assembly program.

Based on the data collected, the $x$ and $y$ standard deviations were found to be 0.000763 and 0.000806 inch, respectively. By using the "Two Sigma" estimation of machine variability, the practical machine positional repeatability with a half-hour warm-up period and including errors due to homing was estimated to be plus or minus 0.0015 inch in the $x$ direction and plus or minus 0.0016 inch in the $y$ direction. An explanation of the tests and all of the data are in the appendices.

\section{Work to Develop Improved Accuracy and Repeatability of Placement and Measurement of Results Using Precision Glass Gauge}

\section{Improvements to Vision System and Use of Calibration Target}

The repeatability of the vision system is dependent on the consistency of the camera-to-spindle offset distance. If the camera or the video cable at the point of attachment to the camera is not rigidly mounted and moves with respect to the spindle, the system will determine the actual fiducial locations incorrectly and the placement accuracy will suffer. To eliminate errors in the repeatability of the vision system, a more rigid camera mount and calibration target were developed. The new camera mount uses a more rigid linear ball slide and mounting plate which include angled supports and a method for holding the video cable still with respect to the camera. The camera movement was reduced as far as possible with a limiting factor in the head assembly itself. The bottom plate in which the camera mount is attached flexes slightly if pulled on but does not flex by itself under the weight of the camera (making the camera mount fairly stable). The head assembly itself could not be made more rigid by any additional bracing without defeating the spring-loaded crash system which prevents damage to the head assembly upon running into an object. To prevent any errors due to camera movement over time, a target consisting of an aluminum plate with a 0.040 -inch fiducial mark was mounted to the fixed rail of the conveyor. This target provides a constant reference spot for calibrating the distance in which the vision camera is offset from the spindle (see Figures 11 and 12). The development of the calibration program for using the target was as follows. 


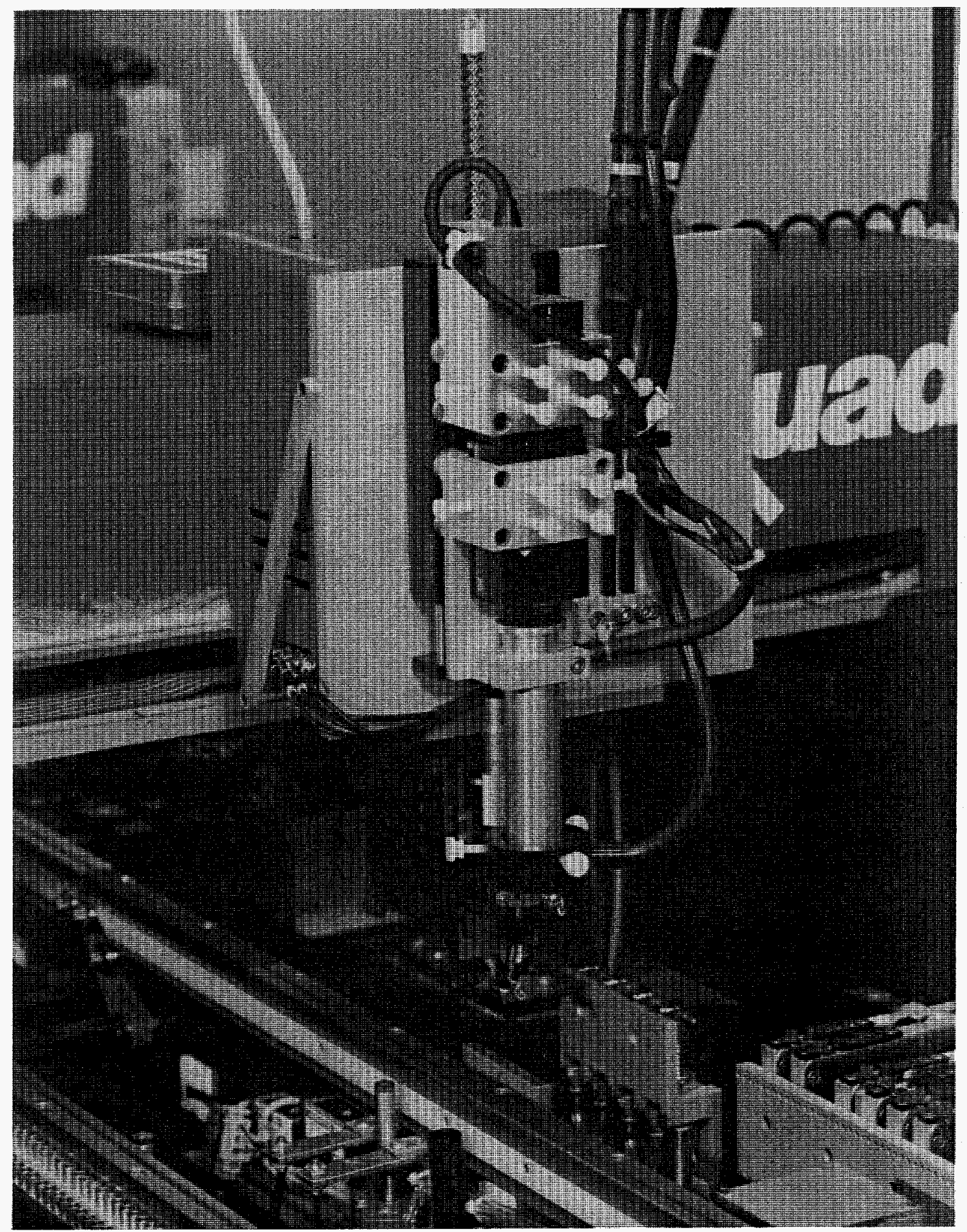

Figure 11. System Over Calibration Target 


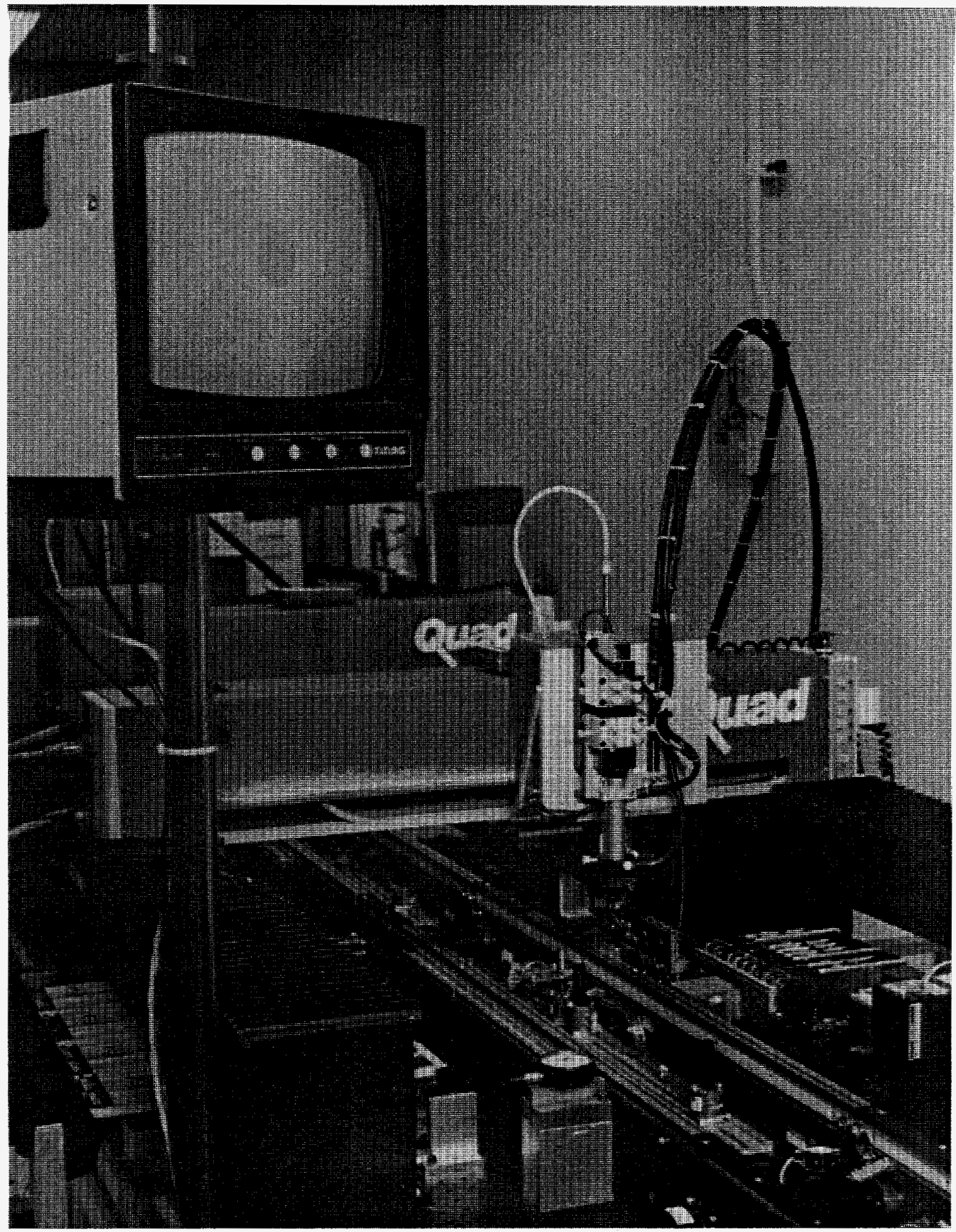

Figure 12. System Over Calibration Target With Target on Monitor 
- Development of Calibration Target Program for Vision System - The program was developed as a placement program with one fictitious pickup and placement. The home position was chosen as the offset from machine home coordinates by entering $x$ and $y$ coordinates of zero. The target was used as both fiducial marks of the program, and they were taught with the camera after accurately finding the camera-to-spindle offset value and using the vision teaching software of the system. As the placement program is run, it displays the $\mathrm{x}$ and $\mathrm{y}$ correction values for each fiducial mark on the personal computer screen and rounds fractions of a thousandth of an inch off to the nearest one thousandth. Since the fiducial marks are the fixed target, if the spindle-to-camera offset value is accurate, the corrections in the $\mathrm{x}$ and $\mathrm{y}$ directions for each fiducial mark will be zero or a positive or negative one thousandth of an inch. After the correct camera-to-spindle offset is found, the system can be checked and calibrated easily by running the calibration target program. The numbers displayed on the screen show the amount that the camera position has moved. If the $x$ or $y$ correction factors values are larger than positive or negative one, the value for the camera-to-spindle offset stored on the hard drive of the personal computer is edited by subtracting the values displayed for the $\mathrm{x}$ and $\mathrm{y}$ corrections.

Another source of error in the vision system due to an error in the perpendicularity of the camera axis is the change of the camera-to-spindle offset distance as the camera is moved in the vertical $z$ direction when focused. To determine the magnitude of this error, the camera-tospindle offset was found for creating accurate placements at two different heights. The offset changed less than $0.003^{\prime \prime}$ in either the $x$ or $y$ directions with a movement of the camera of 0.217 ". To eliminate this error, the calibration target was adjusted to the same height as the fiducial marks on the circuit, and the aluminum carriers developed for any additional circuits used on the system were designed to position the circuit pattern at this same height.

\section{Improvements to Chuck Assembly and Method of Aligning Centering Jaws}

The ability of the centering jaws to accurately and consistently center the component on the end of the vacuum tip is vital to the placement accuracy and repeatability of the machine. In the beginning use of the machine, there was no way to align the centering jaws other than by judging their position visually. The centering jaws were consistent, but the accuracy of positioning the component on the center of the spindle was poor. The consequence was that the machine suffered inaccuracies in both the $x$ and $y$ directions on the order of 0.005 " to $0.010^{\prime \prime}$ but suffered no other errors in repeatability due to the centering jaws. After a number of placements were made on the circuit to be assembled, the offsets in the $x$ and $y$ directions due to centering jaw inaccuracies could be evaluated. To compensate for these inaccuracies, the offsets were then subtracted from the CAD data coordinates used in the placement program. This process can lead to proper placements on the circuit but is inconvenient due to the following considerations.

- Offset values need to be evaluated for each chuck assembly.

- The true coordinates from the CAD data can not be used, and the offsets need to be subtracted from the coordinates for each placement position of the circuit. This process is time consuming and subject to error when done manually and would best be done by a spreadsheet or program. 
- Attention needs to be paid to the orientation of the component (the $x$ offset at zero degrees rotation becomes the $y$ offset at ninety degrees rotation, etc.) and the positive or negative sign change of the offset due to rotation.

- Any change or further adjustment in the centering jaws requires the process to be repeated. To improve the accuracy with which the chucks center components, the chuck assembly used on the smallest components $(0.055 \times 0.050 \times 0.020$ resistor) was altered to provide better centering accuracy. This chuck assembly was chosen to be modified and characterized since the smaller components require greater placement accuracy to be placed on the small surface mount pads of the circuit, and the small resistor is the most common component used on the circuits assembled by the machine. The errors in the centering accuracy of the chuck assembly were found to be related to the following:

- Centering jaws not properly aligned,

- Rollers of centering jaws not contacting the flat plate of the linear ball slide,

- Vertical misalignment of slanted testing jaws, and

- Compression of end of leaf springs.

\section{Chuck Assembly Improvements and Development of the Centering Jaw Alignment Tool}

In order to improve the accuracy and repeatability of the placement system and the operation of the chuck assembly, some features of the chuck assembly were redesigned and the centering jaw alignment tool was developed. A description of the changes are as described below and as shown in Figure 13.

- Centering Jaw Alignment Tool - The centering alignment tool is a turned stainless steel alignment aid which provides a precisely centered pin for the vacuum chuck to act as a positive stop for aligning the centering jaws. The stainless steel vacuum nozzle assembly is replaced by threading the alignment tool in its place. When aligning the centering jaws on the chuck which is used on the smallest components, the centering jaws which do the electrical verification testing must be kept vertical. The width of the smallest components is about $0.050^{\prime \prime}$ and the width of the testing jaws is about $0.040^{\prime \prime}$. If the testing jaw rotates slightly from vertical, it will interfere with the closure of the non-testing jaws as shown in Figure 14. To eliminate this problem, two alignment tools were designed for this chuck (see Figure 15). The first design consists of two pieces. The first piece threads into the chuck body in place of the nozzle assembly. The second piece slip-fits onto the first and contains the center pin to align the testing jaws against. It also contains four dowel pins which act as guides to minimize the rotation of the testing jaws. The second piece is rotated to orient the narrow gap between the dowel pins with the direction of the testing jaws and locked into position by tightening a socket head cap screw. The second design also contains two main pieces. It differs from the first design in that small adjustable stainless steel blocks are used instead of dowel pins to guide the testing jaws. This creates larger flat surfaces to guide the testing jaws and allows the flexibility of adjusting the width of the gap between these surfaces. 


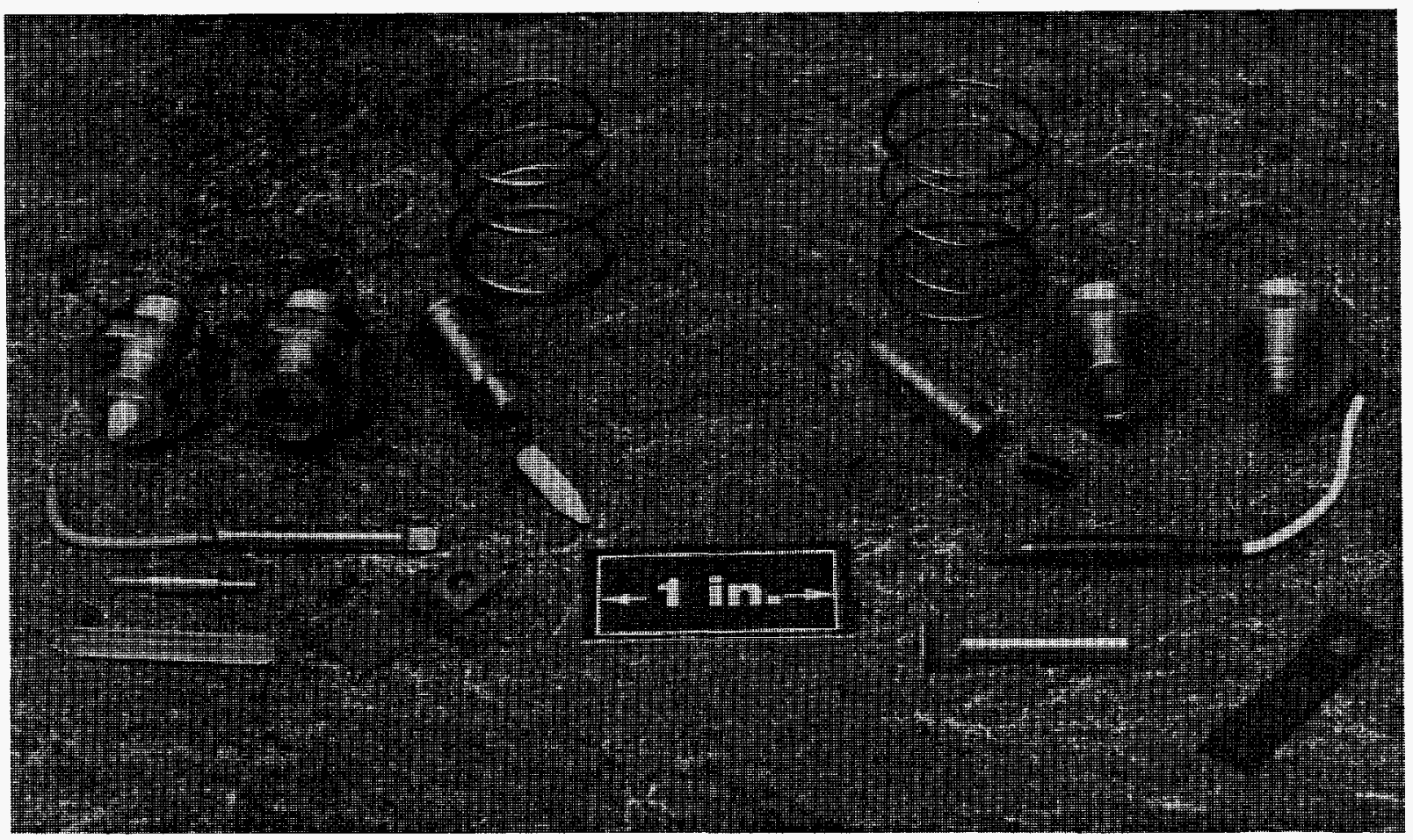

Figure 13. Changes to Chuck

- Nozzle Assembly and Vacuum Tip - The vacuum tip was changed from the original design to a standard tapered tip as shown in Figure 16. This required a redesign of the vacuum nozzle. The advantages to the new tip are the strength of the tip at the end, due to the long taper; the repeatability of the position of the end of the tip; and the ease with which the tip can be replaced. This increase in repeatability and ease of replacement comes from the way the tip is held in the nozzle. The original tip fit inside the original vacuum nozzle design until the tapered portion of the tip became tight in the nozzle and was difficult to remove. Usually it needed to be drilled out. The repeatability of the bottom of the nozzle with this system was found to be about plus or minus 0.016 " based on measurements of 20 brand new tips inserted into the same nozzle. The new nozzle and tip design are much more repeatable and easier to remove since the tip is lightly pressed into the vacuum nozzle until it meets a positive stop. This repeatability is dictated only by the tolerance of the length of the vacuum tip (generally plus or minus $0.005^{\prime \prime}$ ), and the tip can be easily pulled out with pliers or wire cutters. Another change in the nozzle design was the method to prevent rotation of the component. The anti-rotation feature of the original nozzle used a tapered contact between the two stainless steel nozzle components. The inside component of the nozzle assembly falls under its own weight and wedges itself in place. The new nozzle design uses a slip-fit between flat surfaces to prevent rotation and does not require any wedging action. The problem encountered with the original design was that the force necessary to break loose the friction of the tapered surfaces could be large. These forces were imparted onto the component during placement. Measurements were made to determine how large this force could become by running the system through a placement, carefully removing the chuck, and then pressing the nozzle against a digital scale to measure the force required to break the two surfaces loose. The placement position drove the inside component of the nozzle upward as far as possible (approximately $0.150^{\prime \prime}$ ) 


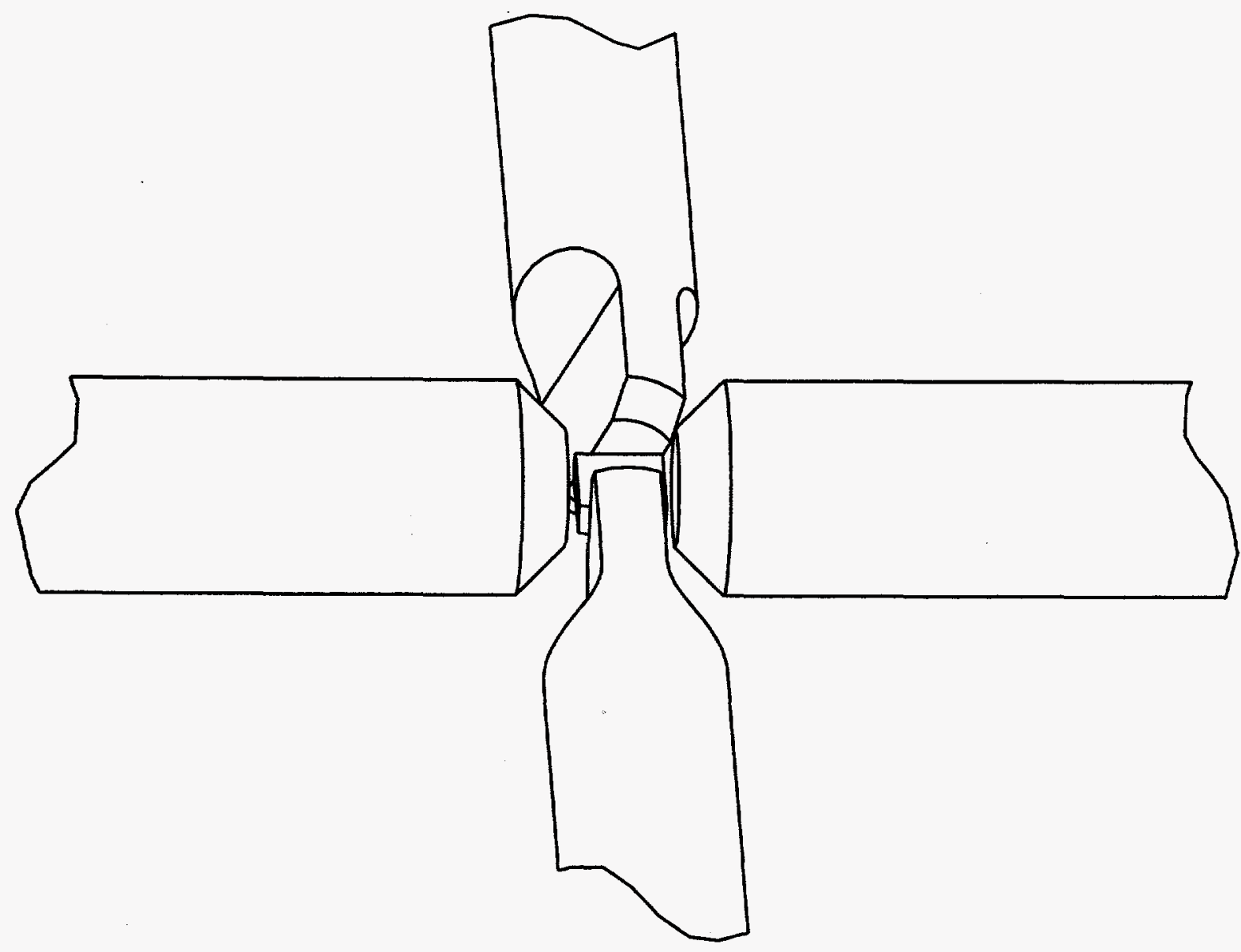

Figure 14. Testing Jaw Rotating and Interfering With Non-Testing Jaws

- to create the worst case (allowing the nozzle component to fall into position from the highest possible point). The force required varied from 2.9 grams (due to only the weight of the inside component of the original nozzle assembly) to a maximum force of 200 grams. With the new design, there is no wedging action and the force on the component is never above five grams (the weight of the inside portion of the new nozzle assembly) unless the forcesensing feature of the machine is activated to provide a specified programmed placement force.

- Centering Jaws - Both the electrical verification testing and non-testing centering jaws were changed to allow them to be used with the alignment tool and with the new tapered vacuum tip. The original design of the testing jaws used a beryllium copper material with a shrink sleeve insulator. The faces of the original testing jaws were at a three-degree angle from vertical. This angle was not large enough to prevent the testing jaws from interfering with the new tapered nozzle. In the new testing jaw design, the faces of the jaws are vertical to allow full contact with the center pin of the centering alignment tool with a 


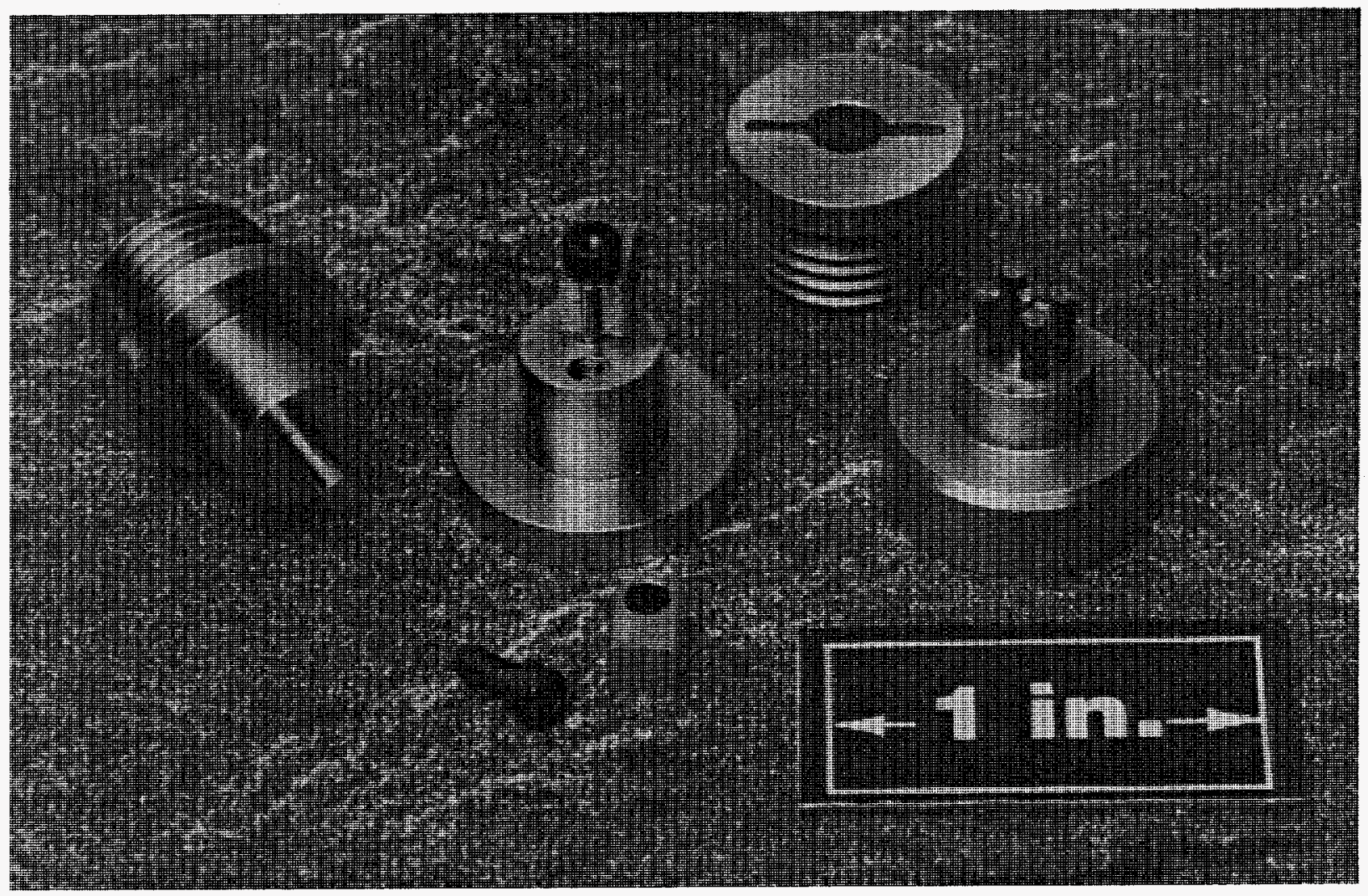

Figure 15. Alignment Tools

- 45-degree chamfer to prevent interference with the new tapered vacuum tip. The threedegree angle of the original testing jaw design only contacts the center pin of the alignment tool at one point. The distance downward of this point of contact affects the width of the gap between the jaws. If this point of contact is too low with respect to the size and position of the component to be centered, the testing jaws will not close on the component. The flat testing jaws allow the center pin of the alignment tool to extend below the testing jaws, allowing a good contact along the full length of the jaws without affecting the gap between them. (See Figure 17.) The new testing jaws were insulated from the rest of the chuck assembly by wrapping the jaws in ordinary transparent cellulose tape. This allows the diameter of each insulated jaw to be custom made to slip-fit in the hole of the centering finger for which it will be mounted. The original design testing jaws with shrink sleeving fit too tightly in the centering fingers to allow them to be aligned using the centering tool. Brass was used for the new testing jaws. The machine manufacturer has begun to use a hardenable alloy designed for use as electrical contacts. This material could be used to replace the brass used for the new testing jaw design. 


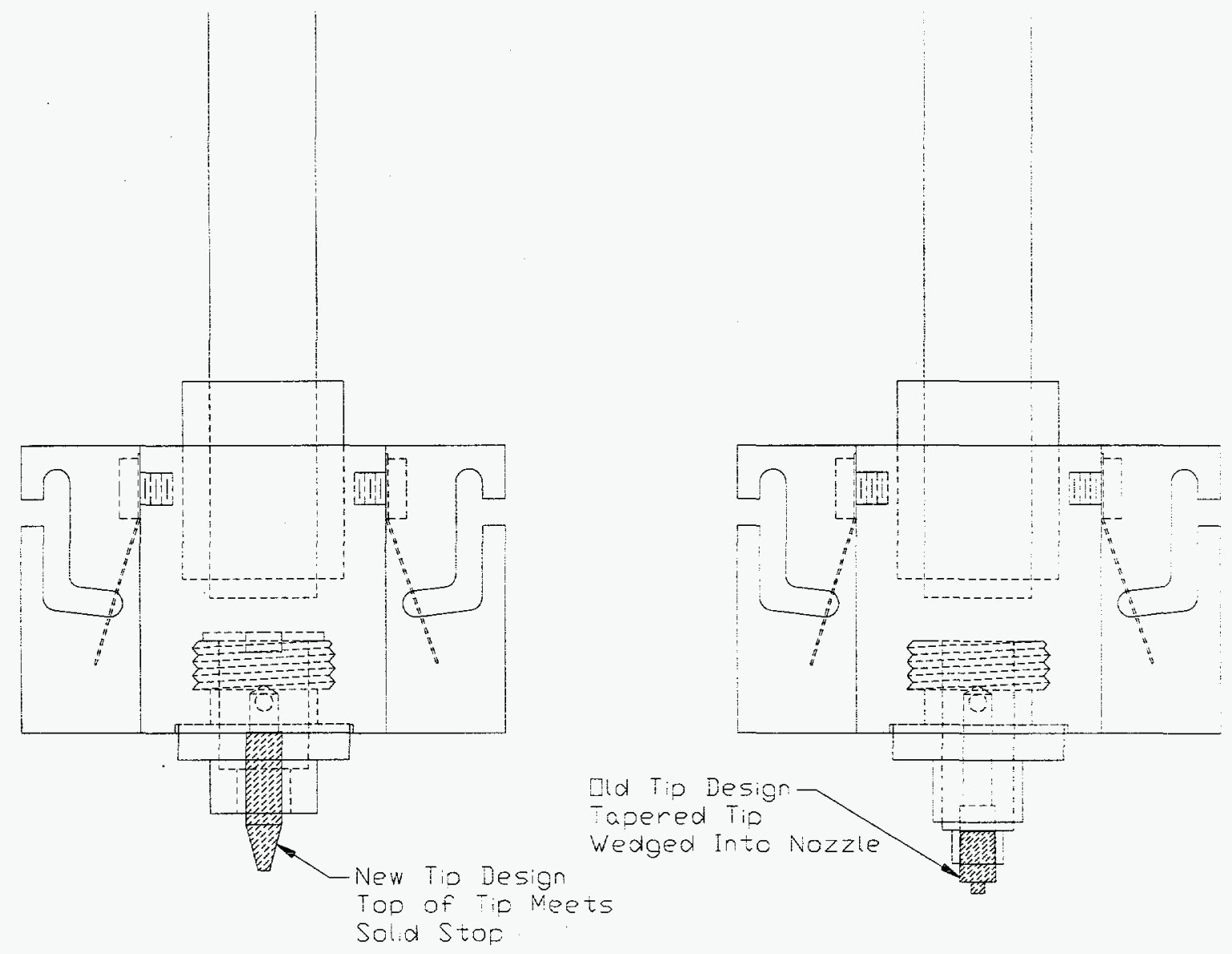

Figure 16. New Versus Old Vacuum Tips

- Shortened Leaf Springs - The leaf springs that act to open up the centering jaws were shortened to prevent them from affecting the alignment of the centering jaws. They were shortened as shown in Figure 18. Before the shortening of the leaf springs, the bend at the end of the leaf springs acted as the stop for the fingers of the centering system. The alignment of the centering jaws was made more difficult since the fingers were not resting against a rigid stop when aligned. The springs were shortened enough to allow the fingers to come against the chuck body as a rigid stop. 
NEW CENTERING JAW DESIGN:

Vertical Faces of Jaws

Allow Full Contact of Center

Pin of Alignment Tool and

Component During Centering
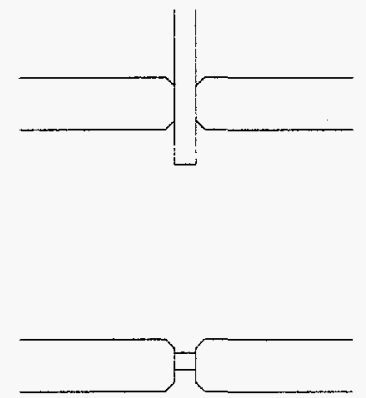

OLD CENTERING JAW DESIEN WITH 3 DEJREE ANGLED FACE

Centering jaws and Components Dniy Jontact jows at Sne Point, Making Alignment of Centering jaws Difficult A Gap (Resulting in a lack of Component Centering) Also Dccurs if the Alignment Tool Contacts the jows Below the Point of Contact for Smali Components
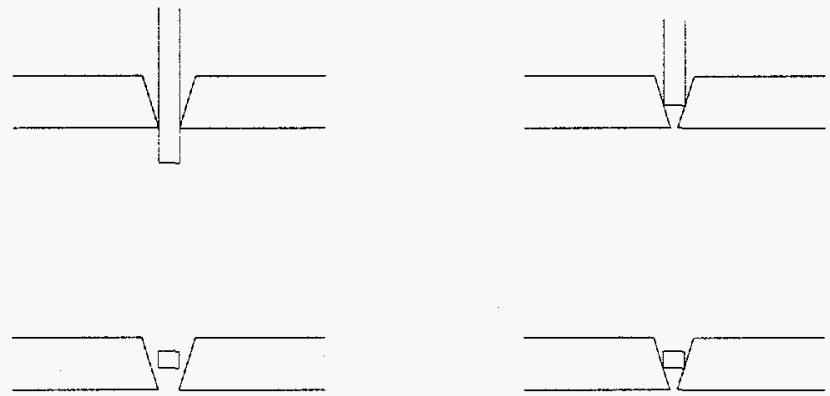

Figure 17. 3-Degree Angle Centering Jaws Versus Flat Centering Jaws on Alignment Tool

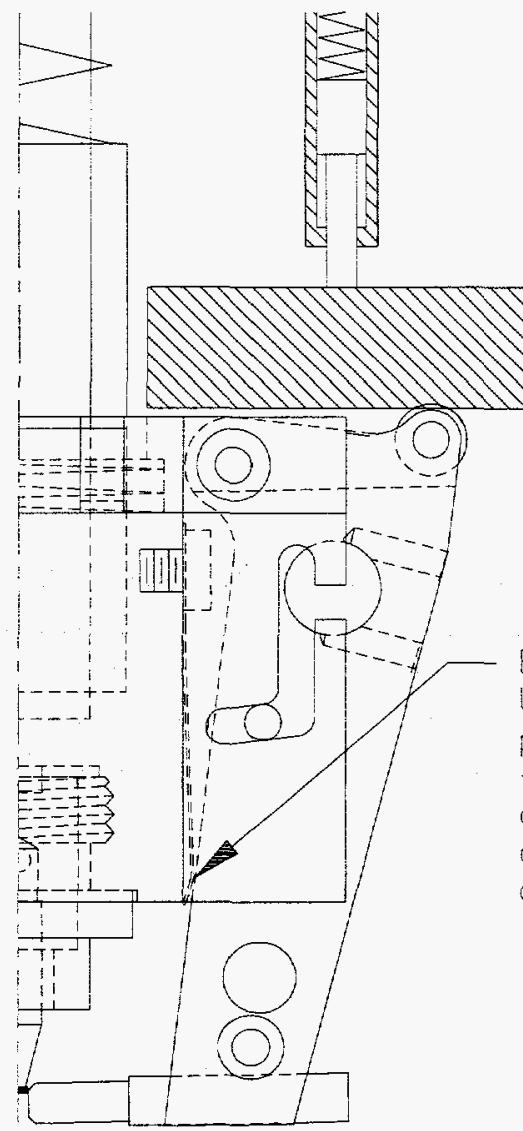

Ends of original leaf springs did not provide a rigid stop for fingers as jaws closed and made alignment of jaws difficult

Shortened springs provide a rigid 5 top against chuck body for fingers as jaws close making alignment of jaws
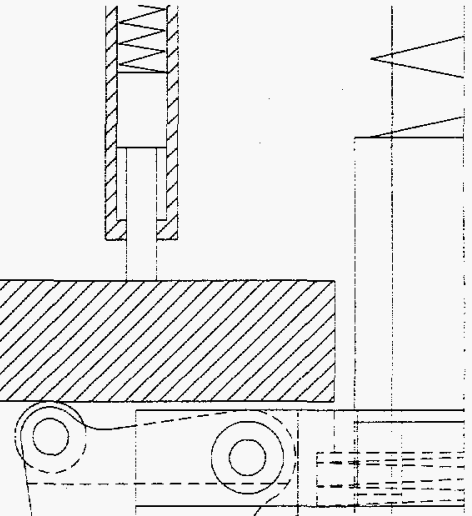

easier

Figure 18. Chuck With Shortened Versus Long Leaf Springs 
- Alterations of Guide Pins - The 3/32" dowel pins pressed into the chuck fingers were altered to prevent them from catching on the openings in the side of the chuck body. The pins slide along the slots in the chuck body as the fingers are opened and closed. The leaf springs push the fingers out until the pin slides along the vertical area of the slot. If the leaf springs are bent at too sharp an angle, the fingers will be pushed out far enough for the pins to try to slip out of the openings used for dismantling the chuck and catch on the opening. If the leaf springs are not bent at a sharp enough angle, the pin will catch at the corner where the slot begins to become vertical. Because of the close fit between the pins and the slot, it is difficult to bend the leaf spring to a position that will work properly, and problems existed with some of the chuck assemblies. The ends of the pins were ground down to a smaller diameter as shown in Figure 19 to relieve the accuracy required in the angle of the leaf springs and eliminate the problems of the pins catching on any feature of the slots. The pins only serve to hold the fingers together with the chuck body, and no changes were made in the placement accuracy or repeatability of the system from this change.

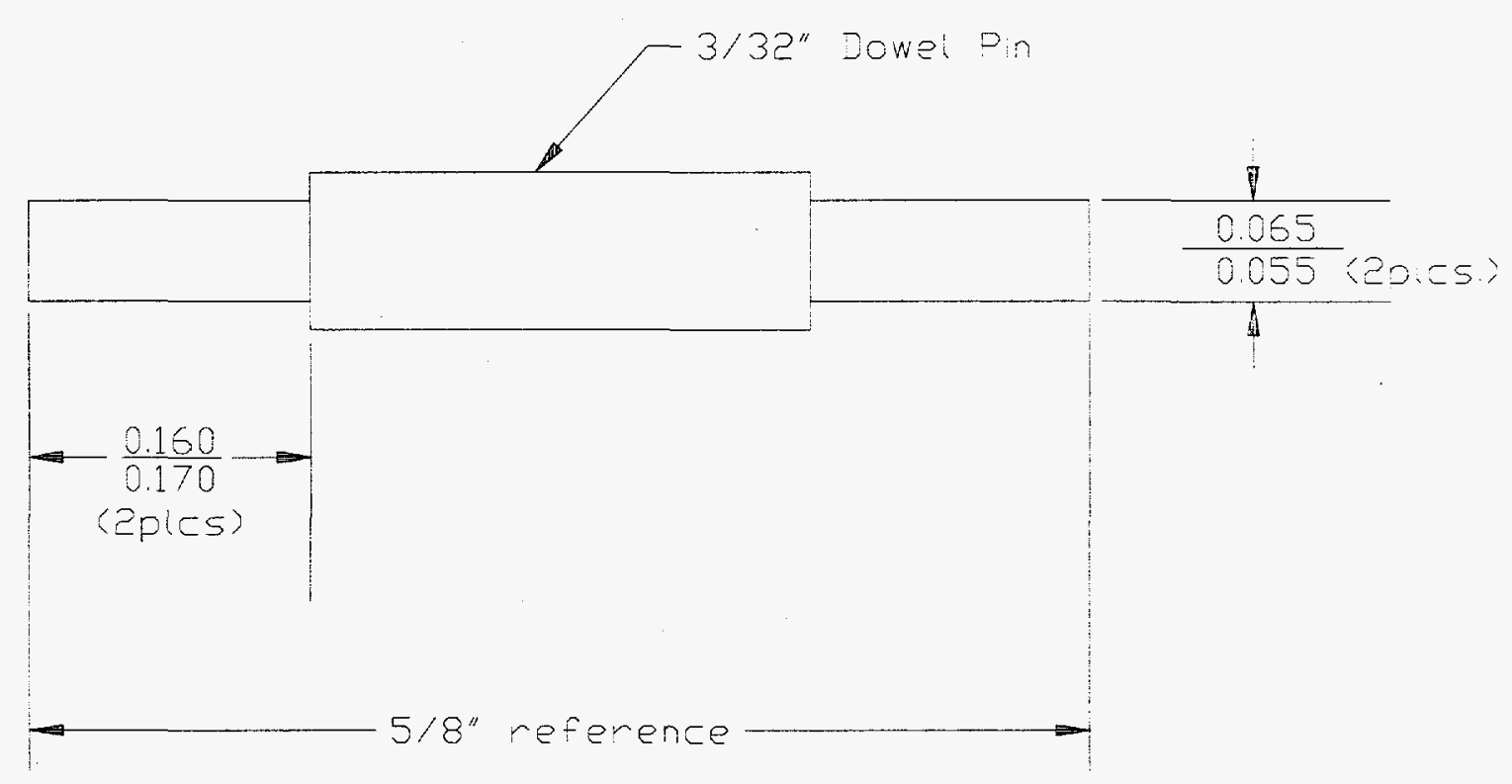

Figure 19. Ground Pins

\section{Method for Aligning Centering Jaws}

A method for aligning the centering jaws was developed for the chuck on the first head used to place the smallest components. This method was used for the electrical testing jaws and was evaluated by placing the small precision steel blocks on the glass accuracy gauge. The best results were achieved by aligning the centering jaws with the chuck assembly on the spindle. The contact between the rollers within the fingers and the flat plates attached to the linear ball slides and loaded by the spring plungers affects the way the chuck assembly closes. Efforts to adjust the chuck assembly on a bench by holding the chuck assembly closed by hand or by 
using a tool designed for this purpose did not exactly duplicate the actual closing of the chuck fingers by the machine. The centering jaws fit in the holes in the center of the fingers of the chuck assembly. Errors in the position of the fingers or the location of the holes for the centering jaws cause the centering jaws to be offset slightly from the true center of rotation of the spindle and chuck assembly (see Figure 20). The alignment of the non-testing jaws must create a spacing between the jaws when fully closed that is greater than the addition of the width of the testing jaws and the offset error in their positioning. This prevents the non-testing jaws and testing jaws from interfering with each other as they begin to close on the component. In the case of the chuck used with the smallest component, the width of the electrical testing jaws was nearly as wide as the component and required a reduction in the width of the jaw and the offset error of the jaws from the center of rotation of the spindle. The changes to the design of the electrical testing jaws included making them narrower, and the alignment of the electrical testing jaws included shimming the jaws to reduce the offset error with the same cellulose tape used as the insulator. The alignment of the electrical testing jaws was given more importance than the alignment of the non-testing jaws since the geometry of the surface mount pads of the circuits used on the machine allowed more placement error in the direction of the non-testing jaws. The step-by-step method used for aligning the electrical testing jaws used to center the smallest components is described below (see Figure 21).

1. The centering alignment tool was threaded in place of the vacuum nozzle.

2. The centering jaws were wrapped with cellulose tape to insulate them and provide a slip-fit with the hole in the fingers.

3. The chuck was closed and testing jaws were pushed against center pin of the alignment tool and examined under a microscope.

4. The amount by which the centering jaws were not centered with the pin was compensated for by removing some of the tape from the jaws and shimming one side of the hole in the fingers which hold the chuck using the cellulose tape as a shim.

5. The amount of tape wrapped around the testing jaws was adjusted until the slip-fit was again achieved and the jaw was centered with the center pin of the alignment tool.

6. The alignment tool was rotated until either the dowel pins used with the first alignment tool design or the blocks used with the second design were in line with the testing jaws, and the capscrew was tightened to hold the alignment tool in this position.

7. If the second design of the alignment tool was used, the blocks used with the alignment tool to hold the testing jaws vertical were adjusted inward until they touched the testing jaws when they were closed.

8. The capscrews in the fingers that clamp the centering jaws in place were tightened to create a snug slip-fit with the testing jaws. The fit created makes it easy to slide the jaws within the fingers but with enough frictional resistance to keep the jaws in place until the capscrews can be tightened to secure them from moving. 


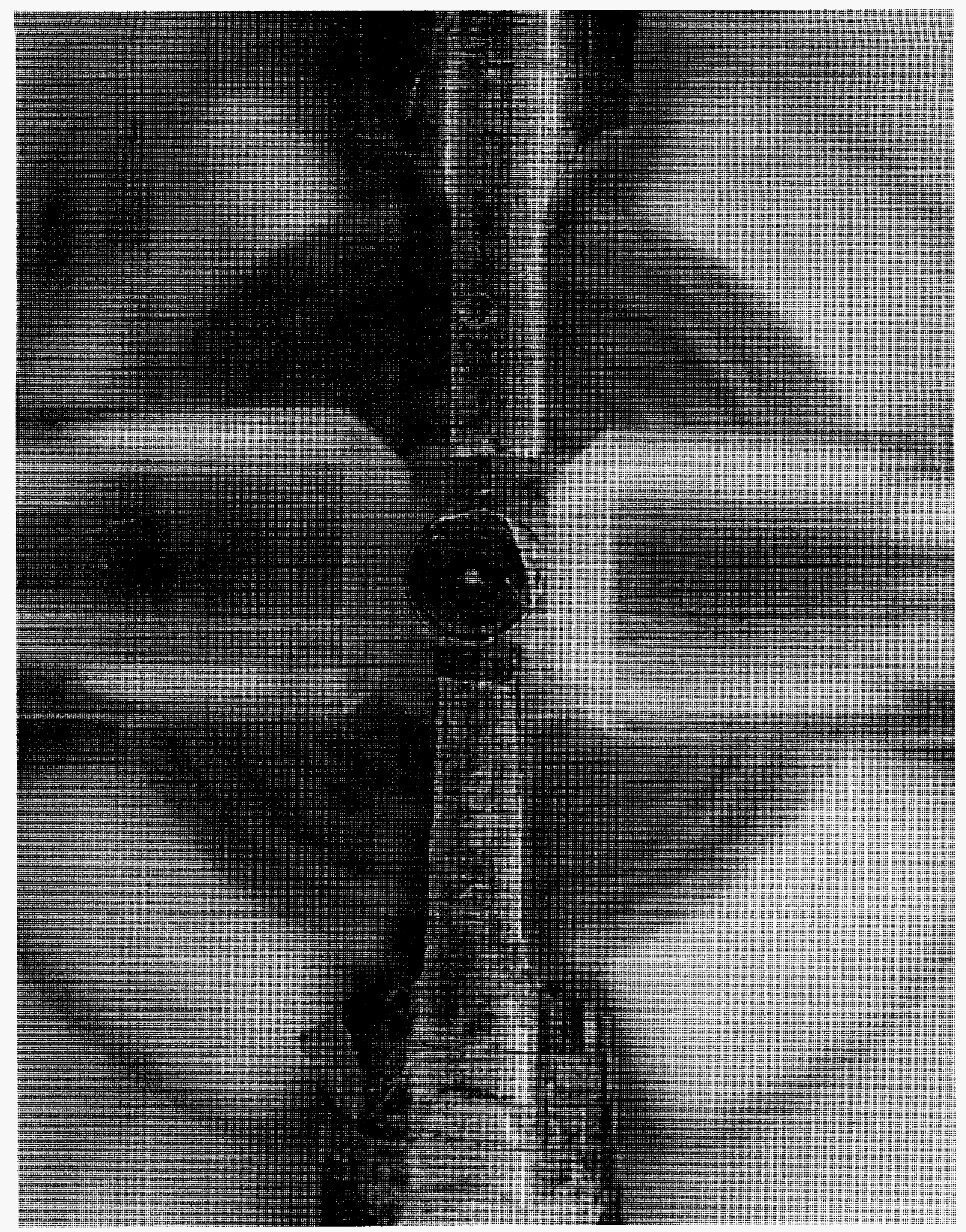

Figure 20. Offset in Jaws 


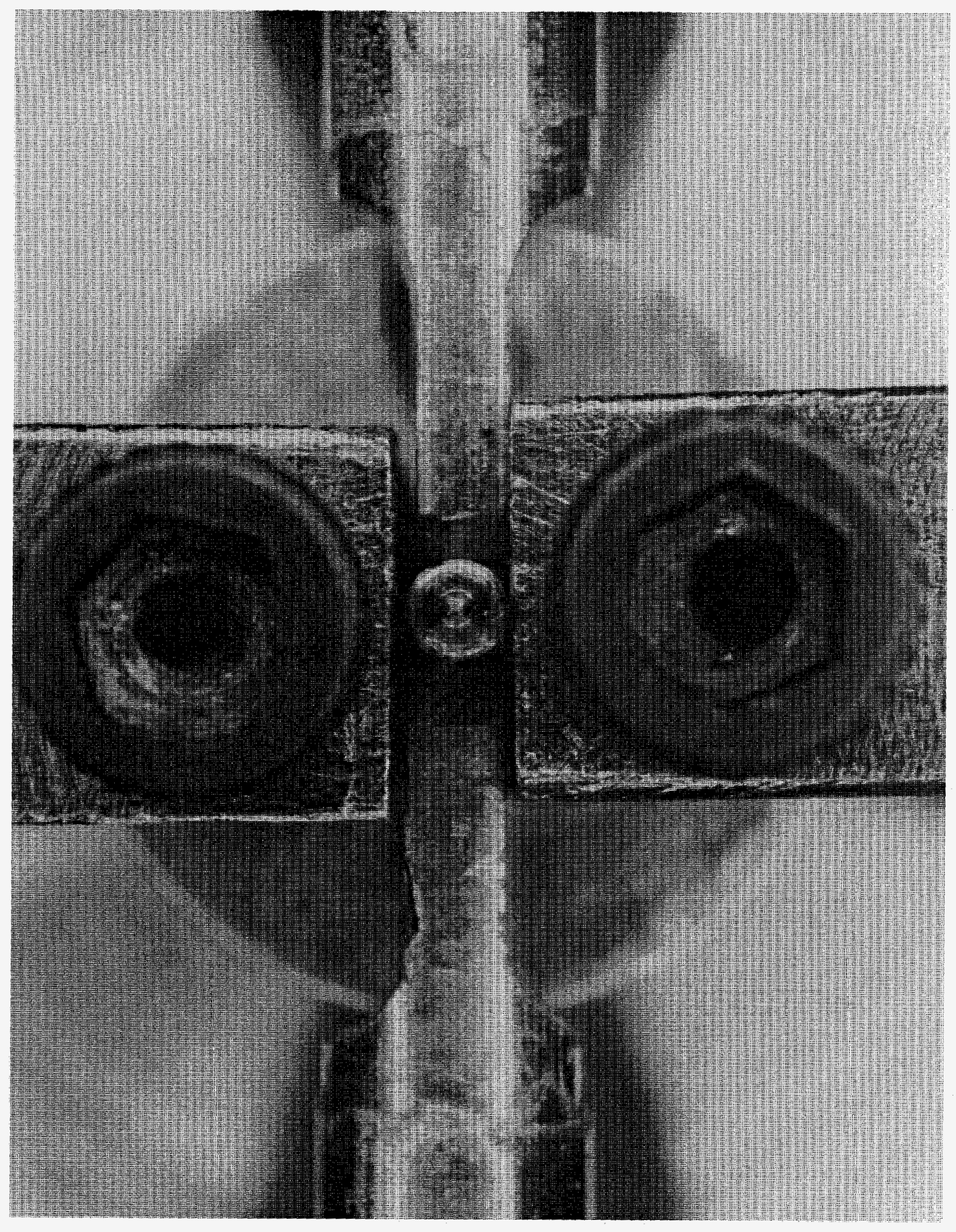

Figure 21. Jaws on Centering Tool 
9. The centering jaws were pulled back so they did not touch the center pin of the alignment tool when the jaws were fully closed.

10. The chuck assembly was put on the spindle.

11. A pickup position was taught and the chuck was run through the pickup routine a couple of times to position it as it would be after an actual pickup.

12. The testing jaws were gently pushed inward until they contacted the center pin of the alignment tool.

13. The chuck was lowered by teaching a position and gently removed from the spindle by hand without bumping the jaws or allowing the jaws to close.

14. The capscrews were tightened to clamp the jaws in place.

Once the testing jaws were insulated and shimmed with tape, the process did not need to be repeated unless the testing jaws were replaced. The alignment tool was used to realign the testing jaws without shimming them again with tape. The same procedure was used for the chuck assemblies used to place the larger components except the shimming of the jaws within the fingers was not required since the components were much wider than the width of the testing jaws. The same procedure was also used for the non-testing jaws of all chuck assemblies except that the non-testing jaws are made to slip-fit within the holes in the fingers and do not require any tape for insulation or shimming. To measure how well the centering jaws were aligned, a precision steel block was placed precisely into one of the squares formed by the grid lines of the glass accuracy gauge and then placed using the same $x$ and $y$ coordinates but with a rotation of 180 degrees. The placement coordinates at 0 degrees rotation were taught using the hand-held control and corrected by evaluating the actual placements with the vision camera. After about three or four iterations, the steel block fit precisely into the square. After placing the block at 180 degrees rotation, the centering errors for the testing and non-testing jaws were viewed with the camera. At 0 and 180 degrees rotation, the testing jaws lie along the $y$ axis of the machine and the non-testing jaws lie along the $x$ axis. The change in the placement of the precision block in the $y$ direction represents twice the centering error by the testing jaws. The change in the $x$ direction represents twice the error by the non-testing jaws. The width of $0.005^{\prime \prime}$ for the grid lines of the glass accuracy gauge served as a convenient reference for estimating the change in the position of the block when placed at 180 degrees.

\section{Investigation of Relative Difference in Spring Plunger Forces for Effect on Accuracy}

The electrical testing centering jaws have two spring plungers acting on the flat plate which press against the rollers in the fingers and close the jaws. (The non-testing jaws are only acted upon by one spring plunger). The effect of having unbalanced forces in the spring plungers on the centering accuracy of the chuck assembly was evaluated. To check the worst case, a steel block was placed on the glass gauge at 0 and 180 degrees and then placed at both angles again with one of the spring plungers removed. The removal of one spring created no change in the placements. The linear ball slide causes the flat plate to close the centering jaws evenly even though the forces on it are unbalanced. 


\section{Best Shot at Accuracy and Repeatability Using All Developments}

All of the improvements developed for the system were used to evaluate how accurately and repeatedly the system could be made to place components on a circuit as programmed. Placements were made using a program to place 14 precision blocks $(0.050 \times 0.050 \times$ 0.020 inch) on two precision glass slides. (These parts were representative of the component requiring the greatest placement accuracy.) The placements on the precision glass were made by developing a placement program from CAD data with no special programming to compensate for machine inaccuracy. It represents the performance of the system as programmed including all inaccuracies and non-repeatability due to the positional system, component centering, and vision system with the exception that it does not include errors due to homing. The following procedures were used for aligning the centering jaws and finding the camera-to-spindle offset as accurately as possible.

1. The centering jaws were aligned with a special emphasis placed on the proper alignment of the testing jaws and checked by placements of the precision steel blocks on the glass gauge. A slight error in the alignment of the testing jaws was corrected by placing one thickness of tape on one side of the center pin of the alignment fixture as the jaws were aligned.

2. The camera-to-spindle offset was found by comparing the coordinates of the spindle at the placement position with the coordinates of the spindle with the camera crosshairs over the center of the block. Care was taken to make sure the system did not go through the homing routine before these two coordinates could be compared. If some error still existed in the centering of the component, the coordinates of the camera centered over the block were compensated by the error found by placing the block at 0 and 180 degrees.

3. The correct camera-to-spindle offset value was entered into the memory of the system.

4. The coordinates to the center of the circle for the vision calibration program were generated using the vision teaching software of the system (which compensates for the distance between the camera and spindle by the camera-to-spindle offset value). The edge of the camera crosshairs was lined up along the near and far edges of the circle in the $x$ and $y$ directions, and the coordinates were averaged to find the circle center.

The program for the glass slide was generated using one fiducial mark as the origin of the CAD coordinate system. The second fiducial mark and all placement coordinates were calculated mathematically and referenced from the center of this fiducial mark. The program was run twice, and measurements of the accuracy of the placements were made using a measuring microscope. The placements on the glass gauge were performed with the home position established before the vision system correction of the program. Any errors in the repeatability of the homing routine were compensated for by the vision system and do not affect the accuracy or repeatability of the placements on the glass gauge. Errors in the placement accuracy and repeatability due to errors in homing may occur if the system runs through the homing routine during the assembly of the circuit. This occurs whenever the system is unable to pick up a component after three attempts or if the head crashes. If the added inaccuracy and unrepeatability due to homing are unacceptable, the program may need to be started again at the beginning to perform the vision correction and then returned to the previous step in 
the program. A replacement of the through-beam sensor with a more precise sensor or sensing method could be used to eliminate any error due to homing. The squareness of the faces of the centering jaws had an effect on the placement angle of the steel blocks on the glass gauge. After a few placements of the steel blocks on the glass gauge, it was noticed that each placement had a rotational error of about five degrees clockwise. Based on the previous measurements of the actual angle of the spindle and chuck assembly at zero degrees rotation (about 0.5-degree error maximum), the squareness of the centering jaws was suspected to have caused the error. A testing jaw which looked questionable was changed and any noticeable rotational error disappeared. The results of the placements on the glass gauge were as shown in Figure 22.

Using the "Two Sigma" method, the practical accuracy of the machine as programmed and using the vision pattern correction system were plus or minus 0.0038 inch in the $x$ direction and plus or minus 0.0035 inch in the $y$ direction. The vision correction system eliminated any error due to homing from these results. To estimate the additional error due to homing, during the running of a placement program, the largest (worst-case) variances in the $x$ and $y$ directions due to homing from the repeatability studies were added to the variances in both directions from the placement on the glass slide, and new standard deviations were found. Based on these adjustments, the worst-case estimates of the machine placement accuracy including homing error were found to be plus or minus $0.0045^{\prime \prime}$ in the $x$ direction and $0.0059^{\prime \prime}$ in the y direction. An explanation of the tests and all of the data are in the appendices.

\section{Sensitivity of Component Placement Accuracy to Alignment Tool}

A series of centering jaw alignment tools with different diameter center pins was developed to align the centering jaws for a range of component sizes. The alignment tools were designed with pins slightly smaller than the component to be placed in an effort to ensure that the jaws would close tightly on the component and properly center it. To determine the sensitivity of centering accuracy to the difference between the component size and center pin of the alignment tool, some larger components were placed using a chuck aligned for use with smaller components. The chuck used in the previous evaluations to place the steel blocks representing the smallest component was used to place the steel blocks representing the second smallest and the largest component size. The centering accuracy of the system was very good when placing both larger components. In the placement of the largest steel blocks, a placement program was generated using the mathematical data generated for the precision glass and the vision system was used. Two of the smallest blocks were placed beside the largest blocks using the same chuck in this program. The placement of these precision stainless steel blocks was as good as the placements of the smallest precision blocks from the previous tests. The results of the placements in these experiments are as shown in Figures 23 and 24 . The measurements of the placement error of the $(0.105 \times 0.050 \times 0.020$-inch $)$ precision blocks are in Table 1. 


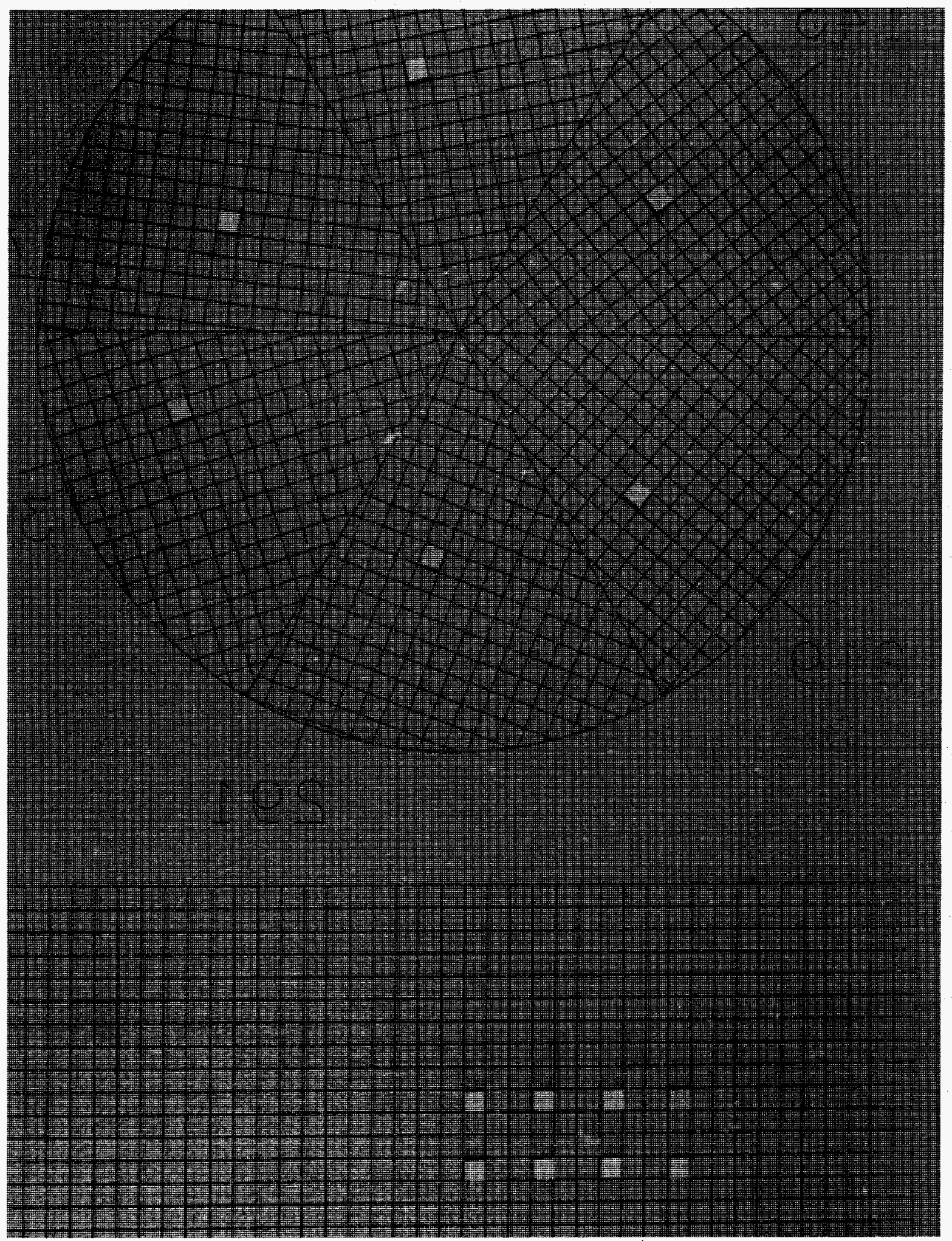

Figure 22. Small Parts on Glass 


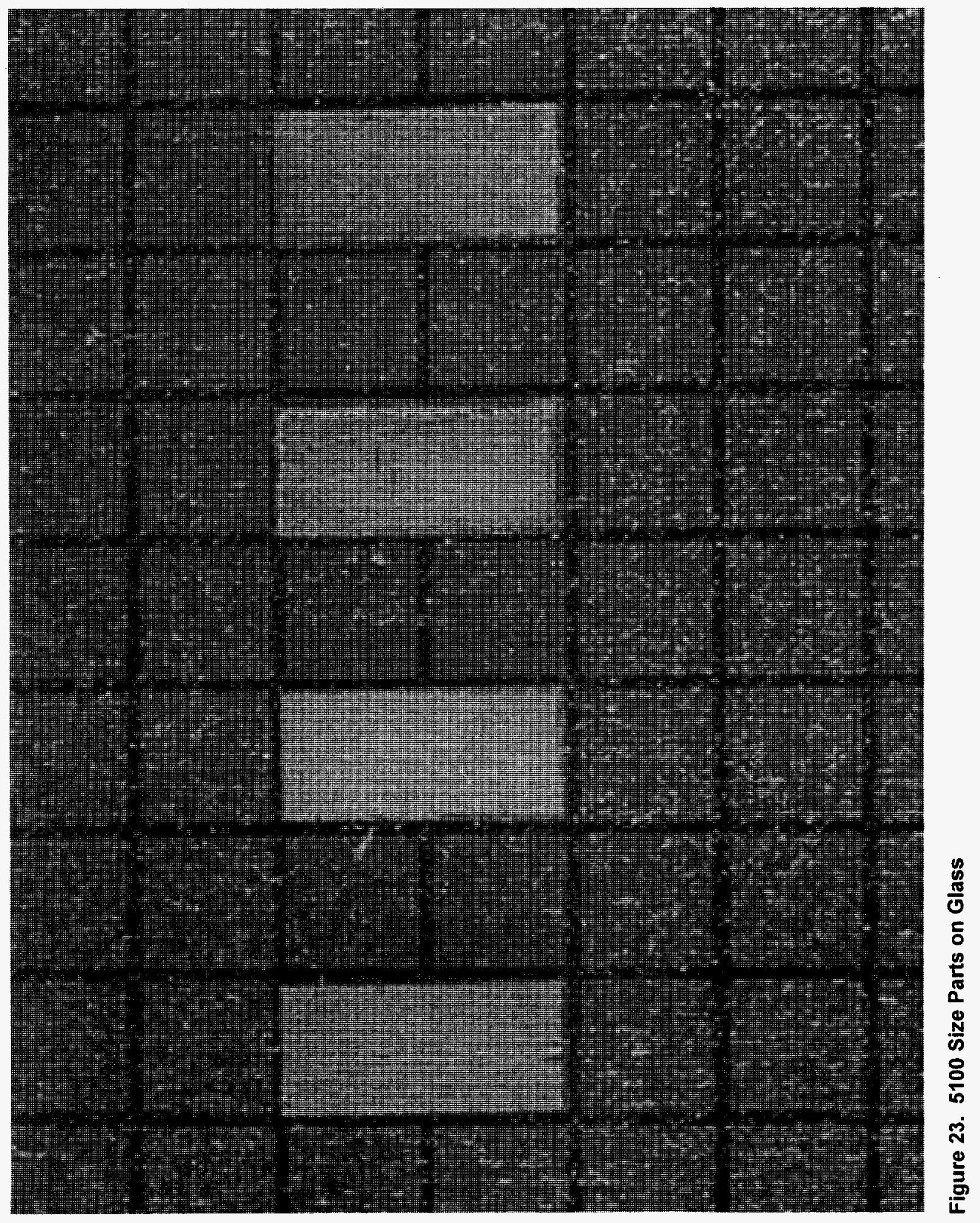




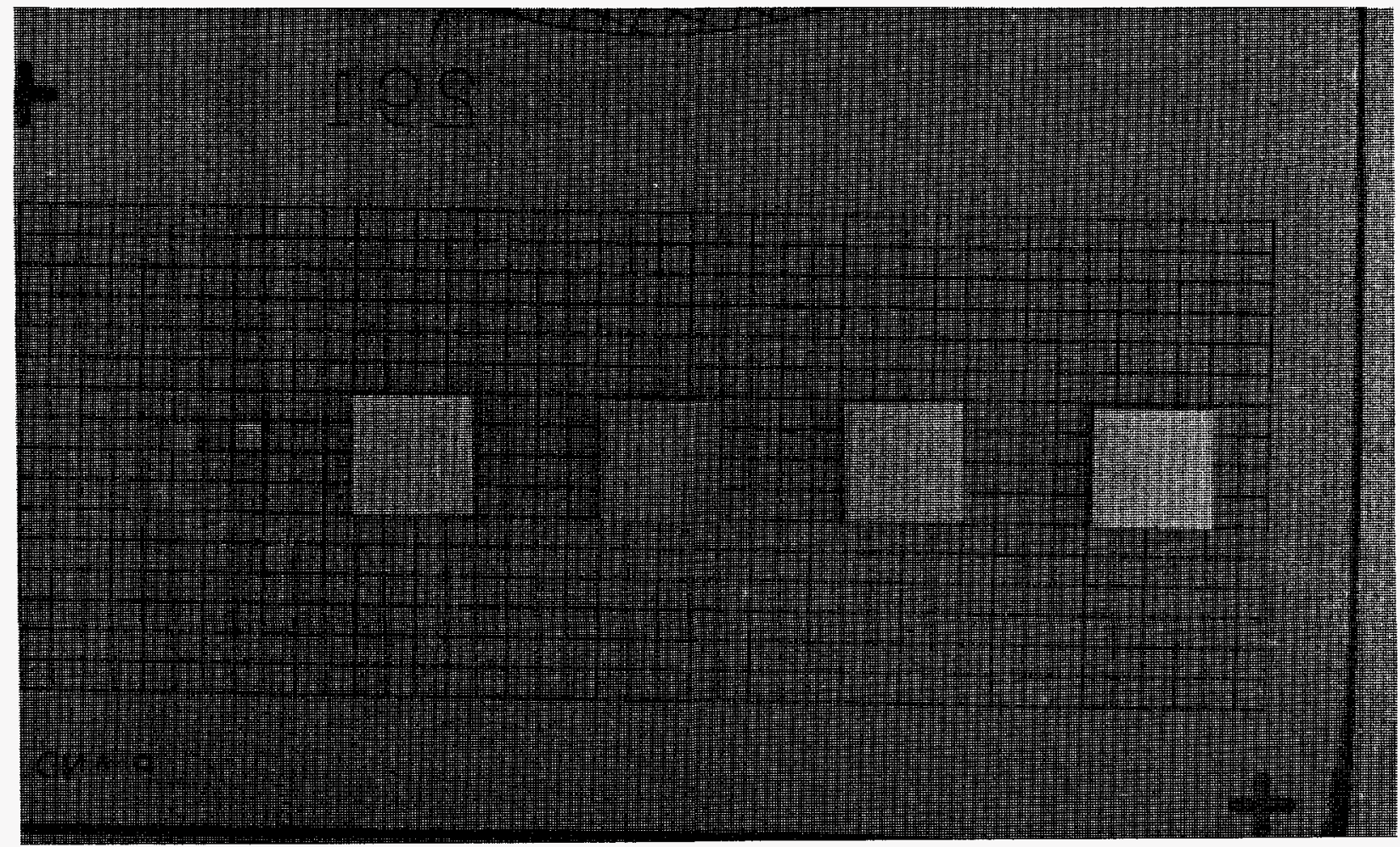

Figure 24. Small and Large Parts on Glass

Table 1. Measurements of the Placement Error

\begin{tabular}{|c|c|c|}
\hline $\begin{array}{l}\text { Placement Number } \\
\text { and Angle }\end{array}$ & $\begin{array}{l}\text { Thick Jaws in the X } \\
\text { Direction (mils) }\end{array}$ & $\begin{array}{l}\text { Thin Jaws in the Y } \\
\text { Direction (mils) }\end{array}$ \\
\hline \#1 @ 0 degrees & 2.65 & 1.25 \\
\hline \#2 @ 0 degrees & 2.45 & 1.8 \\
\hline \#3 @ 180 degrees & -1.8 & -0.4 \\
\hline \#4 @ 180 degrees & -2.55 & 0.9 \\
\hline & Average $=0.1875$ & Average $=0.8875$ \\
\hline & Range $=5.20$ & Range $=2.20$ \\
\hline
\end{tabular}

\section{Stress Analysis of Components Due to Centering Jaw Loading and Placement}

A classical strength of materials analysis was done to determine the likelihood of the system damaging ceramic resistors and capacitors. The analysis consisted of worst-case models of the component in a straight compression mode and in a buckling and bending mode resulting from the centering jaws and the nozzle during placement. The model used for this analysis was a $0.105 \times 0.050 \times 0.015$-inch resistor. This component was chosen as the worst case due to its geometry. The body of this resistor is $96 \%$ alumina. All equations used were found in Mechanics of Materials by Ferdinand P. Beer and E. Russell Johnston, Jr. ${ }^{1}$ The 
compressive strength of alumina found from literature and used in the analysis ranged from $140,000-400,000 \mathrm{psi}$. The tensile strength found in the literature for alumina ranged from $20,000-50,000$ psi. The loading models used for the stress analysis due to bending were based on point loads at the locations which would generate the largest stresses to create exaggerated worst-case estimates. By comparing these exaggerated stresses to the allowable stresses for the material, they were found to be far lower, and a more detailed stress analysis was not needed.

\section{Stresses From Pure Compression}

The electrical verification jaws have a 0.040 -inch wide bearing surface. These jaws contact the curved irregular surfaces of the solder. The shape of the solder prevents the full bearing area of the jaw from contacting the component. This causes high stresses at the points of contact. The assumption is made that as long as the yield strength of the solder is significantly less than the compressive strength of the ceramic, the solder will yield in the local areas in contact with the jaws before appreciable stresses are created in the ceramic. Under this assumption the solder will continue to yield (deform) as the load increases until the full bearing area of the jaw is in contact with the solder (see Figure 25). The compressive stress formed in the solder and in the ceramic is:

$\sigma=\frac{\mathrm{F}}{\mathrm{A}}$

where:

$\sigma=$ stress

$F=$ force between component and centering jaws

$\mathrm{A}=$ bearing area between centering jaw and component

The force between the component and the jaws was calculated to be $0.95 \mathrm{lbf}$. This number was calculated by measuring the spring force in the machine head and using statistics to find the force at the centering jaw. The contact area will be assumed to be the width of the centering jaw by the height of the component $(0.040 \times 0.015$ for the chip resistor). The $0.95-1 b f$ load was rounded off to a more conservative 1.0 -lbf load used in the calculations.

$$
\begin{aligned}
& \sigma=\frac{1.0}{(0.040)(0.015)} \\
& \sigma=1667 \text { psi (compression) }
\end{aligned}
$$



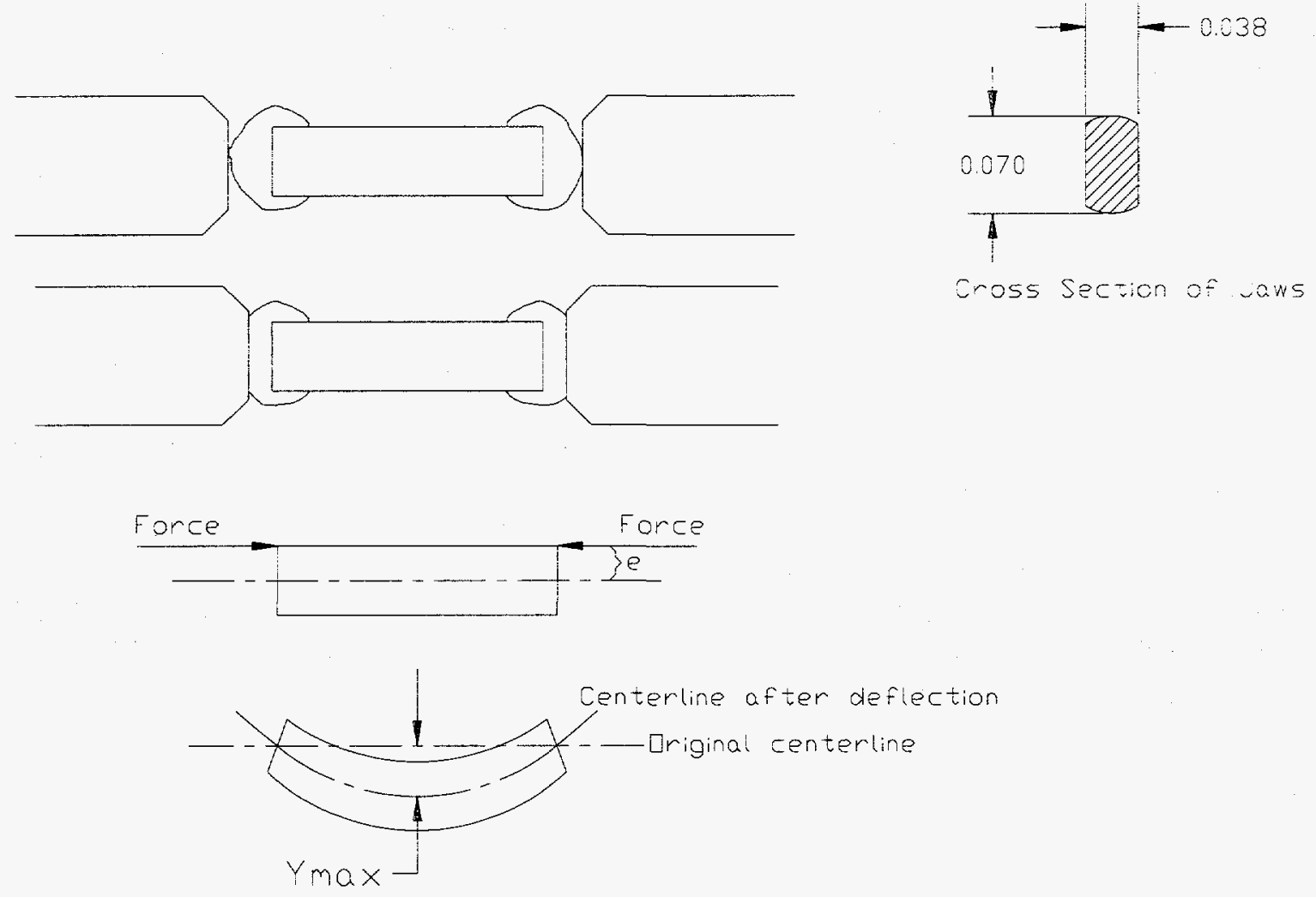

Figure 25. Compressive Stresses Contacting Solder, Compressive Stresses Yielding Solder, Buckling Load and Deflection, Bending Stresses Due to Eccentric Axial Loads

\section{Stresses From Buckling and Bending Due to Centering Jaws}

A calculation was made to determine what force would be required to buckle a long, narrow component $(0.105 \times 0.050 \times 0.015$-inch resistor). This component was chosen because its geometry was the most likely to buckle under a given load. Because the component is free to rotate with respect to its contact with the centering jaws under load, the Euler buckling criteria for a column with pinned connections was used to determine the critical load at which the component becomes unstable and may tend to buckle. This criteria is given by:

$\mathrm{P}_{\mathrm{cr}}=\frac{\pi^{2} \mathrm{EI}}{\mathrm{L}^{2}}$

where:

$P_{c r}=$ critical load value at onset of buckling

$I=$ area moment of inertia about the axis of the cross section which gives the smallest value

for the moment of inertia

$\mathrm{L}=$ length of component

$E=$ Young's modulus of elasticity for alumin a $\left(53 \times 10^{6} \mathrm{psi}\right)$ 
The moment of inertia is smallest about the horizontal cross-sectional axis as the component is being centered. This moment of inertia is of the cross section with a base ( $b=0.050 \mathrm{inch})$ and a height $(h=0.015$ inch):

$$
\begin{aligned}
& I=\frac{1}{12} b h^{3} \\
& I=\frac{1}{12}(0.050)(0.015)^{3}=1.406 \times 10^{-8}\left(\text { in. }^{4}\right) \\
& P_{\text {cr }}=\frac{\pi^{2}\left(53 \times 10^{6}\right)\left(1.406 \times 10^{-8}\right)}{(0.105)^{2}} \\
& P_{\text {cr }}=667 \mathrm{lbf}
\end{aligned}
$$

This calculation shows that a 1.0-lbf load is far below the 667-lbf load required to create a buckling situation for the component geometry most likely to buckle. To estimate the stresses from the bending moments created by the loading of the component by the centering jaws, a conservative model was created with the forces applied horizontally at the top corners of the component. The calculation of the bending moment used with this model includes the increase in the bending moment due to the moment arm increase from the deflection of the component under loading. This is the same effect which causes buckling of slender columns under an eccentric load in compression. This conservative model was employed even though the effects of buckling were previously found to be negligible and act as a further proof of that conclusion. Under this loading the bending moment which causes the stress due to bending is due to both the distance between the force and the component centerline and the deflection of the component under bending. An illustration of the loading and an exaggerated illustration of this deflection and the shear and moment diagrams for the stress calculation is shown in Figure 25. The deflection was found by using the formula below:

$y_{\max }=e\left[\sec \left(\frac{L}{2} \sqrt{\frac{P}{E I}}\right)-1\right]$

where:

$e=$ distance from centerline to line of force from centering jaws

$\mathrm{L}=$ length of component

$\mathrm{P}=$ force from centering jaws

$E=$ Young's modulus of elasticity for alumina

$I=$ area moment of inertia for cross section 


$$
\begin{aligned}
& e=0.0075 \mathrm{inch}(\text { worst case of } 1 / 2 \text { component height) } \\
& L=0.105 \mathrm{inch} \\
& P=1.0 \mathrm{lbf} \\
& E=53 \times 10^{6} \\
& I=1.406 \times 10^{-8} \\
& y_{\max }=0.0075\left[\frac{1}{\cos \left(\frac{0.105}{2} \sqrt{\frac{1}{\left(53 \times 10^{6}\right)\left(1.40 \times 10^{-8}\right)}}\right)}\right. \\
& y_{\max }=1.40 \times 10^{-4} \text { (in.) }
\end{aligned}
$$

The fact that the value for $y_{\max }$ is less than one tenth the value of the distance " $e$ " (which acts as the moment arm for the bending moment) suggests that the additional moment from the deflection can be neglected. This supports the assumption that buckling effects are negligible. The bending moment is therefore equal to the loading "P" multiplied by the moment arm "e."

$$
\mathrm{M}=(\mathrm{P})(\mathrm{e})
$$

where:

$\mathrm{M}=$ bending moment due to eccentric loading

Because the deflection and increase in moment arm from loading are negligible, the bending moment arm is due only to the distance between the centerline of the component and the application of the load. In actuality, the loading of the component occurs at the contact point between the centering jaws at or very near the centerline, and the moment arm is nearly zero. To determine what the stresses would be if the loading could be applied at the largest moment arm possible, a worst-case stress estimate was made by assuming the load is applied at the top corner of the component, creating a bending moment equal to half the component thickness. The bending moment will cause both compressive and tensile stresses in the ceramic. In the case shown in Figure 25 a compressive stress would form above the neutral axis (centerline due to component symmetry). Tensile stresses would form below the centerline. These tensile and compressive stresses reach a maximum at the top and bottom surfaces and are equal in magnitude due to component symmetry. This value for the worst case maximum stresses is given by:

$\sigma_{\max }=\frac{M_{\max } \mathrm{C}}{\mathrm{I}}$

where:

$\mathrm{M}_{\max }=$ Maximum bending moment

$\mathrm{C}=$ Distance from neutral axis to top or bottom surface

$I=$ Area moment of inertia of cross section of component 
for the loading of the component:

$$
\begin{aligned}
& \sigma_{\max }=\frac{(0.0075)(0.0075)}{1.406 \times 10^{-8}} \\
& \sigma_{\max }=4000 \text { psi (top compression, bottom tension) }
\end{aligned}
$$

This value is $1 / 5$ the lowest ultimate tensile stress found for alumina in the literature. The fact that the actual loading will not occur at the top corner of the component indicates that the actual factor of safety is greater than 5 to 1.

\section{Stresses From Bending During Placement}

During placement the vacuum nozzle will press the component against the substrate as shown in Figure 26. A worst-case loading would be to assume that the force between the nozzle and the component is a single point load acting at the center of the component. The actual loading is distributed across the circular wall of the vacuum tip. The assumed point loading along with the corresponding shear and moment diagrams are as shown in Figure 26 . The bending stress is given by the same equation used for the previous bending case using the maximum bending moment found from the shear and moment diagram.

$\sigma_{\max }=\frac{\mathrm{M}_{\max } \mathrm{C}}{\mathrm{I}}$

with:

$\mathrm{M}_{\max }=$ maximum bending moment $=\left[\frac{\mathrm{F}}{2}\right]\left[\frac{\mathrm{L}}{2}\right]$ (derived from shear and moment diagram) where:

$\mathrm{F}=$ downward force of nozzle against component

$\mathrm{L}=$ length of component

The placement force is programmable from 10 to 500 grams. The value programmed for the force when this feature is used is 10 grams. The force sensing is not used on the circuits currently assembled on the machine, and the only force in contact with the component is 5 grams due to the weight of the inside portion of the stainless steel nozzle assembly. A force of 5 grams $(0.011 \mathrm{lbf})$ was used. The maximum normal stress from a 5 -gram load would be:

$$
\begin{aligned}
& M_{\max }=\left(\frac{F}{2}\right)\left(\frac{L}{2}\right)=\left(\frac{0.011}{2}\right)\left(\frac{0.105}{2}\right)=2.888 \times 10^{-4}(\mathrm{in})(\mathrm{lbf}) \\
& \sigma_{\max }=\frac{\mathrm{MC}}{\mathrm{I}}=\frac{\left(2.888 \times 10^{-4}\right)(0.0075)}{1.406 \times 10^{-8}}=154 \mathrm{psi}
\end{aligned}
$$



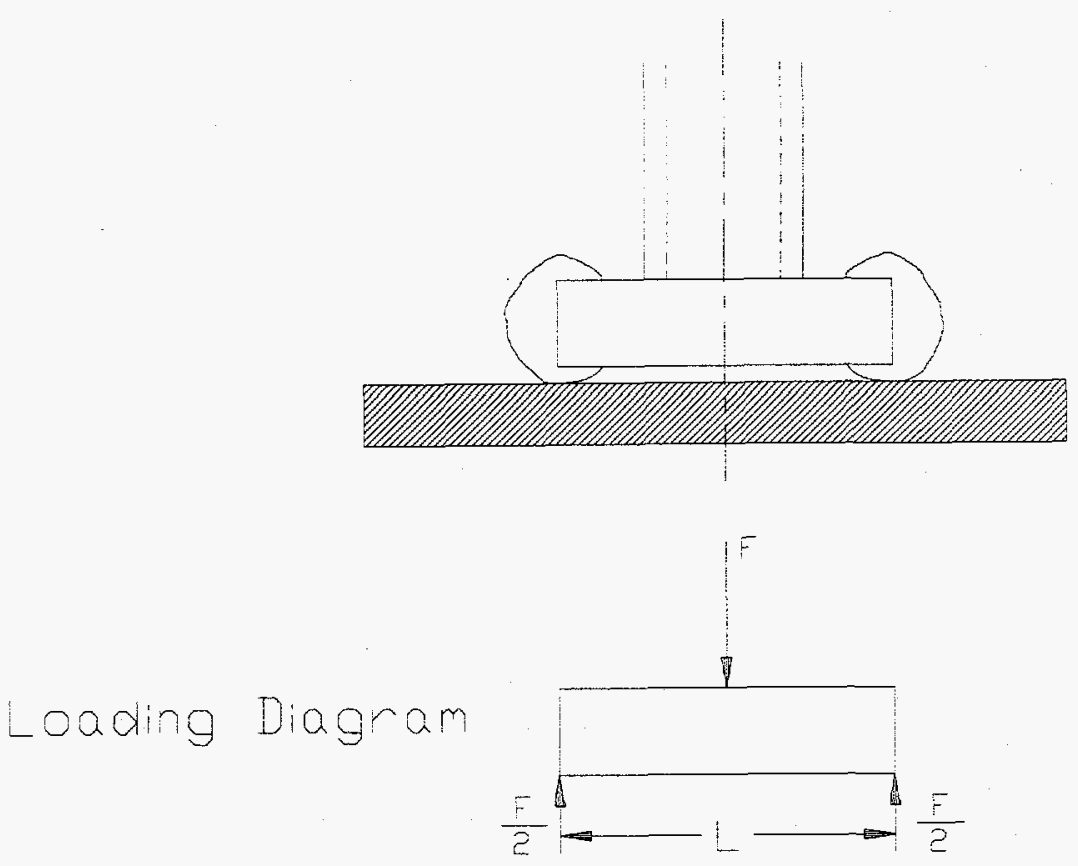

Shear Digram

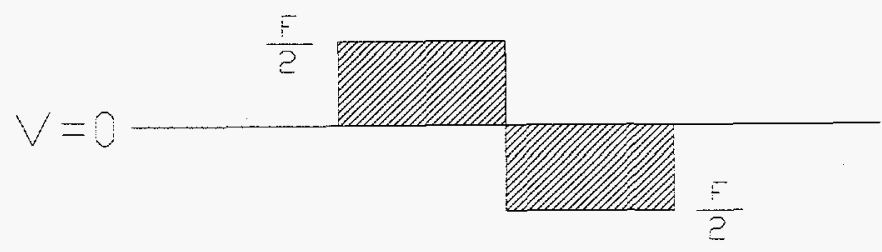

Moment Diagram

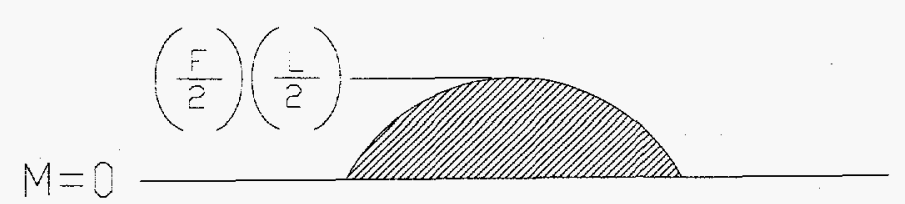

Figure 26. Component Placed on Substrate, Shear and Moment From Component Placed on Substrate

Because the actual loading of the nozzle consists of a distributed load far from the center of the component, this stress calculation is greatly exaggerated. The stress under this exaggerated load was found to be smaller than the stresses due to bending, and since they do not occur simultaneously, the stresses due to component placement can be neglected in comparison to the bending stresses from the centering jaws. 


\section{Static Analysis to Determine Loads on Component Due to Centering}

The spring plungers which drive the centering jaws were loaded in a tensile/compression tester and a plot was made of force versus displacement. A preload of $2 \mathrm{lbf}$ and a spring constant of $8 \mathrm{lbf} / \mathrm{in}$ was determined from this plot. The maximum depression of the spring plungers during use was measured with dial calipers on the machine. This distance was measured to be $0.150 \mathrm{in}$. The total force in the spring plunger due to the preload and deflection was then found to be $3.2 \mathrm{lbf}$. The force at the centering jaws was found by a static analysis of the chuck mechanism to be $0.95 \mathrm{lbf}$. The free-body diagram of a finger of the chuck under the loading during centering is shown in Figure 27.
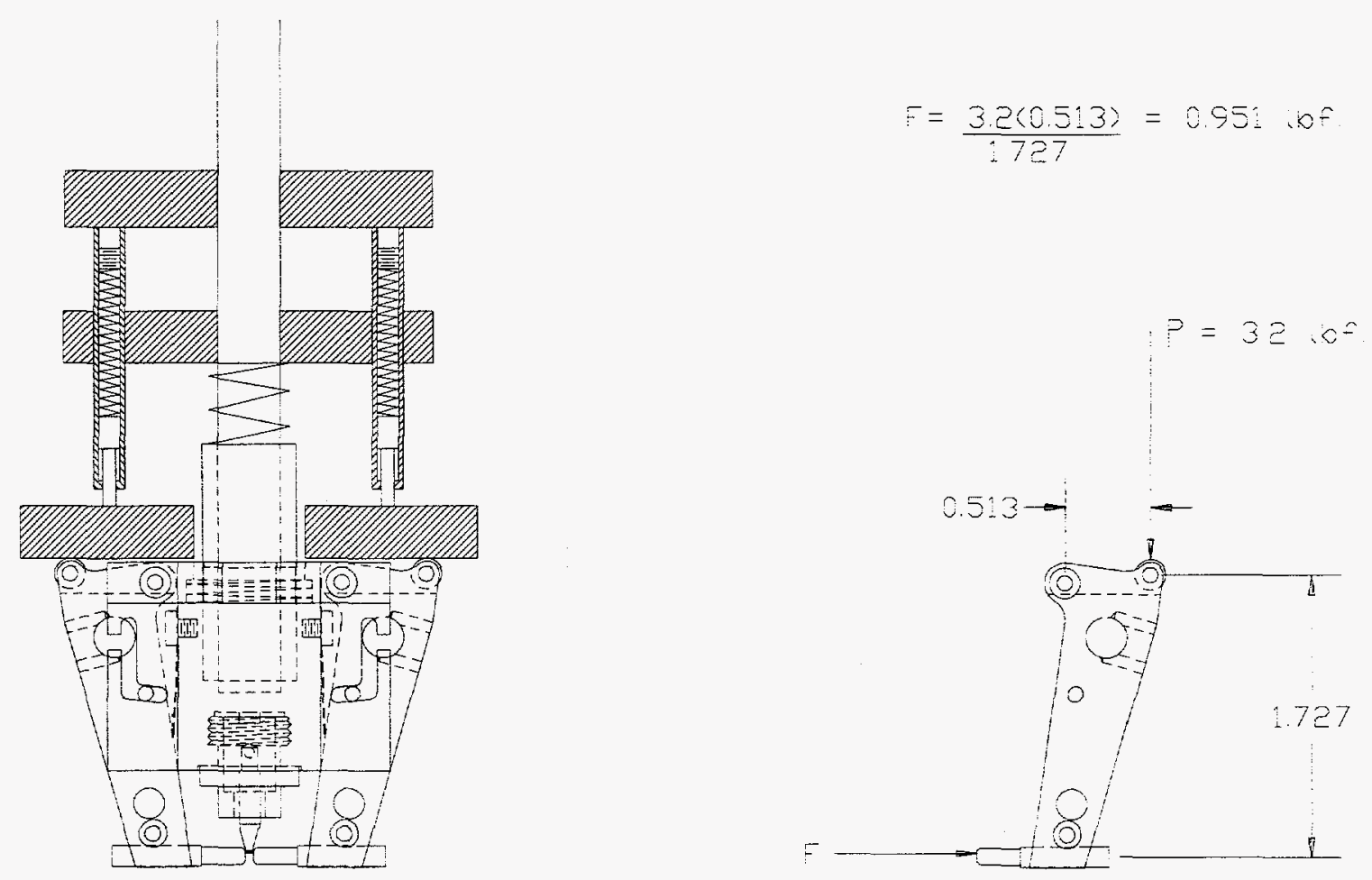

Figure 27. Free-Body Diagram of Chuck

For static equilibrium, a summation of moments about the pin connection must be zero such that:

$P(0.513)=F(1.727)$

where:

$P=$ the force from the spring plunger 
using the spring force found to be $3.2 \mathrm{lbf}$ and rearranging to find the force $F$ :

$$
\begin{aligned}
& F=\frac{3.2(0.51)}{(1.727)} \\
& F=0.95 \mathrm{lbf}
\end{aligned}
$$

\section{Development of Method for Feeding High Reliability Components to System}

The ability to feed high reliability components to the pick and place system was developed. The three common methods found for feeding components to a pick and place machine utilize components packaged in waffle packs, tape reels, and vibratory stick magazines. Waffle pack feeding consists of picking components out of the plastic trays known as waffle packs. The waffle packs are molded with individual pockets for each component arranged in an array pattern. Tape feeding is the method most commonly used in industry. The tape reel consists of a long plastic tape commonly $8 \mathrm{~mm}$ or $16 \mathrm{~mm}$ wide which is formed to include individual pockets for each component. The components are sealed within the pockets by a cover tape and wrapped around a reel similar to an $8 \mathrm{~mm}$ or $16 \mathrm{~mm}$ movie reel. After each component is picked up by the head, the tape feeder automatically peels off the cover tape and indexes the next pocket of the plastic tape forward into the pickup position. Stick magazine feeding uses components packaged within metal or plastic tubes known as magazines. The components are fed forward within the magazines to the pickup head by a linear vibratory feeder.

At the beginning of the project, stick magazine feeding was developed as the primary method since a large number of separate components were to be fed in small quantities per assembly, and the components were not available from the component vendors packaged in tape reels. Stick magazines are commonly used for feeding large components such as DIPs, LCCs, PLCCs, and flatpacks. They are not often used for feeding small components. Waffle packs were not chosen due to their space consumption and the setup problems of opening and positioning a large number of waffle packs next to each other on the machine. The incorporation of vibratory feeding for the system required the following developments:

- Characterization and Development of Vibratory Feeders

- Characterization and Development of Stick Magazines

- Development of Control System for Feeders

- Wear Analysis of Components Fed Within Magazines

- Development of Automatic Stick Magazine Loader

\section{Characterization and Development of Vibratory Feeders}

Vibratory feeders manufactured by Quad System Corporation and Ismeca were compared and characterized. Studies were run with a piezoelectric accelerometer and oscilloscope to characterize the acceleration wave of the feeder. Both feeders are driven by an electromagnet. The pull of the electromagnet acts on a block supported by leaf springs that are positioned at an angle. The block is aluminum with a steel insert that is attracted by the magnet. The top plate used to support the stick magazines is bolted to the top of this aluminum block. The 
deflection and release of the block supported by the leaf springs acts to drive the top plate of the feeder by accelerating it in a direction normal to the angle of the leaf springs. This creates an acceleration vector for the top plate of the feeder with both a horizontal and vertical component. If the vertical component of the acceleration vector is large enough to reduce enough of the friction between the component and magazine surface (by reducing the normal force between the surfaces caused by the force of the weight of the component), the component will slide forward from the horizontal component of the acceleration. If the vertical component of acceleration is greater than the acceleration due to gravity, the component will actually leave the surface of the stick magazine and be thrown forward due to the horizontal component of the acceleration on each cycle of the sinusoidal acceleration wave. If the acceleration is too large, the component will bounce within the magazine, and the feeding will become erratic. The vibration characteristics of the feeders were determined using an Endevco model 2222C piezoelectric accelerometer, PCB Piezoelectronics model 462A charge amplifier, and a Tektronix model 7854 oscilloscope. The accelerometer was attached at various positions on the top plates of both feeders. The acceleration wave or each feeder was analyzed from its display on the screen of the oscilloscope. A discussion of both the Ismeca and Quad feeders and their vibratory characteristics are as follows.

- Ismeca Vibratory Feeder - The Ismeca feeder uses a driving unit with a vertical electromagnet that pulls straight down on the block mounted to the feeder top plate. The leaf springs are at a 65-degree angle from horizontal and force the motion and acceleration of the feeder plate to be at a 25-degree angle from horizontal. The Ismeca feeder supports the top plate of the feeder by the vibratory driver and by two leaf springs at the 65-degree angle at the back of the feeder. The frequency of vibration for the feeder is twice the frequency of the $110 \mathrm{VAC}, 60-\mathrm{Hz}$ power input. This $120-\mathrm{Hz}$ vibration frequency is due to the downward motion from the pull of the electromagnet twice per period of the power input signal independent of the direction of the current running through the magnetic coil. The slots in the top plate of the Ismeca feeder which hold the stick magazines are machined at a 7-degree angle from horizontal. This tilts the magazine on its edge, causing the components to reference against one side of the magazine track as they travel along its length due to gravity and the vibration. The acceleration wave of any position on the top plate of the Ismeca feeder was a smooth $120-\mathrm{Hz}$ sinusoid and it fed all components very well. The top plate of the feeder was rigidly mounted by the driver and back leaf springs and provides a level surface for placing the stick magazines.

- Quad Systems Vibratory Feeder - The Quad feeder uses a driving unit with both the spring and electromagnet at a 65-degree angle from horizontal. The top plate is 4 inches wide and is positioned onto the driver by tooling pins and supported only by an attachment of the back end of the plate to the vibratory driving unit. This attachment method does not provide a rigid mount for the top plate. As a result, pressure against it will cause the top plate to shift and change the pickup position of each stick magazine loaded on that plate. The slots in the top plate of the Quad feeder which hold the stick magazines are flat in contrast to the 7-degree angle from horizontal of the Ismeca feeder. This does not create the edged reference for the components provided by the angle but allows the components to lie flat. The edge reference is unnecessary since the components are positioned on the center of the vacuum tip by the centering jaws, and the flat position of the component 
allows the vacuum tip to sit squarely on it for a better vacuum seal during pickup. The Quad feeder uses a circuit to drive the electromagnet. It contains an option designed to double the vibration frequency by the selection of the three-position on/off switch. This bottom setting of the switch is labeled "half wave." The top setting, designed to double the vibration frequency, is labeled "full wave." The feeder uses a 24-VAC, $60 \mathrm{~Hz}$ power input signal. The Quad feeder functioned very poorly. The ability to feed the smallest component $(0.055 \times 0.050 \times 0.020$ resistor) was poor. It was difficult to adjust the vibration level to a value which would feed the smallest components along the stick magazine well without causing the components to cascade out of the front end of the magazine. The acceleration waves and power input to the electromagnet for the feeder at the two wave settings was investigated. The acceleration waves displayed on the oscilloscope at the half and full wave settings were rough but periodic with jagged peaks and valleys. The shape, amplitude, and frequency of the acceleration waves varied at different positions along the plate. A comparison of the full and half wave settings was made using the same feeder set at the same vibration level and the accelerometer placed at the same position. For the full wave setting, the shape of the wave repeated itself on every other major peak. The frequency found by measuring the time needed for the wave to repeat itself on the oscilloscope screen was about $250 \mathrm{~Hz}$. If the wave was assumed to be a sinusoid with each major peak as part of a sinusoidal wave, the frequency would be doubled to $500 \mathrm{~Hz}$. At the half wave setting, the wave shape repeated itself on every fourth major peak. The frequency found from the time needed for the wave to repeat itself was about $60 \mathrm{~Hz}$. If the wave was assumed to be a sinusoid with each major peak as part of a sinusoidal wave, the frequency would be quadrupled to about $250 \mathrm{~Hz}$. When the power output from the control circuitry to the electromagnet was viewed on the oscilloscope, the half wave setting looked like a rectified sinusoid and the full wave added a short pulse in between the peaks of the half wave.

Based on the investigations of the Ismeca and Quad vibratory feeders, a feeder was designed incorporating the positive attributes of both. The feeder uses an Ismeca driver and a 4-inch wide top plate. The top plate is positioned by tooling pins and attached by thumb screws to a bar which is supported by the vibratory driver in the front and leaf springs in the back. This arrangement provides a rigid support for the top plate similar to the Ismeca feeder but allows the top plate to be easily removed and precisely replaced via the tooling pins. The slots in the top plate which hold the stick magazines are flat to benefit the pickup process. Another addition to the design of the top plate used for the smallest components was the addition of $1 / 16^{\prime \prime}$ dowel pins to act as the stops for the components and stick magazines. These dowel pins were pressed into the plate at a 5-degree angle facing away from the component and reduce the drag against the component during pickup.

\section{Characterization and Development of Stick Magazines}

Most of the stick magazines used were shapes extruded from aluminum to form a long tube. Some magazines were machined from aluminum or other soft metal alloy or stainless steel sheet formed into a tube. The magazines are shaped to form the track that the components slide within when they are being fed to the machine or loaded into the magazine and two flanges which partially cover the track in order to hold the components inside. Standard extruded aluminum stick magazines were ordered when possible. At the beginning of the project, the only supplier found to offer extruded aluminum stick magazines was the Ismeca 
Company. Since that time, vibratory stick magazines and feeders have become available from the U.S. Vibra Company. Some component sizes required the development of custom stick magazines. The following processes were developed to either alter existing magazines or manufacture custom magazines when necessary.

- Trisodium Phosphate Etch and Re-anodize - A process was developed to modify existing stick magazines to accommodate slightly larger components than will fit within the track of the magazine. The magazines were submerged in a tank of trisodium phosphate which etched away the anodize coating and some of the aluminum from all surfaces. The etching process was controlled by the amount of time the magazine was left in the tank. This time was dependent on the condition of the tank solution. To determine how long the magazines should be left in the tank, one magazine was timed as it was processed separately with frequent removals from the tank for measurements of the inside width or height of the track. To perform these measurements small "go, no-go" gauges that could be slid inside the length of the magazine track were made from number drills as shown in Figure 28 . The rest of the magazines were left in the tank as long as was required for the "go" gauge to slide inside the track of the first magazine. The anodize coating was then reapplied by a clear sulfuric anodizing process.

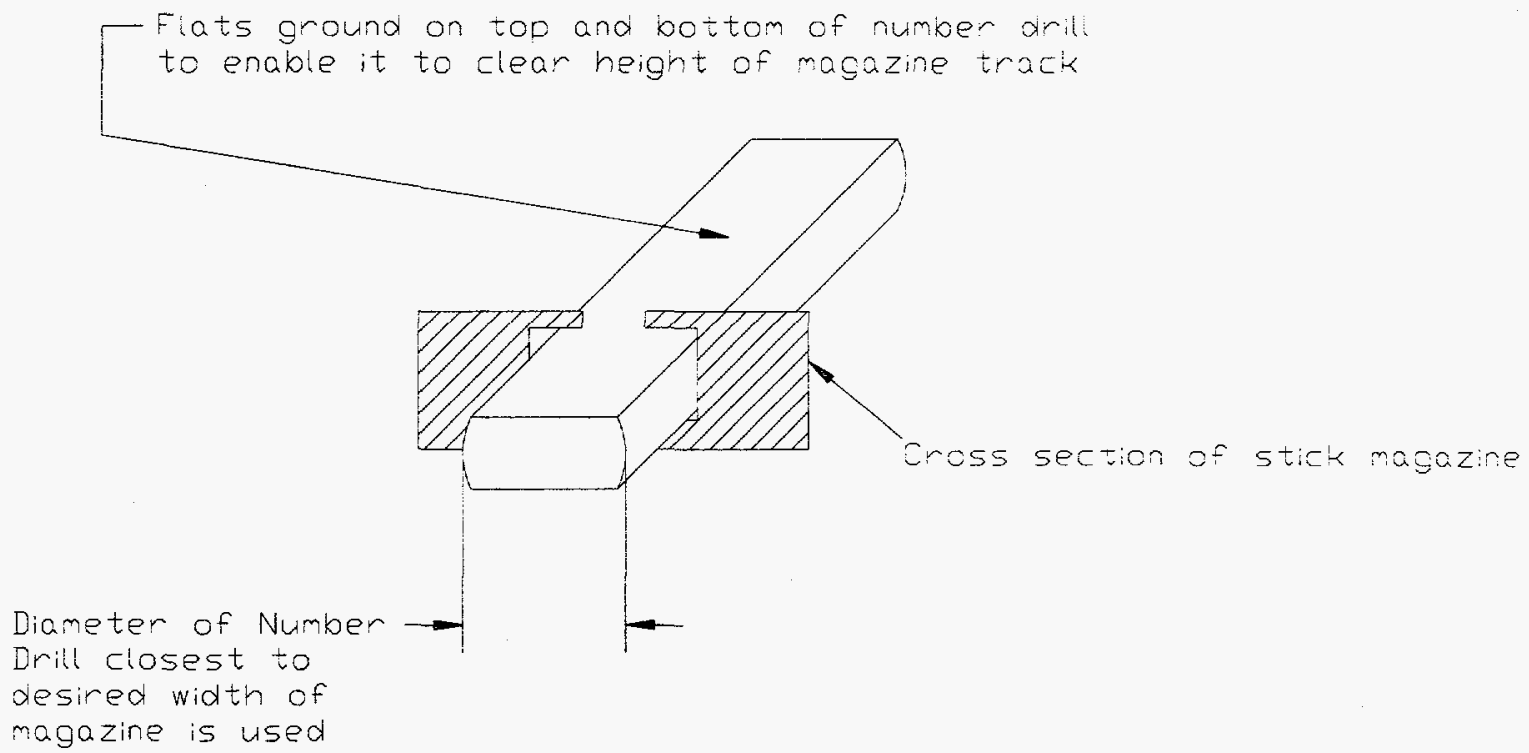

Figure 28. Magazine Go and No-Go Plugs

- Reforming Flanges Covering Magazine Track - A process was developed for pressing down the flanges which cover the track of the magazine to prevent thin components from stacking on top of each other. The stick magazine used to feed a chip resistor measuring $0.100 \times 0.105 \times 0.050$ inch plus or minus 0.005 inch was made from a standard extruded aluminum magazine with a nominal track width of $2.7 \mathrm{~mm}(0.106 \mathrm{in}$.) and height of $0.75 \mathrm{~mm}(0.030 \mathrm{in}$.). The components at the high limit of the tolerance would often jam within the magazine when loaded with the 0.100 -inch dimension across the width of the 
track. It was also desirable to load the component into the magazine with the 0.105 -inch dimension across the width of the magazine track to accommodate the sensor arrangement of the automatic loader. The magazine was placed in the trisodium phosphate bath until the width of the track became 0.113 in. plus or minus 0.002 in. This also increased the height of the magazine track to about 0.037 in. This additional height allowed the chip resistors at the smaller end of the thickness tolerance to stack within the magazine and jam. The flanges were pressed down until the bottom of the flanges were at a height above the track of 0.028 in. plus or minus 0.004 in. to prevent stacking. To bend the flanges down, a $5 / 16$ in. steel rod was laid on top of the flanges along the full length of the magazine and the magazine and rod were placed in a hydraulic press. The setting of the press was determined using one stick magazine and incrementally adjusting the depth of the stroke of the press until the flanges were pressed down to the correct depth. To obtain even results along the length of the magazine, the magazine and rod were pressed and then turned around 180 degrees and pressed again.

- Custom Made Stainless Steel Tubes For LCCs - Custom stainless steel tubes were made to feed LCCs in order to meet their tight static sensitivity requirements. The tubes were made from a three hundred series stainless steel and electropolished. They provided a conductive enclosure to act as a static shield for the components. To test if the tubes created a static charge as the components slide within them, they were slid inside the tubes and allowed to drop into a Faraday Cup. The charges created on the components were about 100 times less than the charges generated by sliding the components in a plastic tube. The stainless steel generated a 0.003-nanocoulomb charge on the component. The aluminum generated a 0.04 -nanocoulomb charge. The charge generated sliding through the plastic tube was 4.05 nanocoulombs.

- Custom Machined Stick Magazines - Custom stick magazines were machined from aluminum using an endmill or keyseat cutter that was ground to a custom shape. After machining, the magazines are anodized using a sulfuric acid solution. The limiting factor for machining the t-slot-like track in a magazine lies in the narrow width of the space needed between the flanges of magazines used for small components. The shank of the cutting tool must fit between the flanges. A magazine similar to the extruded aluminum stick magazine used to feed the smallest resistor would be very difficult to machine. This magazine has a gap between the flanges of only 0.020 in. A custom-made magazine for a component this small would probably need to be made by machining the track and then covering it with flanges that would attach with small capscrews.

- Electropolish Deburr of Inside Magazine Track - A method was developed for deburring the inside track of a stick magazine using an electropolish process. This process was used to deburr the inside track of a magazine used for feeding the smallest resistor. At the beginning of the development of vibratory feeding, an extruded aluminum magazine was not available for the smallest resistor. The Ismeca Company offered a machined nickel brass magazine $(62 \% \mathrm{Cu}, 18 \% \mathrm{Ni}, 20 \% \mathrm{Zn})$. None of these magazines fed well. Upon investigation of the component stoppage points, burrs from the machining process were found in the inside track of the magazines. Due to the small size of the magazine track $(0.060 \times 0.029$ inch $)$, magazine deburring was difficult. Methods tried included bead 
blasting, chemical polishing, lapping with diamond compound using a custom-made tool, and electropolishing. Feeding was greatly improved after the electropolish process. This process used a masking solution on all but the inside track of the magazine. This forced the path of the current to the magazine track. An extruded aluminum version of this magazine became available and eliminated the need to use this process.

\section{Development of Control system for Vibratory Feeders}

The components were originally fed with all vibratory feeders running continuously. The collection of working feeders vibrated the machine top, hampering the feeding ability of each individual feeder, and produced unnecessary wear of the solder terminations of the components. A control system was developed to eliminate these problems using OMRON E3HF-1E2 infrared through-beam sensors and an OMRON C40K-CDR-A programmable logic controller (PLC) with the OMRON 3GA6-PRO15-E programming console. The sensors were mounted on each side of the vibratory feeder with the infrared beam projected across the pickup area of the stick magazines. The inputs to the PLC were a pair of through-beam sensors for each feeder. The output consisted of an internal relay for each feeder which acts to turn it on or off. The controller was programmed to turn the feeder on for a short period of time (three seconds for most feeders) in order to feed a component into position each time a component is picked up from that feeder. This greatly reduces the amount of time the components are vibrated and only allows one feeder to vibrate at a time. The controller detects the pickup (or attempted pickup) as the vacuum tip of the chuck assembly moves downward into the position to pick up a component and blocks the infrared beam between the sensors. The logic for this program was created to turn the feeder on only if the through-beam of the sensors was broken and restored. This prevents a blockage of the through-beam or malfunction of the sensors from causing the feeder to vibrate continuously. A separate input was created to allow any or all feeders to run continuously if desired. This input was a toggle switch that when closed provides a signal to a particular input location of the controller. The timers, contained within the PLC for controlling the time the feeders are programmed to vibrate, begin timing when the input to the timer is turned on and create an output when the time has elapsed. This output from the timer remains on until an input is received, resetting the timer. The through-beam sensors provide an input signal to the controller when the beam is broken. A discussion of the programmed logic the controller uses each time it samples the condition of the system follows.

1. The controller checks the input from the sensor assigned to the feeder (through-beam blocked $=$ ON).

2. If the sensor is OFF (not blocked), the input of the timer assigned to that feeder is turned ON or is allowed to remain ON. If the sensor is ON (blocked), the timer input is turned OFF. (This resets the timer.) The timer output turns $\mathrm{ON}$ when the programmed time elapses after the timer input is initially turned $\mathrm{ON}$ (three seconds). Once this time has elapsed, the timer output remains ON until the timer input is turned OFF.

3. If the output of the timer is OFF (less than three seconds has elapsed since the sensor was blocked) and the sensor is OFF (not blocked), the output relay is closed, turning the feeder ON. 
4. If the input from the toggle switch for continuous feeding in $\mathrm{ON}$, the feeder is turned $\mathrm{ON}$.

5. The system begins again at step 1.

An example program for a feeder with sensor input number 4, timer number 5 (set at three seconds; note that one unit of time for the timer equals 0.1 second), feeder output relay number 102 and toggle switch input number 207 is as follows.

- $\quad$ LD NOT 0004

- TIM 05

- TIM DATA 30

- $\quad$ LD NOT TIM 05

- AND NOT 0004

- LD 0207

- OR LD

- OUT 0102

\section{Wear Analysis of Components Fed Within Magazines}

A study was conducted to determine if the solder on the terminations of the components was excessively worn from the stick magazines due to the vibration. This study was done prior to the development of the control system for the vibratory feeders. The control system reduces the vibration time of the components to a small fraction of that with the feeders running continuously. The components which would have the greatest time of vibration are the smallest size of resistor $(0.055 \times 0.050 \times 0.015$-inch resistor), used only once per assembly. For this component the best case for the time at vibration without the controller was about 145 hours (approximately 30 minutes assembly time per circuit with about 290 components loaded within the stick magazine). This only accounts for the time the feeder is on during the assembly process, neglecting vibration time when the feeder is unintentionally left on. With the controller, the time at vibration is dependent on the size of the component and the relative usage the component has with respect to the other components on the same feeder plate. If the usage is constant for all positions on the feeder plate, the magazines will become empty at the same time and the last few components in the stick magazines of each position will experience about the same amount of vibration. This time at vibration is about 3.9 hours for the smallest resistor ( 3 seconds each time a component is picked up from a feeder plate for 16 stick magazines loaded with 290 components each). Components used less often than others on the same feeder plate will experience more than 3.9 hours at vibration. This additional wear is due to the vibration experienced after each pickup as the magazines of the higher usage components are emptied and replaced. The largest component (64-pin LCC with dimensions of $0.700 \times 0.700 \times 0.090$ inch) would have the least time of vibration when used only once per assembly. For this component the best case for the time at vibration without the controller was about 7.5 hours (approximately 30 minutes assembly time per circuit with 15 components loaded within the stick magazine). If the usage of these components is common for all four positions on the feeder plate, the time at vibration is only about 5 minutes (5 seconds each time a component is picked up from the feeder for four stainless steel tube magazines loaded with 15 components each). To determine the wear of the solder 
terminations, samples of each component size were vibrated at an amplitude slightly higher than normally used to feed them and analyzed with a scanning electron microscope and microprobe. The chip resistors and capacitors were vibrated for 26 hours. The solder terminations were then analyzed on the worn surface of the solder and along a cross section made through the termination. The cross-sectioned view of the terminations of the smallest resistor showed a significant amount of wear of the solder along the thin areas around the edges of the component. Only a thin layer of tin/lead solder was left in some areas as the vibration nearly wore through to the nickel barrier layer within the solder termination. The thickness of the solder is much greater on the chip capacitors. From this evaluation it was determined that no foreign particles were found in the worn solder surfaces due to the vibration against the anodized surface of the stick magazines. The transistors and LCCs were analyzed after 2 hours at vibration. The surfaces were hardly worn, but a few trace nickel particles from the nickel-plated aluminum stick magazine were found in the surface of the transistor solder. A few trace stainless steel particles from the stainless steel tubes were found in the solder surface of the LCCs. As the transistors and LCCs vibrate within the stick magazines or tubes, the top corners of the ceramic edges of the components rub against the nickel plating or stainless steel. The transistors are no longer fed within stick magazines, due to pickup problems with the stick magazines. The transistor to be picked up often became caught on the front lead of the transistor behind. The transistors are now picked out of a specially machined waffle pack carrier and do not experience any vibration. The use of the control system reduced the vibration time of the LCCs to only a few minutes.

\section{Development of Automatic Loader for Stick Magazines}

A custom automatic loading machine for stick magazines was developed which could be used for all chip component sizes to be used on the circuits assembled with the system. The existing loading systems which could have been purchased were not designed for loading the smallest chip resistor which was the component most commonly placed by the system. Another problem with the existing loaders is the large amount of time required for a small quantity of components to be loaded due to the use of large spiral bowl feeders in their design. The loader was developed using a back and forth design to feed components from bulk to the loading area of the machine. This design reduces the time required for loading a small quantity of components by reducing the distance the component travels from the bottom of the bowl to the loading area. To properly orient the components before loading into the magazine, both mechanical orientation features and sensors were used. The mechanical orientation features are commonly used to ensure that the components are presented to the magazine in single file without being stacked on top of one another and to orient rectangular-shaped components. Square components can not be oriented mechanically. Photoelectric sensors were used to automatically determine the orientation of the solder terminations of square components. Photoelectric sensors were also used for all chip resistors to ensure that they were loaded with the dark resistive element facing upwards. The sensors detect either the bright solder of the component termination or the white ceramic of the body of the component opposite of the dark resistive element. The sensors were connected to controlling circuitry which, if activated by a misoriented component, opens a solenoid valve, supplying air to a nozzle that blows the component back into the vibratory bowl. One of two systems is used, depending on the geometry of the component to be loaded. To orient square components, a single sensor is positioned over the center of a component just before it is to be loaded into the magazine. 
The controlling circuitry used with this system energizes the solenoid to blow the component back into the bowl if either the solder termination or white ceramic is seen by the sensor. This ensures that square resistors are only loaded with the terminations parallel to the direction of feeding (never crossing the sensor) and with the dark resistive element facing upwards. Two sensors are used to orient rectangular resistors. The tips of these sensors are positioned next to each other over the component in line with the direction of feeding. As the component passes into the view of both sensors, one sensor will "see" the solder termination while the other sensor "sees" the body of the resistor. If the dark resistive element is facing upwards, the sensor over the body of the resistor will not be energized. The controlling circuitry used with this system energizes the solenoid to blow the component back into the bowl only if both sensors are energized at the same time due to the detection of both the solder termination and the white ceramic. The loader incorporates micrometer adjustments along three independent axes to properly align the magazine to be loaded. The automatic loader is defined by an FM\&T tool drawing.

\section{Accomplishments}

The ability was developed to automatically assemble surface mount devices on circuits, including the characterization of the assembly process and improvements made to the system to increase the accuracy and repeatability of this process. Accuracy and repeatability of the system were characterized by measurements of the individual system components as well as the actual placement of components on a specially designed gauge. Forces and stresses experienced by the components when handled by the system were analyzed. The ability to deliver surface mount components to the system was developed by the design and development of stick magazines, vibratory feeders, feeder control system, and an automatic stick magazine loader.

\section{Future Work}

Trends in surface mount circuitry may require additional development of greater placement accuracy and repeatability than established by this system to correctly place fine pitch gull wing packages, smaller chip components, or semiconductor die. 


\section{Reference}

${ }^{1}$ Ferdinand P. Beer and E. Russell Johnston, Jr., Mechanics of Materials, New York: McGraw-Hill Inc., 1981. 


\section{Appendix A \\ Pick and Place Data Precision and Accuracy Analysis}

Appendix $A$ is the first analysis performed on the collected data. The difference in centering jaw types (thin testing jaws versus thick insulating jaws) was not considered in the analysis. The paragraph under "Repeatability of Head Movement in $X$ and $Y$ " makes the statement that "there is no significant $z$ travel available in the positioning head." Actually the $Z$ axis was omitted from this part of the study because its accuracy is less critical, and it was investigated separately as mentioned in the body of the report. The results of the studies for repeatability of $x, y, z$, positional system and machine homing were based on the analysis contained in Appendix A.

The variation from one day to another (labeled as the day's effect) was found to correlate well with machine warm-up in the $X$ direction and the results stated in the body of the report. Assume that this variance is due to warm-up and may be factored out if the system is allowed to warm up each day. A third set of data was taken to confirm this in the $X$ direction. A third set of data was not taken in the $Y$ direction, and the inconsistency between the first two sets resulted in factoring the day's effect back in as a random variation. The fourth set of data was taken in both the $X$ and $Y$ directions, with an adequate warm-up period each day resulting in no variation from a day's effect. However, the fourth set of data was taken over only a two-day period. To further prove that the day's effect was actually due only to lack of machine warm-up, data would need to be collected over a longer period. The results mentioned in the body of the report assume that the day's effect variation was due to the system being cold and that this variation is not present if the machine is warmed up. 


\section{Allied-Signal Aerospace Company}

Kansas City Division

Kansas City, Missourn

Date: December 8, 1992

To: Scott Yerganian

From: Jöhn Vic Grice

Subject: Data Analysis of Pick ' $n$ ' Place Capability Data

Analysis of the capability data for the Quad star-T pick ' $n$ ' place system is complete. The text is attached in paper and electronic formats for inclusion and editing in your

report. The capability to place components is estimated to be within 0.005 in. The text describes the data collected, the analysis, and the applicable results.

Data was analyzed in three areas to estimate the expected range of placement errors. All values are based on data reported in thousands of an inch (0.001 in.). The three areas are

1. head positioning in $X$ and $Y$,

2. homing, including old vs. new modify codes, and

3. component centering and placement.

Component centering and placement provides the largest source of variability, due primarily to bias in the rotation of the placement jaws. The biases are less than 0.0065 in. for the $X$ direction and 0.0031 for the $Y$ direction. The variability due to positioning, homing, and repeats using the new modify codes is approximately \pm 0.0021 in. in $X$ direction and \pm 0.0011 in. in the $Y$ direction. If the calibration is performed to center the positioning head in the bias range, the actual bias is only half the bias range. The range of placement errors in this case is approximately $\pm 0.0043 \mathrm{in}$. in the $X$ direction and \pm 0.0021 in. in the $Y$ direction. These values provide a radial error limit of 0.0048 in.

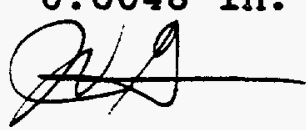

JVG/jvg

Attachment 
The capability of the placement may be evaluated in three main areas.
1. Repeatability of the Positional system in $X$ and $Y$.
2. Repeatability of Homing (dial indicator)
3. Repeatability of Component Centering and Placement

Data was collected in each area and analyzed to estimate the expected range of errors. All values are based on data reported in thousands of an inch (0.001 in.). The analyses of the three areas are included below. A fourth area was observed but is not reported here. The fourth area is the repeatability of the vision portion of the system. This portion is integral to the other functional areas and a separate capability for it is not needed.

Component centering and placement provides the largest source of variability, due primarily to bias in the rotation of the placement jaws. The variability due to positioning and homing using the new modify codes is approximately $\pm 0.002 \mathrm{in}$. in the $X$ direction and \pm 0.001 in. in the $Y$ direction. The bias from jaw rotation increases the expected placement error range to approximately \pm 0.0043 in. in the $x$ direction and \pm 0.0021 in the $Y$ direction when the head is calibrated to the middle of the bias range for head rotation. These values are consistent with a radial range less than \pm 0.005 in.

The term "expected range of errors" is defined as two times the standard deviation of the errors as estimated from the data plus an estimate of any bias detected. The general analysis technique is to separate the components of variance from the data according to the identified factors. This is possible when the factors are observed in a nested fashion where multiple readings are made on successively lower level factors. For example, multiple measurements were made between successive homings. This allows estimation of a component due to homing and one due to repeated measurements. Variance components are added to obtain estimates of the total variance. Then the square root is applied to compute the total standard deviation for a single reading. Thus, the total standard deviation is less than the sum of the standard deviations for the components of variation. Twice this standard deviation is used as the expected range of errors. This value is then added to the estimate of the bias, or range of biases. This yields a value that is likely to cover any errors that occur in using the system under the stated conditions. The factor of two provides coverage that is approximately 90 to 95 percent likely. 


\section{Repeatability of Head Movement in $X$ and $Y$}

The data was collected according to the general layout in Figure $1 \mathrm{~A}$ in the appendix. The $z$ heights were omitted because the placement is essentially two-dimensional and there is no significant $z$ travel available in the positioning head. The analysis results are contained in Table 1 below. The raw data is contained in Table IA in the appendix.

TABLE 1: VARIANCE COMPONENTS OF HEAD MOVEMENT IN X AND $Y$

\begin{tabular}{lcc} 
Source & $\mathrm{X}$ & $\mathrm{Y}$ \\
\hline Location & 0.109 & 0.123 \\
Repeats & 0.046 & 0.060 \\
Total & 0.155 & 0.182 \\
Two Sigma & 0.787 & 0.854
\end{tabular}

The results in Table 1 are the variance components due to changing locations and to performing repeated measurements. The values for 'Two sigma' are two times the square root of the total variance. The Two sigma estimates the practical range for the errors in head movement on a plus/minus basis. A significant portion of this range is due to changing locations, as expected. This analysis does not include effects due to Homing which are discussed later. For example, most of the errors in head movement in the $x$-direction should fall in a range of \pm 0.787 thousandths. That is, the positioning system should be able to return to within about $\pm 0.0008 \mathrm{in.}$ of specified locations regardless of the actual location. (Note that this is valid only if no homing is executed.)

\section{Repeatability of Homing}

The data was taken on two or three days in both $X$ and $Y$ directions. Each direction required a separate set-up. Seven "homings" were performed each day and two measurements were made after each homing. Table 2 summarizes the results. The raw data are contained in Table $2 \mathrm{~A}$ in the appendix. In collecting the data, a different set of conditions was applied for each day.

\section{Set 1. Homing: Default.}

$$
\begin{array}{ll}
\text { Days }(X): & 1^{\text {st }}=\text { Warm, } 2^{\text {nd }} \& 3^{\text {rd }}=\text { Cold } \\
\text { Days }(Y): & 1^{\text {st }} \& 2^{\text {nd }}=\text { Cold, } 3^{\text {rd }}=\text { Warm }
\end{array}
$$


Set 2. Homing: New modify codes for homing.

Days $(X): \quad 1^{\text {st }}=$ Warm, $2^{\text {nd }}=$ Warm, $3^{r d}=$ Cold

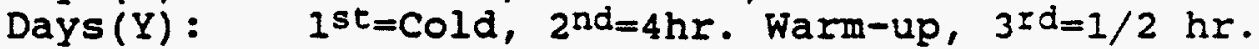
Warm-up

Set 3. Homing: Default.

Days $(\mathrm{X})$ : $\quad$ Same day, Day 1 (Cold) \& Day 2 (1.5hr. Warm-up)

TABIE 2: VARIANCE COMPONENTS FOR HEAD POSITIONING

\begin{tabular}{cccccc} 
& \multicolumn{2}{c}{ Set 1} & \multicolumn{2}{c}{ Set 2} & Set 3 \\
& X & $Y$ & $X$ & $Y$ & $X$ \\
\hline Days & 1.507 & 0.317 & 0.601 & $0.000^{*}$ & 0.560 \\
Homing & 0.477 & 0.489 & 0.201 & 0.069 & 0.242 \\
Reps. & 0.105 & 0.161 & 0.114 & 0.029 & 0.146 \\
Total & 2.089 & 0.967 & 0.916 & 0.098 & 0.948 \\
Two Sigma-Tot & 2.891 & 1.967 & 1.914 & 0.626 & 1.947 \\
Var(Home+Reps) & 0.582 & 0.650 & 0.315 & 0.098 & 0.388 \\
Two Sigma-HR & 1.526 & 1.612 & 1.122 & 0.626 & 1.246 \\
Incr. Due Home & 135.4 & 100.9 & 66.2 & 83.8 & 63.0 \\
Var (Reps. Only) & 0.105 & 0.161 & 0.114 & 0.029 & 0.146 \\
Two Sigma-R & 0.648 & 0.802 & 0.675 & 0.341 & 0.764
\end{tabular}

* Days not significant at alpha $=.05$.

The Total row above represents the sum of the variance components and estimates the overall variance of the head positioning. The 'Two sigma-Tot' row represents two times the standard deviation (the square root of the variance). This row represents the essential range of random head positioning errors to be expected during long term use. Day-to-day differences and variation due to homing contribute significantly in all three sets of conditions except for the $Y$-direction when the new modify codes for homing are used. In this case, the Days effect is not significant.

The values for essential ranges of measurement variability accounting for all components are listed in the Two sigma-Tot row above. These values are 2.891 (in units of 0.001 in.) for the $X$-direction and 1.967 in the $Y$. The values are 1.914 for the $\mathrm{X}$-direction and 0.626 for the $\mathrm{Y}$-direction. 
The set 2 conditions (new modify codes for homing) appear to provide a reduction in total variability for both $X$ and $Y$. This reduction is primarily due to the Days effect and can't be detected as significant. This is especially clear in view of the Days effect as Warm-Up (see Days discussion below). In the Y-direction, the new modify codes (Set 2) do yield significantly smaller variability. Here, the Days effect was not significant and estimated as zero.

The specific effect of variability due to repeated homing of the machine is listed in Table 2. The inclusion of Homing with the Repeats component (as shown on the 'Two Sigma-HR' line above) increases the practical error range by from 63 to 135 percent of the variation over Repeats only. When the Days component is included, the increase due to Homing is less, ranging from 13 to 84 percent (as shown in the Two Sigma-DR and Incr. to Total lines, above).

Set 3 conditions were only observed for the $x$ direction. The data appears to be more consistent with the data from set 2 than that from set 1 . However, all set 3 data was run in one day so that the days effect is not really days and the old modify codes were used. There is no way to tell which is the real effect in this situation but this is not inconsistent with the data in the first two sets. No further analysis was pursued in lieu of the confirmatory data described below.

The Days effect incorporated warm-up time to see how warm-up might affect the machine. The Days effect on the average positioning deviation was significant in the $x$ direction in both set 1 and set 2 and the warm-up time correlates with the differences. Table 3 shows the averages for each direction, day, and set and the corresponding warm-up condition. The overall effect is to decrease the positioning deviation by approximately 0.0015 in. when the machine warms up at least a half hour. The Days variance component was computed and included in the total in Table 2, above. In most production situations, the machine will be run in a warmed-up state and this effect will not be present. The Var(Home+Reps) I ine in Table 2 represents the variation in this situation.

For the $Y$ direction, the Days effect is significant in set 1 but not in set 2 . The warm-up time does not correlate with the Days variability. From this, the Days variability was assumed to be random and added to the total. The estimates of the variability are listed in the Days line in Table 2 . 
TABLE 3: EFFECTS OF WARM-UP ON POSITIONING

\begin{tabular}{ccc|cc|} 
& $\begin{array}{c}\text { Set 1 } \\
\text { Warm-up }\end{array}$ & $\begin{array}{c}\text { Average* } \\
\text { Deviation }\end{array}$ & $\begin{array}{c}\text { Set 2 } \\
\text { Warm-up }\end{array}$ & $\begin{array}{c}\text { Average* } \\
\text { Deviation }\end{array}$ \\
$\begin{array}{c}\text { X-Direction } \\
\text { Day 1 }\end{array}$ & Warm & -0.4357 & Warm & 0.3357 \\
Day 2 & Cold & 1.3857 & Warm & -0.1643 \\
Day 3 & Cold & 1.9786 & Cold & 1.400 \\
$\begin{array}{c}\text { Yirection } \\
\text { Day 1 }\end{array}$ & Cold & -0.7286 & Cold & 0.6357 \\
Day 2 & Cold & 0.1571 & Warm & 0.8071 \\
Day 3 & Warm & 0.4929 & Warm & 1.8429
\end{tabular}

- Averages connected by the vertical bars, 'I', are not significantly different at alpha $=0.05$.

A fourth set of data was collected to confirm the results of the first two sets. The results for this new data are summarized in Table 4. The raw data appears in Table 3A of the appendix. Table 4 also includes the results from sets 1 and 2 for comparison. The results for old (Fast) modify codes are denoted by 'Conf. $F$ ' and for the new (Slow) codes, by 'Conf. S'.

Generally, the new data confirms the trends in the first two sets. The $Y$ direction is again less variable than $X$ with the new modify codes (Set 2 vs. Conf. S). The $X$ and $Y$ directions had about the same variability for the con $F$ data and the $Y$ value was numerically smaller. For this data, the modify codes do not make a significant difference in the variability.

Days were not significant in either new set or direction. This partially due to observing only two days and to the fact that the machine was run in a warmed-up state. For the new modify codes, this was expected in the $Y$. The Homing effect was consistent in all sets. The Repeats variability is for the later data significantly smaller when using the old modify codes. The difference is not significant for the new codes. 
TABLE 4: CONFIRMATION OF FOR HEAD POSITIONING VARIATION

\begin{tabular}{|c|c|c|c|c|c|c|}
\hline & & Days & $\begin{array}{l}\text {-Varian } \\
\text { Homing }\end{array}$ & $\begin{array}{l}\text { Componen } \\
\text { Repeats }\end{array}$ & Total & Two Sigma \\
\hline set $1(F):$ & $\begin{array}{l}X \\
y\end{array}$ & $\begin{array}{l}1.507 \\
0.317\end{array}$ & 0.477 & 0.105 & 2.089 & $\begin{array}{r}2.891 \\
1.967\end{array}$ \\
\hline Conf. F: & $\begin{array}{l}\mathbf{L} \\
X\end{array}$ & $\begin{array}{l}0.0375^{*} \\
0.0802\end{array}$ & $\begin{array}{l}0.0775 \\
0.0742\end{array}$ & $\begin{array}{l}0.0706 \\
0.0250\end{array}$ & $\begin{array}{l}0.186 \\
0.174\end{array}$ & $\begin{array}{l}0.862 \\
0.835\end{array}$ \\
\hline Set $2(s):$ & $\begin{array}{l}X \\
Y\end{array}$ & $\begin{array}{l}0.601 \\
0.000^{*}\end{array}$ & $\begin{array}{l}0.201 \\
0.069\end{array}$ & $\begin{array}{l}0.114 \\
0.029\end{array}$ & $\begin{array}{l}0.916 \\
0.098\end{array}$ & $\begin{array}{l}1.914 \\
0.626\end{array}$ \\
\hline Conf. S: & $\begin{array}{l}X \\
Y\end{array}$ & $\begin{array}{l}0.192^{*} \\
0.263^{*}\end{array}$ & $\begin{array}{l}0.276 \\
0.064\end{array}$ & $\begin{array}{l}0.0125 \\
0.0225\end{array}$ & $\begin{array}{l}0.481 \\
0.1125\end{array}$ & $\begin{array}{l}1.387 \\
0.671\end{array}$ \\
\hline
\end{tabular}

*Days not significant at alpha $=.05$.

III.Best Shot at Accuracy and Repeatability Using All Developments

The evaluation of the best case accuracy and repeatability comes from the data taken by placing the psuedo-components on the calibrated glass slide. The data was taken for two machine configurations, vision system with manual adjustment and full programmed mode. The data analysis is summarized in Table 5. Table 4A of the appendix contains the raw data.

The Vision data represents operation in the most repeatable manner. No homing or days effects are present and additional off-line effort was expended to remove any overall bias to improve the accuracy of placement on other sites on the slide. The Program mode data represents typical operation conditions, which include the effects of days and homings.

This data contains the effect of rotational orientation. This effect is composed of the biases from the rotation of the placement jaws. These biases appear across $X$ and $Y$ directions and changes sign with rotation through 90,180 , and 270 degrees. The quoted range does not attempt to correct for this bias, since it cannot be removed. It is not random in nature and must be added to the Two sigma value to properly cover the expected range of deviations.

The vision system exhibits less variability in the vision mode but more bias, especially in the $x$ direction. The variability estimates are consistent with the values obtained earlier (cf. Tables 2 and 3 ). The major source of error is the bias from the rotation of the jaws. A portion of the bias can be removed mathematically by rotating the data through the negative of the angles of the placement orientation. However, in practice, this is not done. The biases from the corrected data are not reported. 
TABLE 5: PLACEMENT BIAS AND PRECISION USING MANUAL AND PROGRAMMED PLACEMENT

\begin{tabular}{|c|c|c|c|c|c|}
\hline \multirow{2}{*}{\multicolumn{2}{|c|}{ Source }} & \multicolumn{2}{|c|}{ Vision } & \multicolumn{2}{|c|}{ Program } \\
\hline & & $\mathrm{X}$ & $Y$ & $\mathrm{x}$ & $Y$ \\
\hline Bias, & no corr. & 6.150 & 3.700 & 4.408 & 2.025 \\
\hline & $\begin{array}{l}\text { Rep. Var. } \\
\text { std. } \\
\text { Two Sigma }\end{array}$ & $\begin{array}{l}0.3362 \\
0.5798 \\
1.1596\end{array}$ & $\begin{array}{l}0.1863 \\
0.4316 \\
0.8632\end{array}$ & $\begin{array}{l}1.124 \\
1.060 \\
2.120\end{array}$ & $\begin{array}{l}0.3158 \\
0.5620 \\
1.1240\end{array}$ \\
\hline Est. & $\begin{array}{l}\text { Err. Range } \\
\text { Half Range }\end{array}$ & --- & - & $\begin{array}{l}6.528 \\
4.320\end{array}$ & $\begin{array}{l}3.149 \\
2.124\end{array}$ \\
\hline
\end{tabular}

Consistent with the earlier data, the $Y$ direction exhibits less variability. The overall error range for placement accuracy is approximately \pm 0.0065 in. in the $x$ direction and \pm 0.0031 in the $Y$ direction. The variability estimates are approximately \pm 0.001 to \pm 0.002 in. The calibration is performed to center the machine origin coordinates at the center of the bias range. In this situation, only half the estimated bias range is necessary to cover the errors. The values are \pm 0.0043 in. and \pm 0.0021 in., respectively. In view of these estimates, placement within \pm 0.005 in. of target is attainable. 


\section{APPENDIX}

Contents

Figure 1A: Positional Accuracy Experimental Design Layout (\#1)

Table 1A: Pick ' $n$ ' Place Machine Capability

Table 2A: Pick ' $n$ ' Place Data for Head Positioning

Table 3A: Pick ' $n$ ' Place Machine Capability Confirmation Runs

Table 4A: Best Shot at Placement Bias and Precision 
Figure 1A: Positional Accuracy Experimental Design Layout (\#1)

\section{$\mathrm{X}$ - DIRECTION}

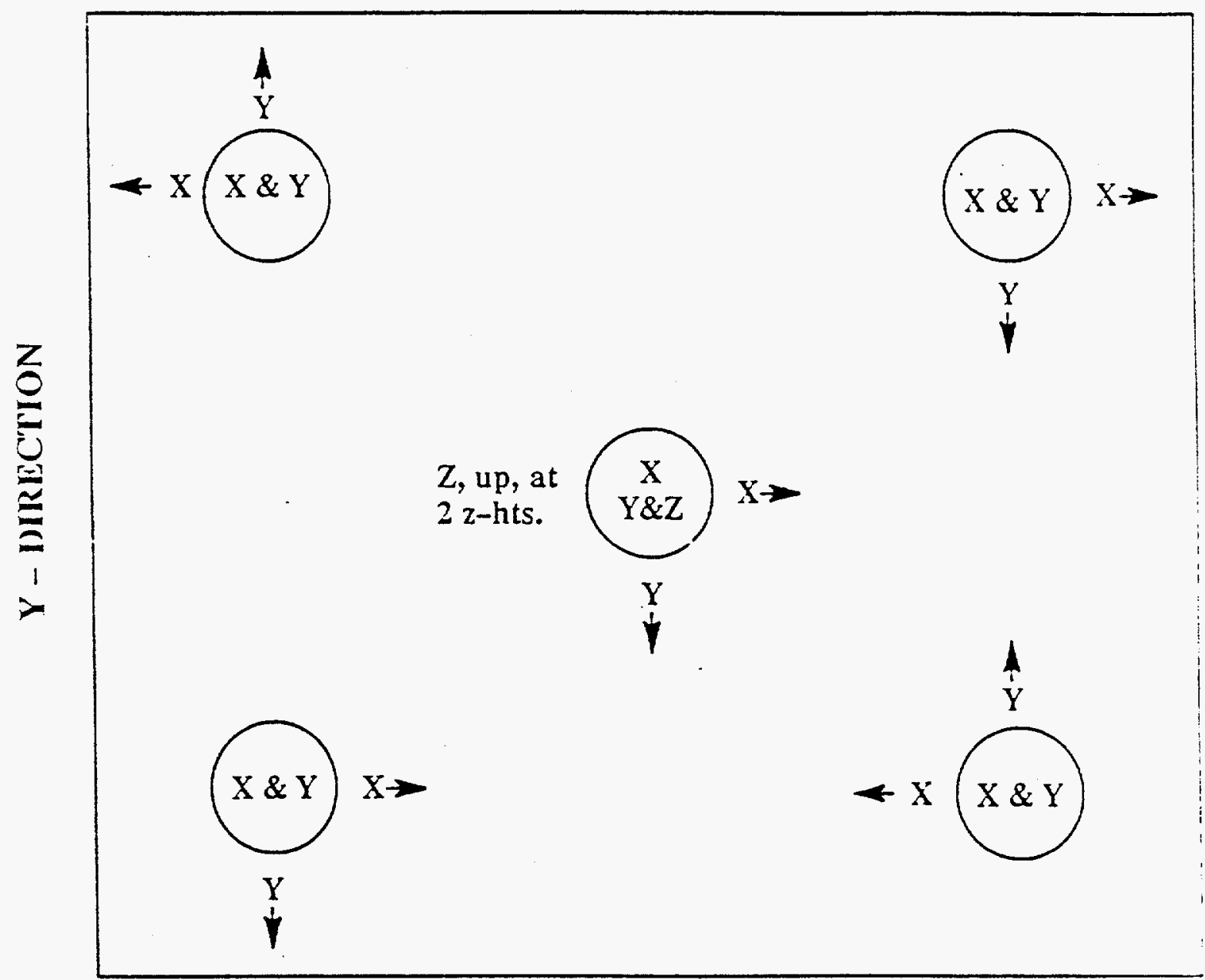

Actual locations may be approximate but should lie in the pattern shown. Th: arrowheads indicate the direction of the dial indicator setup for the corresponding axis of travel. The set-up directions allow both probing dir $=2:$ : to be observed. The corresponding effect is confounded with the two-way interaction in $\mathrm{x} \& \mathrm{y}$ locations. The $\mathrm{Z}$ set-ups assume the head moves down : : :" : indicator. 
TABLE IA: Pick ' $n$ ' Place Machine Capability Repeats and Locations in $X$ and $Y$

$\begin{array}{rrrr}\text { OBS } & \text { Location } & \begin{array}{c}\text { X } \\ \text { Deviation }\end{array} & \begin{array}{c}Y \\ \text { Deviation }\end{array} \\ \text { I } & \text { A } & 0.10 & 0.1 \\ 2 & \text { A } & 0.30 & 0.9 \\ 3 & \text { A } & 0.40 & 0.0 \\ 4 & \text { A } & -0.20 & 0.7 \\ 5 & \text { A } & -0.20 & 0.0 \\ 6 & \text { A } & 0.10 & 0.3 \\ 7 & \text { A } & 0.30 & 0.8 \\ 8 & \text { A } & 0.50 & 1.1 \\ 9 & \text { A } & 0.20 & 1.0 \\ 10 & \text { A } & 0.30 & 1.0 \\ 11 & \text { C } & 0.20 & -0.6 \\ 12 & \text { C } & 0.20 & -0.4 \\ 13 & \text { C } & 0.00 & -0.4 \\ 14 & \text { C } & 0.30 & -0.3 \\ 15 & \text { C } & -0.20 & -0.4 \\ 16 & \text { C } & 0.20 & -0.4 \\ 17 & \text { C } & 0.70 & -0.4 \\ 18 & \text { C } & 0.40 & -0.3 \\ 19 & \text { C } & 0.80 & -0.3 \\ 20 & \text { D } & 0.00 & -0.3 \\ 21 & \text { D } & -0.20 & 0.4 \\ 22 & \text { D } & -0.30 & 0.3 \\ 23 & \text { D } & -0.40 & 0.4 \\ 24 & \text { D } & -0.40 & 0.3 \\ 25 & \text { D } & -0.40 & 0.2 \\ 26 & \text { D } & -0.30 & 0.3 \\ 27 & \text { D } & -0.30 & 0.2 \\ 28 & \text { D } & -0.30 & 0.2 \\ 29 & \text { D } & -0.03 & 0.2 \\ 30 & \text { B } & 0.40 & 0.2 \\ 31 & \text { B } & 0.30 & -0.2 \\ 32 & \text { B } & 0.30 & 0.2 \\ 33 & \text { B } & 0.30 & -0.1 \\ 34 & \text { B } & 0.40 & -0.2 \\ 35 & \text { B } & -0.20 & 0.3 \\ 36 & \text { B } & 0.40 & -0.1 \\ 37 & \text { B } & 0.20 & -0.1 \\ 38 & \text { B } & 0.30 & 0.4 \\ 39 & \text { B } & 0.20 & 0.4 \\ 40 & \text { E } & 0.20 & 0.0 \\ 41 & \text { E } & 0.70 & -0.1 \\ 42 & \text { E } & 0.70 & 0.4 \\ 43 & \text { E } & 0.60 & 0.2 \\ 44 & \text { E } & 0.70 & 0.2 \\ 45 & \text { E } & 0.80 & 0.3 \\ 46 & 0.80 & 0.3 \\ 47 & 0.80 & 0.3 \\ 48 & \text { E } & 0.80 & 0.5 \\ 49 & & & 0.4 \\ 50 & \text { E } & \end{array}$


TABLE 2A: Pick ' $n$ ' Place Data for Head Positioning $X$ and $Y$ Data With Days, Homing, and Repeats

14:48 Wednesday, November 4, 1992

Set No. $=1$

Direction DAYS HOMING REPEATS Deviation

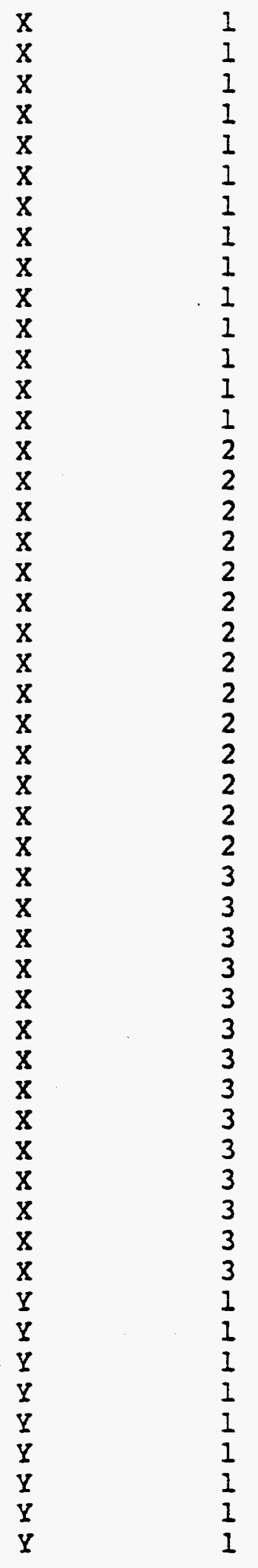

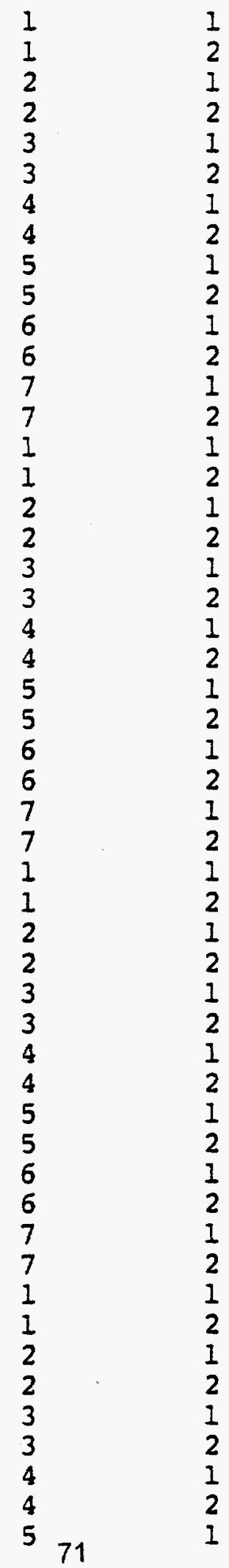

0.5

0.5

$-0.6$

$-0.8$

$-0.1$

$-0.2$

0.0

$-0.2$

$-1.2$

$-0.6$

$-1.7$

$-1.6$

0.0

$-0.1$

0.6

0.8

2.1

2.3

0.6

0.3

3.0

2.2

1.7

1.4

1.6

1.5

1.0

0.3

2.7

2.7

1.9

1.7

3.3

2. 2

2.4

2.5

1.7

0.9

1.5

1. 6

1.7

0.9

$-0.1$

0.1

0.1

0.3

$-0.4$

$-0.6$

$-0.1$

$-0.5$

$-2.5$ 
TABLE 2A: Pick ' $n$ ' Place Data for Head Positioning

$X$ and $Y$ Data With Days, Homing, and Repeats

14:48 Wednesday, November 4, 199

Set No. $=1$

(continued)

Direction DAYS HOMING REPEATS Deviation

\begin{tabular}{|c|c|c|c|c|}
\hline$Y$ & 1 & 5 & 2 & $-2,9$ \\
\hline$Y$ & 1 & 6 & 1 & -2.0 \\
\hline$Y$ & 1 & 6 & 2 & 0.0 \\
\hline$Y$ & 1 & 7 & 1 & -0.7 \\
\hline$Y$ & 1 & 7 & 2 & -0.9 \\
\hline$Y$ & 2 & 1 & 1 & -0.1 \\
\hline$Y$ & 2 & 1 & 2 & -0.4 \\
\hline$Y$ & 2 & 2 & 1 & 0.1 \\
\hline$Y$ & 2 & 2 & 2 & 0.1 \\
\hline$Y$ & 2 & 3 & 1 & 0.2 \\
\hline$Y$ & 2 & 3 & 2 & 0.7 \\
\hline$Y$ & 2 & 4 & 1 & -0.2 \\
\hline$Y$ & 2 & 4 & 2 & -0.5 \\
\hline$Y$ & 2 & 5 & 1 & 0.5 \\
\hline$Y$ & 2 & 5 & 2 & 0. \\
\hline$Y$ & 2 & 6 & 1 & 0.7 \\
\hline$Y$ & 2 & 6 & 2 & 0.4 \\
\hline$Y$ & 2 & 7 & 1 & 0.4 \\
\hline$Y$ & 2 & 7 & 2 & 0. \\
\hline$Y$ & 3 & 1 & 1 & 1. \\
\hline$Y$ & 3 & 1 & 2 & 1.7 \\
\hline$Y$ & 3 & 2 & 1 & 0.0 \\
\hline$Y$ & 3 & 2 & 2 & -0. \\
\hline$Y$ & 3 & 3 & 1 & 1. \\
\hline$Y$ & 3 & 3 & 2 & I. \\
\hline$Y$ & 3 & 4 & 1 & I. \\
\hline$Y$ & 3 & 4 & 2 & 1. \\
\hline$Y$ & 3 & 5 & 1 & -0. \\
\hline$Y$ & 3 & 5 & 2 & -0 . \\
\hline$Y$ & 3 & 6 & 1 & 0. \\
\hline$Y$ & 3 & 6 & 2 & 0 . \\
\hline$Y$ & 3 & 7 & 1 & \\
\hline$Y$ & 3 & 7 & 2 & -1 \\
\hline
\end{tabular}

Set No. $=2$

$\begin{array}{ccccc}\text { Direction } & \text { DAYS } & \text { HOMING } & \text { REPEATS } & \begin{array}{r}\text { Positio } \\ \text { Deviatio }\end{array} \\ \text { X } & 1 & 1 & 1 & 0.0 \\ \text { X } & 1 & 1 & 2 & 0.8 \\ \text { X } & 1 & 2 & 1 & 0.0 \\ \text { X } & 1 & 2 & 2 & 0.6 \\ \text { X } & 1 & 3 & 1 & 0.0 \\ \text { X } & 1 & 3 & 2 & 0.7 \\ \text { X } & 1 & 4 & 1 & -0.1 \\ \text { X } & 1 & 4 & 2 & 0.7 \\ \text { X } & 1 & 5 & 1 & -0.1 \\ \text { X } & 1 & 5 & 2 & 0.6\end{array}$


TABLE 2A: Pick ' $n$ ' Place Data for Head Positioning 3 $X$ and $Y$ Data With Days, Homing, and Repeats

14:48 Wednesday, November 4, 1992

Set No. $=2$ (continued)

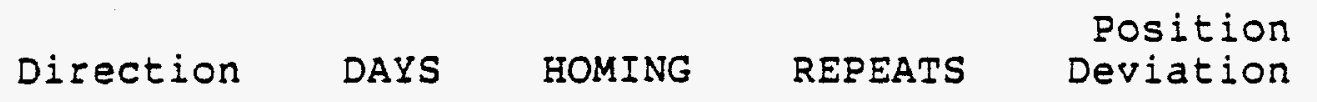

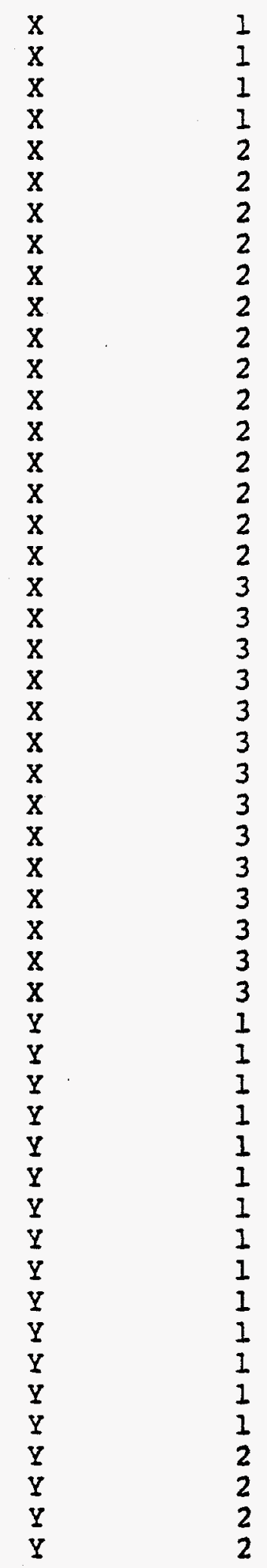

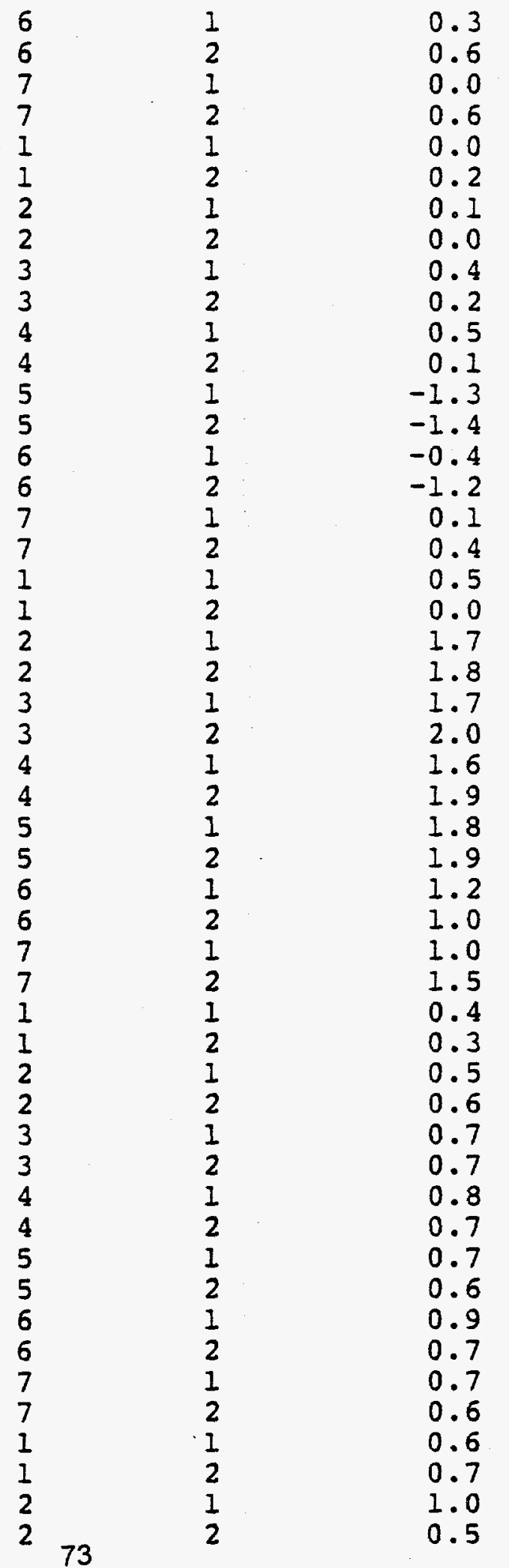


TABLE 2A: Pick ' $n$ ' Place Data for Head Positioning

$X$ and $Y$ Data With Days, Foming, and Repeats

14: 48 Wednesday, November 4,19

Set No. $=2$

(continued)

$\begin{array}{ccccc}\text { Direction } & \text { DAYS } & \text { HOMING } & \text { REPEATS } & \begin{array}{r}\text { Positio } \\ \text { Deviatio }\end{array} \\ Y & 2 & 3 & 1 & 0.9 \\ Y & 2 & 3 & 2 & 0.7 \\ Y & 2 & 4 & 1 & 1.0 \\ Y & 2 & 4 & 2 & 0.9 \\ Y & 2 & 5 & 1 & 1.2 \\ Y & 2 & 5 & 2 & 1.2 \\ Y & 2 & 6 & 1 & 0.5 \\ Y & 2 & 6 & 2 & 0.2 \\ Y & 2 & 7 & 1 & 1.0 \\ Y & 2 & 7 & 2 & 1.4 \\ Y & 3 & 1 & 1 & 0.4 \\ Y & 3 & 1 & 2 & 0.5 \\ Y & 3 & 2 & 1 & 0.2 \\ Y & 3 & 2 & 2 & 0.9 \\ Y & 3 & 3 & 1 & 1.1 \\ Y & 3 & 3 & 2 & 1.1 \\ Y & 3 & 4 & 1 & 1.2 \\ Y & 3 & 4 & 2 & 1.2 \\ Y & 3 & 5 & 1 & 1.2 \\ Y & 3 & 5 & 2 & 1.3 \\ Y & 3 & 6 & 1 & 0.3 \\ Y & 3 & 6 & 2 & 0.5 \\ Y & 3 & 7 & 1 & 0.7 \\ Y & 3 & 7 & 2 & 0.7\end{array}$

Set No. $=3$

\begin{tabular}{|c|c|c|c|c|}
\hline Direction & DAYS & HOMING & REPEATS & $\begin{array}{r}\text { Positic } \\
\text { Deviatic }\end{array}$ \\
\hline $\mathrm{x}$ & 1 & 1 & 1 & 1.3 \\
\hline $\mathrm{x}$ & $\bar{I}$ & 1 & 2 & 1.3 \\
\hline $\mathbf{X}$ & 1 & 2 & 1 & 2.1 \\
\hline $\mathrm{X}$ & 1 & 2 & 2 & 2.1 \\
\hline $\mathrm{X}$ & 1 & 3 & 1 & 1.2 \\
\hline $\mathrm{x}$ & 1 & 3 & 2 & 1.4 \\
\hline $\mathrm{x}$ & 1 & 4 & 1 & 2.6 \\
\hline $\mathrm{x}$ & 1 & 4 & 2 & 2.1 \\
\hline $\mathrm{x}$ & 1 & 5 & 1 & 1.3 \\
\hline $\mathbf{x}$ & 1 & 5 & 2 & 0 . \\
\hline $\mathrm{x}$ & 1 & 6 & 1 & 1 . \\
\hline $\mathrm{x}$ & 1 & 6 & 2 & 0. \\
\hline$x$ & 1 & 7 & 1 & 1. \\
\hline$x$ & 1 & 7 & 2 & 0 . \\
\hline$x$ & 2 & 1 & 1 & 0 . \\
\hline $\mathrm{x}$ & 2 & 1 & 2 & -0 . \\
\hline $\mathrm{x}$ & 2 & 2 & 2 & 1. \\
\hline $\mathrm{X}$ & 2 & 2 & 2 & 1.3 \\
\hline$x$ & 2 & 37 & 1 & 0. \\
\hline
\end{tabular}


TABLE 2A: Pick ' $n$ ' Place Data for Head Positioning

$X$ and $Y$ Data With Days, Homing, and Repeats

14:48 Wednesday, November 4, 1992

Set No. $=3$

(continued)

$\begin{array}{ccccr}\text { Direction } & \text { DAYS }^{-} & \text {HOMING } & \text { REPEATS } & \begin{array}{r}\text { Positio } \\ \text { Deviation }\end{array} \\ \text { X } & 2 & 3 & 2 & 0.2 \\ \text { X } & 2 & 4 & 1 & 0.6 \\ \text { X } & 2 & 4 & 2 & 0.3 \\ \text { X } & 2 & 5 & 1 & -0.2 \\ \text { X } & 2 & 5 & 2 & -0.4 \\ \text { X } & 2 & 6 & 1 & 0.5 \\ \text { X } & 2 & 6 & 2 & -0.1 \\ \text { X } & 2 & 7 & 1 & 0.2 \\ \text { X } & 2 & 7 & 2 & -0.4\end{array}$




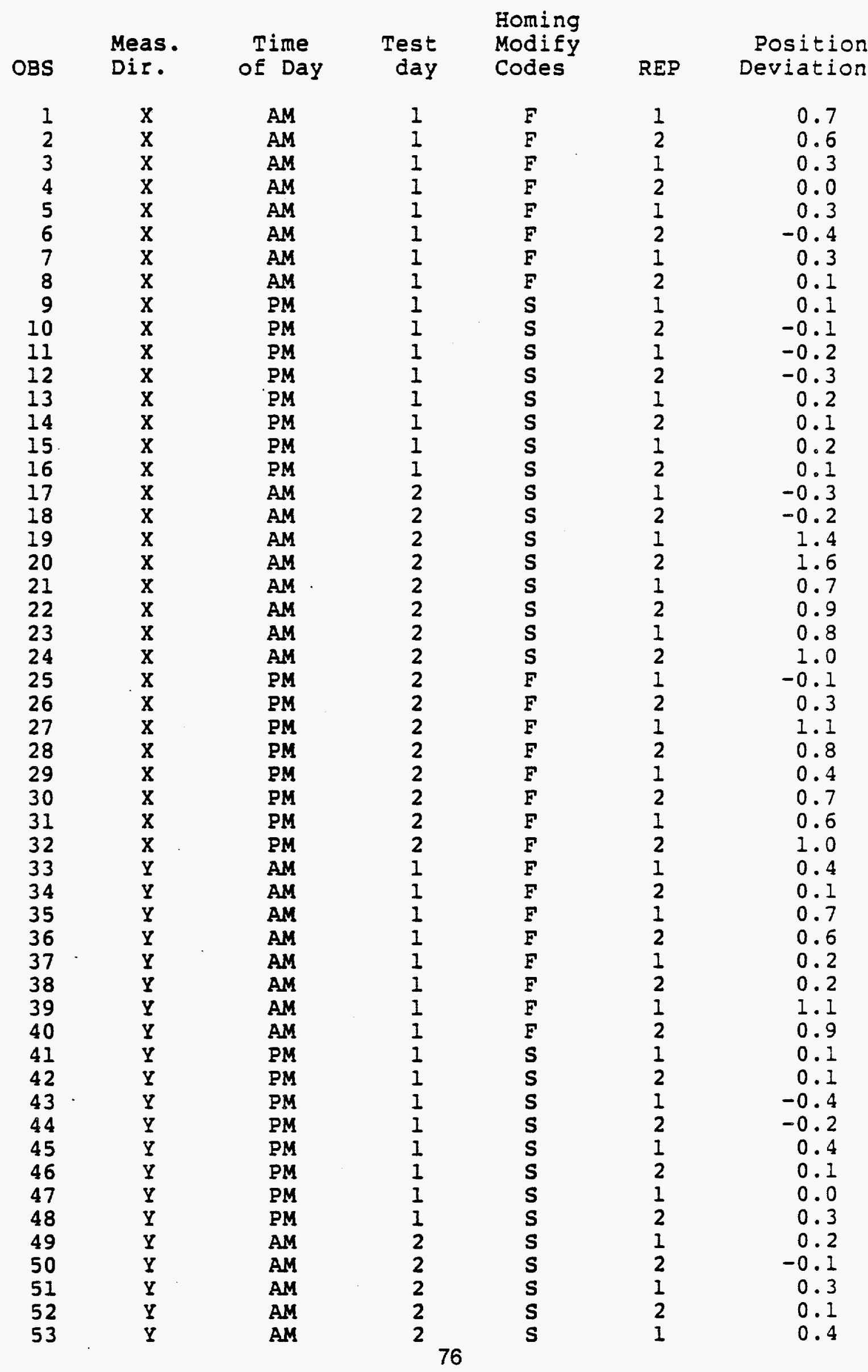




$\begin{array}{rcccccc}\text { Meas } & \begin{array}{c}\text { Time } \\ \text { of Day }\end{array} & \begin{array}{c}\text { Test } \\ \text { day }\end{array} & \begin{array}{l}\text { Homing } \\ \text { ModiEy } \\ \text { Codes }\end{array} & \text { REP } & \begin{array}{r}\text { Position } \\ \text { Deviation }\end{array} \\ 54 & Y & \text { AM } & 2 & \text { S } & 2 & 0.4 \\ 55 & Y & \text { AM } & 2 & \text { S } & 1 & 0.7 \\ 56 & Y & \text { AM } & 2 & \text { S } & 2 & 0.8 \\ 57 & Y & \text { PM } & 2 & \text { F } & 1 & 0.1 \\ 58 & Y & \text { PM } & 2 & \text { F } & 2 & 0.3 \\ 59 & \text { Y } & \text { PM } & 2 & \text { F } & 1 & -0.2 \\ 60 & Y & \text { PM } & 2 & \text { F } & 2 & -0.1 \\ 61 & Y & \text { PM } & 2 & \text { F } & 1 & 0.1 \\ 62 & Y & \text { PM } & 2 & \text { F } & 2 & 0.3 \\ 63 & Y & \text { PM } & 2 & \text { F } & 1 & 0.2 \\ 64 & \text { Y } & \text { PM } & 2 & \text { F } & 2 & -0.1\end{array}$


TABLE 4A: Best Shot at Placement Bias and Precision ThkJ aws $=x_{-}$dev*cos (angle) $-y_{-}$dev*sin(angle)

ThinJaws $=\bar{x}_{\text {_dev*sin (angle) }}+\bar{y}_{-}$dev*cos (angle)

\begin{tabular}{|c|c|c|c|c|c|}
\hline $\begin{array}{l}\text { Setup } \\
\text { Condns }\end{array}$ & ANGLE & $X$ Dev & Y Dev & $\begin{array}{l}\text { Thk } \\
\text { Jaws } \\
\text { Dev. }\end{array}$ & $\begin{array}{l}\text { Thin } \\
\text { Jaws } \\
\text { Dev. }\end{array}$ \\
\hline No ViPr/Homing & 0 & 3.6 & 0.0 & 3.60000 & 0.00000 \\
\hline No ViPr/Homing & 90 & 0.0 & 2.0 & 2.00000 & 0.00000 \\
\hline No ViPr/Homing & 180 & -3.7 & 0.8 & 3.70000 & -0.80000 \\
\hline No ViPr/Homing & 270 & 0.0 & -1.6 & 1.60000 & 0.00000 \\
\hline No ViPr/Homing & 270 & 0.0 & -1.8 & 1.80000 & 0.00000 \\
\hline No ViPr/Homing & 180 & -2.4 & 0.0 & 2.40000 & 0.00000 \\
\hline No ViPr/Homing & 90 & 0.0 & 2.0 & 2.00000 & 0.00000 \\
\hline No ViPr/Homing & 0 & 2.6 & -0.9 & 2.60000 & -0.90000 \\
\hline Vision Prgm & 0 & 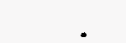 & & & \\
\hline Vision Prgm & 90 & 0.7 & 1.7 & 1.70000 & -0.70000 \\
\hline Vision Prgm & 180 & -1.3 & 1.8 & 1.30000 & -1.80000 \\
\hline Vision Prgm & 270 & 2.6 & 0.0 & -0.00000 & 2.60000 \\
\hline Vision Prgm & 0 & 3.8 & 0.0 & 3.80000 & 0.00000 \\
\hline Vision Prgm & 90 & 0.8 & 1.9 & 1.90000 & -0.80000 \\
\hline Vision Prgm & 180 & -2.3 & 3.3 & 2.30000 & -3.30000 \\
\hline Vision Prgm & 270 & 3.0 & -0.7 & 0.70000 & 3.00000 \\
\hline Vision Prgm & 0 & 1.4 & 0.0 & 1.40000 & 0.00000 \\
\hline Vision Prgm & 90 & 1.3 & 2.8 & 2.80000 & -1.30000 \\
\hline Vision Prgm & 180 & -2.9 & 1.6 & 2.90000 & -1.60000 \\
\hline Vision Prgm & 270 & 1.0 & 0.6 & .0 .60000 & 1.00000 \\
\hline Vision Prgm & 0 & 1.2 & 1.0 & 1.20000 & 1.00000 \\
\hline Vision Prgm & 90 & 0.0 & 2.2 & 2.20000 & 0.00000 \\
\hline Vision Prgm & 180 & -2.6 & 1.9 & 2.60000 & -1.90000 \\
\hline Vision Prgm & 270 & 0.0 & 0.6 & -0.60000 & -0.00000 \\
\hline
\end{tabular}




\section{Appendix B}

\section{Second Analysis}

Appendix $B$ is another look at the same data relating to the placement of components on the glass slide, but with the consideration of the difference in the different types of centering jaws. The results mentioned in the body of the report for the system placement accuracy are based on the analysis performed in Appendix B. 
The data for the evaluation of the placement capability is in two tables, labeled Glass \#1 and Glass \#2. This data was obtained by placing pseudo-components on a glass slide using the programmed vision system in a production setup. Each table presents the $x$ and $y$ placement deviations of the pseudo-components placed in four rotational orientations of the jaws; $0,90,180$, and 270 degrees as indicated. Due to these rotations, the data falls into four categories according to the combination of $j$ aw type and coordinate axis orientation. For example, Thick-X indicates that the placements were made with the thick jaws oriented along the $x$-axis. The Thin-Y placement data is the corresponding $y$-axis data from the pseudo-component placements.

An analysis of the data was performed to estimate the overall bias in the jaws in each direction, the bias between the 180 degree rotations (i.e., 0 vs. 180 degrees and 90 vs. 270 degrees), the corresponding variation, and the overall expected variation of the placement deviations in typical use. The following table summarizes the data computations and analysis.

Component Placement Uncertainty Data Analys is Summary

\begin{tabular}{|c|c|c|c|c|c|}
\hline & Thick-X & Thick-Y & Thin- $\mathrm{X}$ & Thin-Y & \\
\hline $\begin{array}{r}\text { Slide } 1 \text { ave } \\
\text { range }\end{array}$ & $\begin{array}{l}1.1000 \\
5.2000\end{array}$ & $\begin{array}{l}0.7125 \\
2.4000\end{array}$ & $\begin{array}{l}1.5125 \\
2.8000\end{array}$ & $\begin{array}{l}1.2125 \\
2.4250\end{array}$ & \\
\hline $\begin{array}{r}\text { Slide } 2 \text { ave } \\
\text { range }\end{array}$ & $\begin{array}{r}-.7500 \\
4.0000\end{array}$ & $\begin{array}{l}1.4750 \\
2.3000\end{array}$ & $\begin{array}{l}0.5250 \\
0.9500\end{array}$ & $\begin{array}{l}1.3125 \\
2.3000\end{array}$ & \\
\hline $\begin{array}{r}\text { Manual ave } \\
\text { range }\end{array}$ & $\begin{array}{l}0.075 \\
6.6\end{array}$ & $\begin{array}{l}0.325 \\
3.7\end{array}$ & $\begin{array}{l}0.0 \\
0.0\end{array}$ & $\begin{array}{l}0.025 \\
1.05\end{array}$ & \\
\hline $\begin{array}{r}\text { ave } \\
\text { range }\end{array}$ & $\begin{array}{l}0.1750 \\
4.6000\end{array}$ & $\begin{array}{l}1.1000 \\
2.3500\end{array}$ & $\begin{array}{l}1.0500 \\
1.8750\end{array}$ & $\begin{array}{l}1.2625 \\
2.3625\end{array}$ & \\
\hline R-bar within & 0.5000 & 0.3750 & 0.5875 & 0.9330 & Ied \\
\hline s-hat & 0.4065 & 0.3100 & 0.4850 & 0.7580 & 0.5175 \\
\hline Q(angles) & 8.9900 & 4.5400 & 3.6200 & 4.5600 & \\
\hline
\end{tabular}

LSR is 4.11 for alpha=.05, and 3.56 for alpha=.10.

The rows marked 'ave' are the overall average bias estimates for the corresponding configuration. Similarly, the rows marked 'range' are the ranges due to the 180 degree change in rotation, e.g., from 90 to 270 degrees. The 'R-bar within' row is the average range of the pairs of deviations of the placements at each specific site from Glass \#1 to Glass \#2. These ranges were converted to estimates of the standard deviation, in the $\mathrm{S}$-hat row. The four estimates were combined into the pooled value, 0.5175 . 
The ' $Q$ (angles)' row displays the test value for significance of the 180 degree change in rotation. All four configuration provide significant (i.e., real) bias changes when the component orientation undergoes a 180 degree rotation. From the test, the bias in all but the Thick-X configuration are just barely significant. The Q(angles) value is significant if it is greater than the LSR (least significant range) value for the alpha risk for the test. The LSR values are listed at the bottom of the table for alpha-.10 and .05 .

These results may be interpreted to mean that the set up of the machine is accurate to the limits of the vision system to measure its own bias. The estimate of the overall range of deviations that would be encountered in use is $3.478 \mathrm{mils}$ for $x$ deviations and is $3.810 \mathrm{mils}$ for $\mathrm{y}$ deviations. This estimate is based on the Thick-X configuration for the $x$ deviations and the Thin-Y configuration for the $y$ deviations.

The overall range is computed as the sum of the average bias, one-half the average range due to 180-degree rotations, and the expected random variation (in terms of two times the standard deviation). The computations for the $\mathrm{x}$ and $\mathrm{y}$ deviations are illustrated below.

\section{Programmed Placement Summary}

\begin{tabular}{llc} 
& $\begin{array}{c}\text { x deviation } \\
\text { (Thick-X/Thin-X) }\end{array}$ & $\begin{array}{c}\text { y deviation } \\
\text { (Thick-Y/Thin-Y) }\end{array}$ \\
\hline average & $0.175 / 1.050$ & $1.100 / 1.263$ \\
$0.5 *$ range & $2.600 / 0.938$ & $1.175 / 1.181$ \\
$2 *$ std dev & $1.035 / 1.035$ & $1.035 / 1.035$ \\
\hline Total & $3.810 / 3.043$ & $3.310 / 3.478$
\end{tabular}

These results are consistent with the results quoted for the earlier investigations that predict a range of uncertainty of 5 mils (or 0.005 in.) in the placement of components.

Components were placed on a third slide using manual placement capabilities. This data exhibited similar patterns but, with one slide, no estimate of the standard deviation of the deviations was possible. The ranges of deviations due to the rotations were numerically smaller for the thin jaws than for the thick jaws $(0.0$ and 1.05 for thin vs. 6.6 and $3.7 \mathrm{mils}$ for thick). This is consistent with the jaw design efforts to center the thin jaws first then center the thick jaws. 


\section{Glass \#1}

\begin{tabular}{|c|c|c|c|c|}
\hline $\begin{array}{l}\text { PLACEMENTS } \\
\text { USING } \\
\text { PROGRAM ON } \\
\text { GLASS \#! }\end{array}$ & $\begin{array}{l}\text { PLACEMENT } \\
\text { NUMBER AND } \\
\text { ANGLE }\end{array}$ & $\begin{array}{l}\text { THICK JAWS } \\
\text { WHEN IN X } \\
\text { DIRECTION }\end{array}$ & $\begin{array}{l}\text { PLACEMENT } \\
\text { NUMBER AND } \\
\text { ANGLE }\end{array}$ & $\begin{array}{l}\text { THICK JAWS } \\
\text { WHEN IN Y } \\
\text { DIRECTION }\end{array}$ \\
\hline & \#1@0 degrees & no data & \#2@90 degrees & 1.6 \\
\hline & \#3 @ 180 degrees & -0.95 & $\# 4 @ 270$ degrees & $-0.05 *$ \\
\hline & \#5@0 degrees & 3.7 & $\# 6$ @ 90 degrees & 1.85 \\
\hline & $\# 7 @ 180$ degrees & -2.05 & $\# 8 @ 270$ degrees & -0.55 \\
\hline & & Average $=1.10$ & & Average $=0.7125$ \\
\hline & & Range $=5.75$ & & Range $=2.40$ \\
\hline
\end{tabular}

$+9.9$

* Was originally 0.0 with a component dimension. Could have been changed to plus or minus 0.05 ( -0.05 was chosen because the other measurement at 270 degrees was negative).

\begin{tabular}{|c|c|c|c|c|}
\hline $\begin{array}{l}\text { PLACEMENTS } \\
\text { USNG } \\
\text { PROGRAM ON } \\
\text { GLASS \#1 }\end{array}$ & $\begin{array}{l}\text { PLACEMENT } \\
\text { NUMBER AND } \\
\text { ANGLE }\end{array}$ & $\begin{array}{l}\text { THIN JAWS } \\
\text { WHEN IN X } \\
\text { DIRECTION }\end{array}$ & $\begin{array}{l}\text { PLACEMENT } \\
\text { NUMBER AND } \\
\text { ANGLE }\end{array}$ & $\begin{array}{l}\text { THIN JAWS } \\
\text { WHEN NN Y } \\
\text { DIRECTION }\end{array}$ \\
\hline & \#2@90 degrees & 0.45 & \#1 @ 0 degrees & no data \\
\hline & $\# 4$ @ 270 degrees & 2.5 & \#3@180 degrees & 1.6 \\
\hline & $\# 6 @ 90$ degrees & 0.15 & \#5@0 degrees & $0 * *$ \\
\hline & \#8 @ 270 degrees & 2.95 & $\# 7$ @ 180 degrees & 3.25 \\
\hline & & Average $=1.5125$ & & Avg $=1.2125$ \\
\hline & & Range $=2.80$ & & Range $=3.25$ \\
\hline
\end{tabular}

** component dimension was 50.2 but no compensation was made since the direction is not known

Range for the thick jaws was 5.75 mils and 2.40 mils for glass \#1 (average of 4.08 )

Range for the thin jaws was 2.8 mils and 3.25 mils for glass \#1 (average of 3.03) 


\section{Glass \#2}

\begin{tabular}{|c|c|c|c|c|}
\hline $\begin{array}{l}\text { PLACEMENTS } \\
\text { USING } \\
\text { PROGRAM ON } \\
\text { GLASS } \# 2\end{array}$ & $\begin{array}{l}\text { PLACEMENT } \\
\text { NUMBER AND } \\
\text { ANGLE }\end{array}$ & $\begin{array}{l}\text { THICK JAWS } \\
\text { WHEN IN X } \\
\text { DIRECTION }\end{array}$ & $\begin{array}{l}\text { PLACEMENT } \\
\text { NUMBER AND } \\
\text { ANGLE }\end{array}$ & $\begin{array}{l}\text { THICK JAWS } \\
\text { WHEN IN Y } \\
\text { DIRECTION }\end{array}$ \\
\hline & \#1@0 degrees & 1.05 & \#2 @ 90 degrees & 2.7 \\
\hline & \#3 @ 180 degrees & -2.75 & \#4@270 degrees & 0.4 \\
\hline & \#5@0 degrees & 1.25 & \#6@90 degrees & 2.2 \\
\hline & \#7 @ 180 degrees & -2.55 & $\# 8 @ 270$ degrees & 0.65 \\
\hline & & Average $=-0.75$ & & Average $=1.475$ \\
\hline & & Range $=4.00$ & & Range $=2.30$ \\
\hline
\end{tabular}

\begin{tabular}{|c|c|c|c|c|}
\hline $\begin{array}{l}\text { PLACEMENTS } \\
\text { USING } \\
\text { PROGRAM ON } \\
\text { GLASS \#2 }\end{array}$ & $\begin{array}{l}\text { PLACEMENT } \\
\text { NUMBER AND } \\
\text { ANGLE }\end{array}$ & $\begin{array}{l}\text { THIN JAWS } \\
\text { WHEN IN X } \\
\text { DIRECTION }\end{array}$ & $\begin{array}{l}\text { PLACEMENT } \\
\text { NUMBER AND } \\
\text { ANGLE }\end{array}$ & $\begin{array}{l}\text { THIN JAWS } \\
\text { WHEN IN Y } \\
\text { DIRECTION }\end{array}$ \\
\hline & \#2@90 degrees & 0.9 & $\# 1 @ 0$ degrees & $0.05 * *$ \\
\hline & \#4@. 270 degrees & 0.95 & \#3 @ 180 degrees & 2.35 \\
\hline & \#6@90 degrees & $0.25^{*}$ & \#5 @0 degrees & 0.85 \\
\hline & \#8 @ 270 degrees & 0 & \#7 @ 180 degrees & \\
\hline & & Average $=0.525$ & . & Average $=1.3125$ \\
\hline & & Range $=0.95$ & & Range $=2.30$ \\
\hline
\end{tabular}

* original measurement was 0.0 with component dimension of 49.5

0.25 was chosen since the other 90 degree error was positive

** original measurement was 0.0 with component dimension of 50.1

0.05 was chosen since the other 0 degree error was positive

Range for the thick jaws was 4.00 mils and 2.30 mils for glass \#2 (average of 3.15)

Range for the thin jaws was 0.95 mils and 2.30 mils for glass \#2 (average of 1.625 ) 


\section{Manual Placements}

\begin{tabular}{|c|c|c|c|c|}
\hline $\begin{array}{l}\text { MANUAL } \\
\text { PLACEMENTS } \\
\text { ON GLASS }\end{array}$ & $\begin{array}{l}\text { PLACEMENT } \\
\text { NUMBER AND } \\
\text { ANGLE }\end{array}$ & $\begin{array}{l}\text { THICK JAWS } \\
\text { WHEN IN X } \\
\text { DIRECTION }\end{array}$ & $\begin{array}{l}\text { PLACEMENT } \\
\text { NUMBER AND } \\
\text { ANGLE }\end{array}$ & $\begin{array}{l}\text { THICK JAWS } \\
\text { WHEN IN Y } \\
\text { DIRECTION }\end{array}$ \\
\hline & $\# 1 @ 0$ degrees & 3.3 & \#2@90 degrees & 2.1 \\
\hline & \#3@180 degrees & -3.3 & \#4 @ 270 degrees & -1.45 \\
\hline & \#6@180 degrees & -2.45 & \#5 @ 270 degrees & -1.6 \\
\hline & \#8@0 degrees & 2.3 & \#7 @ 90 degrees & 1.6 \\
\hline & & Average $=0.075$ & & Average $=0.325$ \\
\hline & & Range $=6.6$ & & Range $=3.7$ \\
\hline
\end{tabular}

\begin{tabular}{|c|c|c|c|c|}
\hline $\begin{array}{l}\text { MANUAL } \\
\text { PLACEMENTS } \\
\text { ON GLASS }\end{array}$ & $\begin{array}{l}\text { PLACEMENT } \\
\text { NUMBER AND } \\
\text { ANGLE }\end{array}$ & $\begin{array}{l}\text { THIN JAWS } \\
\text { WHEN IN } X \\
\text { DIRECTION }\end{array}$ & $\begin{array}{l}\text { PLACEMENT } \\
\text { NUMBER AND } \\
\text { ANGLE }\end{array}$ & $\begin{array}{l}\text { THIN JAWS } \\
\text { WHEN IN Y } \\
\text { DIRECTION }\end{array}$ \\
\hline & \#2 @9 90 degrees & & 0\#1 @ 0 degrees & $-0.15^{*}$ \\
\hline & \#4 @ 270 degrees & & |\#3 @ 180 degrees & 0.5 \\
\hline & \#5 @ 270 degrees & & 0 \#6@ 180 degrees & $0.15 * *$ \\
\hline & \#7 @ 90 degrees & & 0|\#8@0 degrees & -0.55 \\
\hline & & Average $=0.0$ & & Average $=0.025$ \\
\hline & & Range $=0.0$ & & Range $=1.05$ \\
\hline
\end{tabular}

* original measurement was 0.0 with component dimension of 49.7 -0.15 was chosen since the other 0 degree error was negative

** original measurement was 0.0 with component dimension of 49.7

0.15 was chosen since the other 180 degree error was positive

Range for the thick jaws was 6.6 mils and 3.7 mils for the manual case (average of 5.15) Range for the thin jaws was 0.0 mils and 1.05 mils for the manual case (average of 0.525 ) 
Appendix C

Drawings 


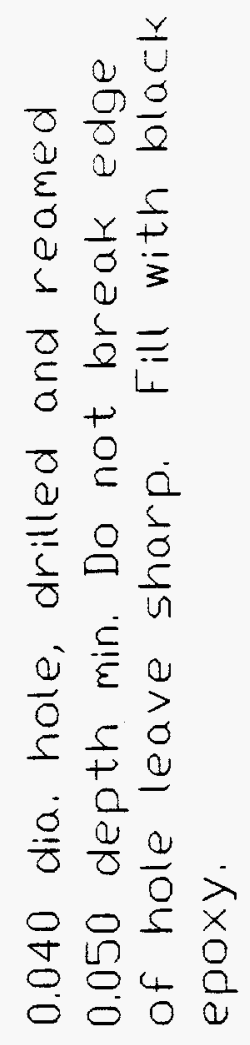

$\underset{\ddots}{0}$
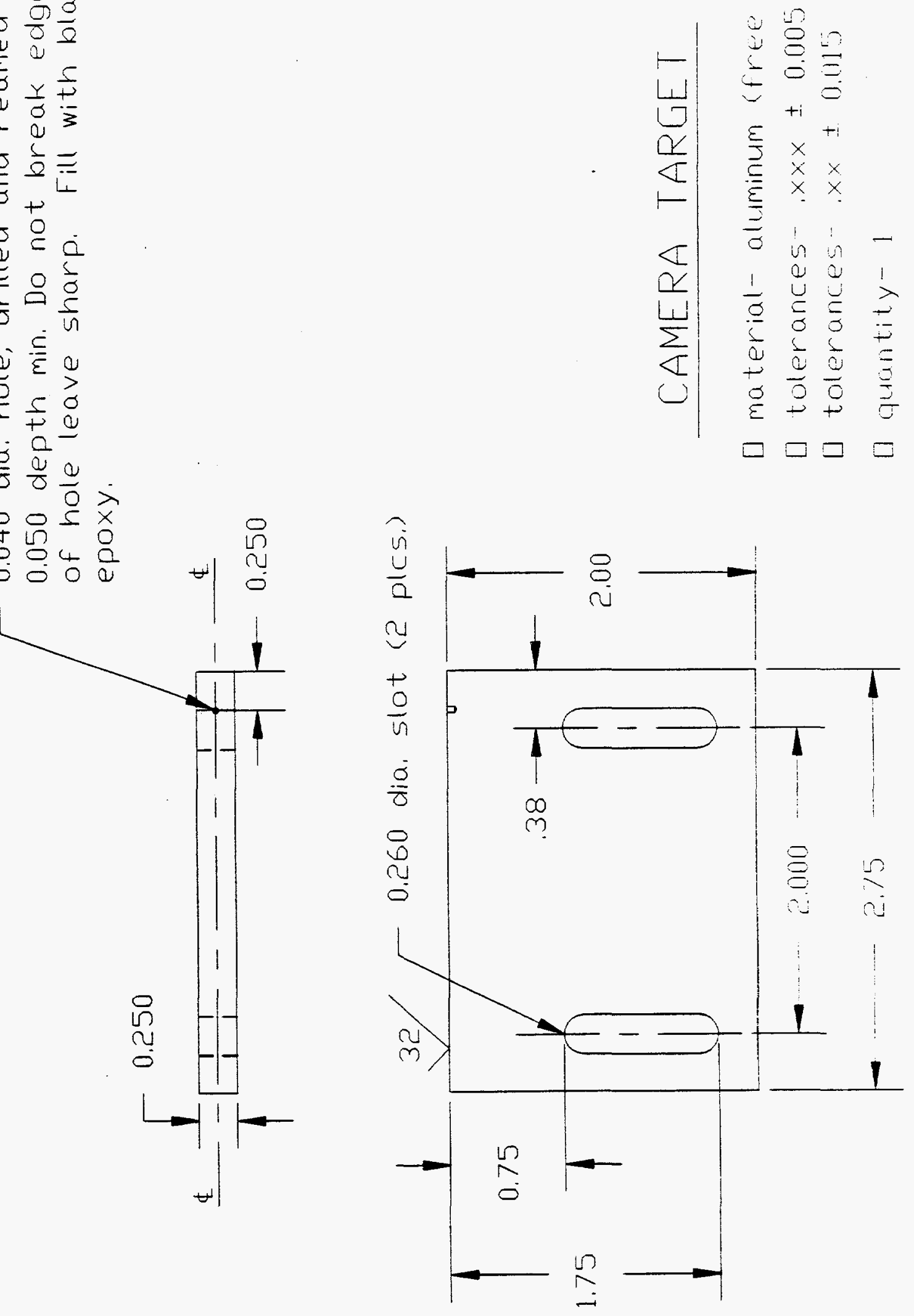


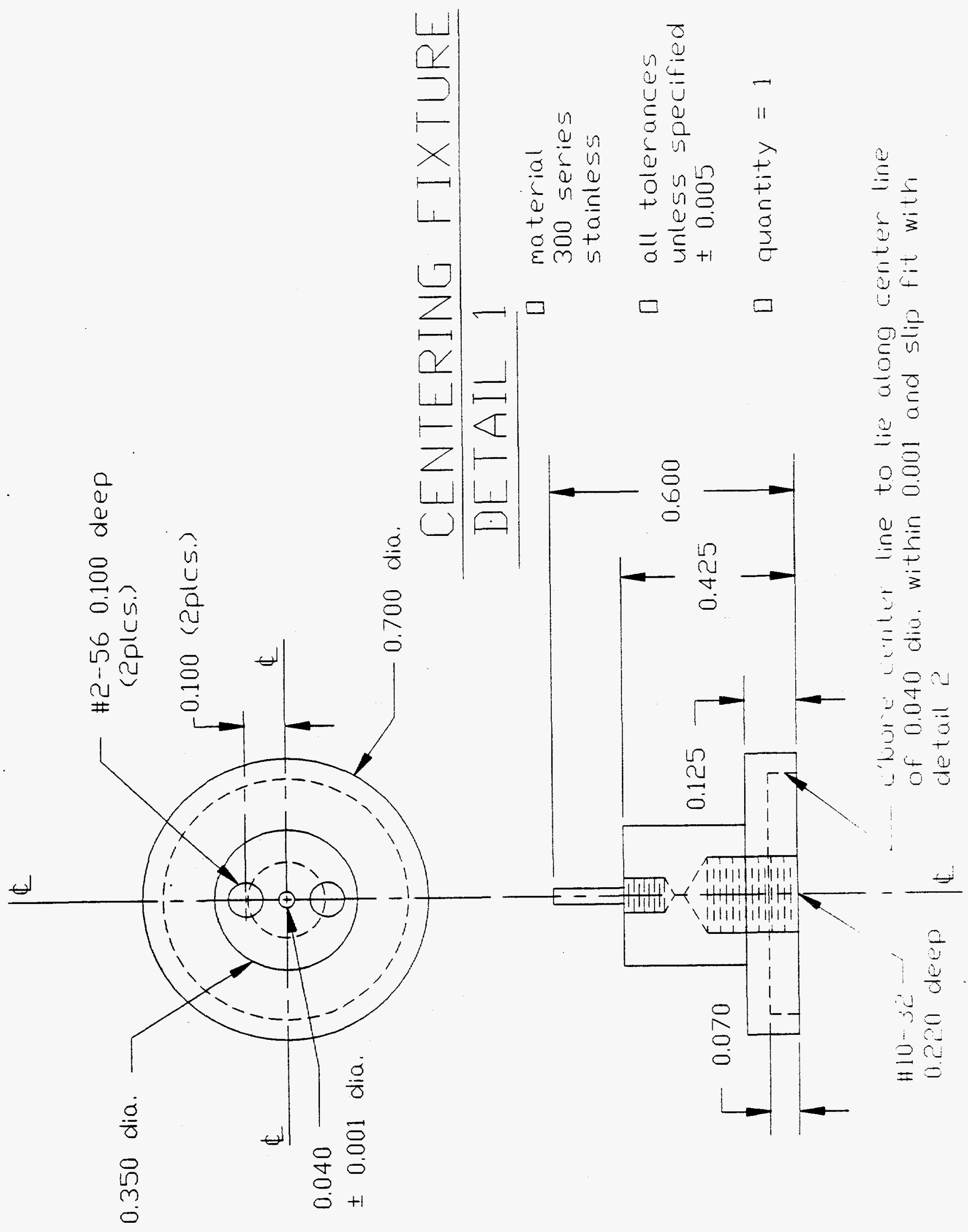




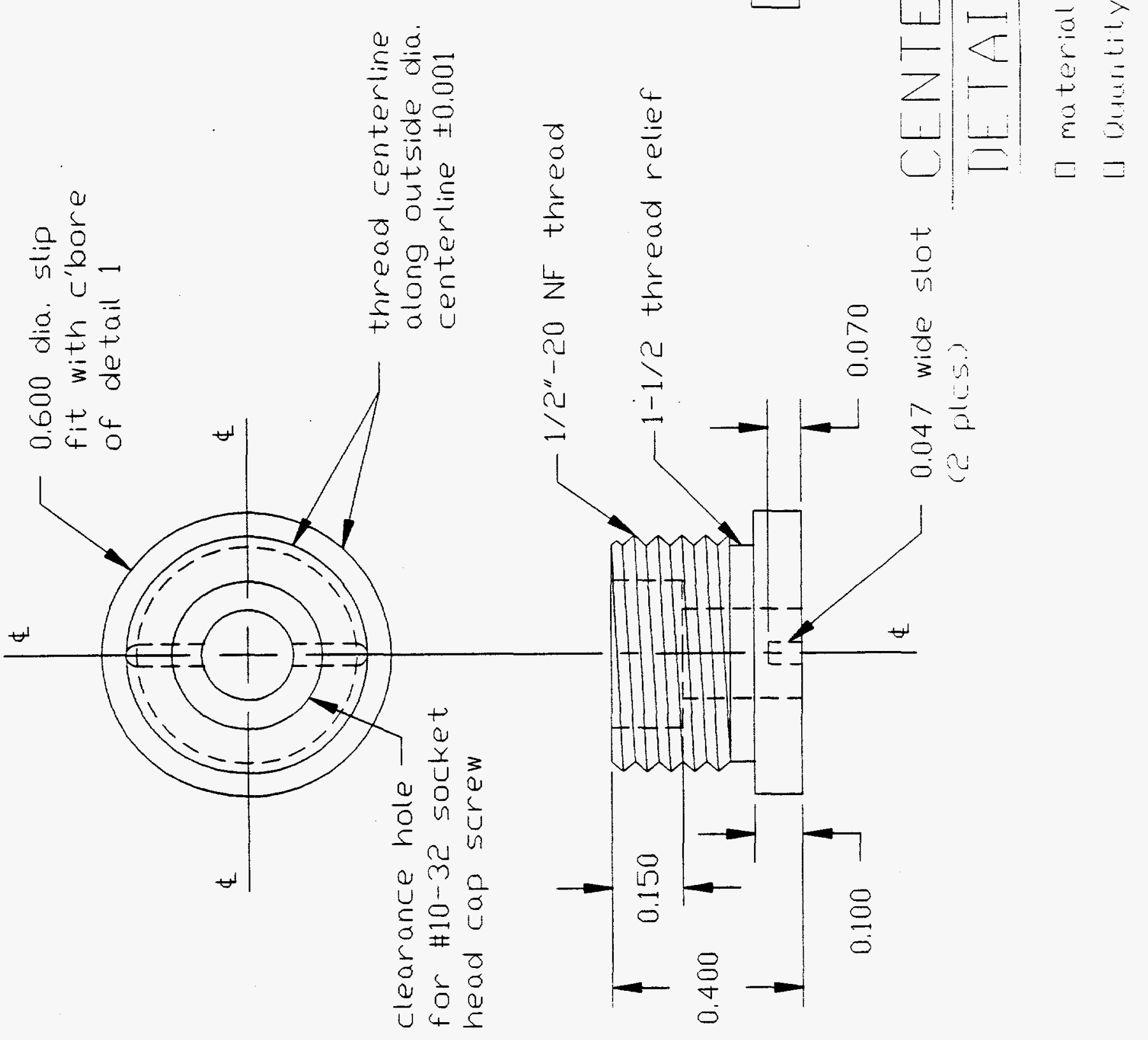




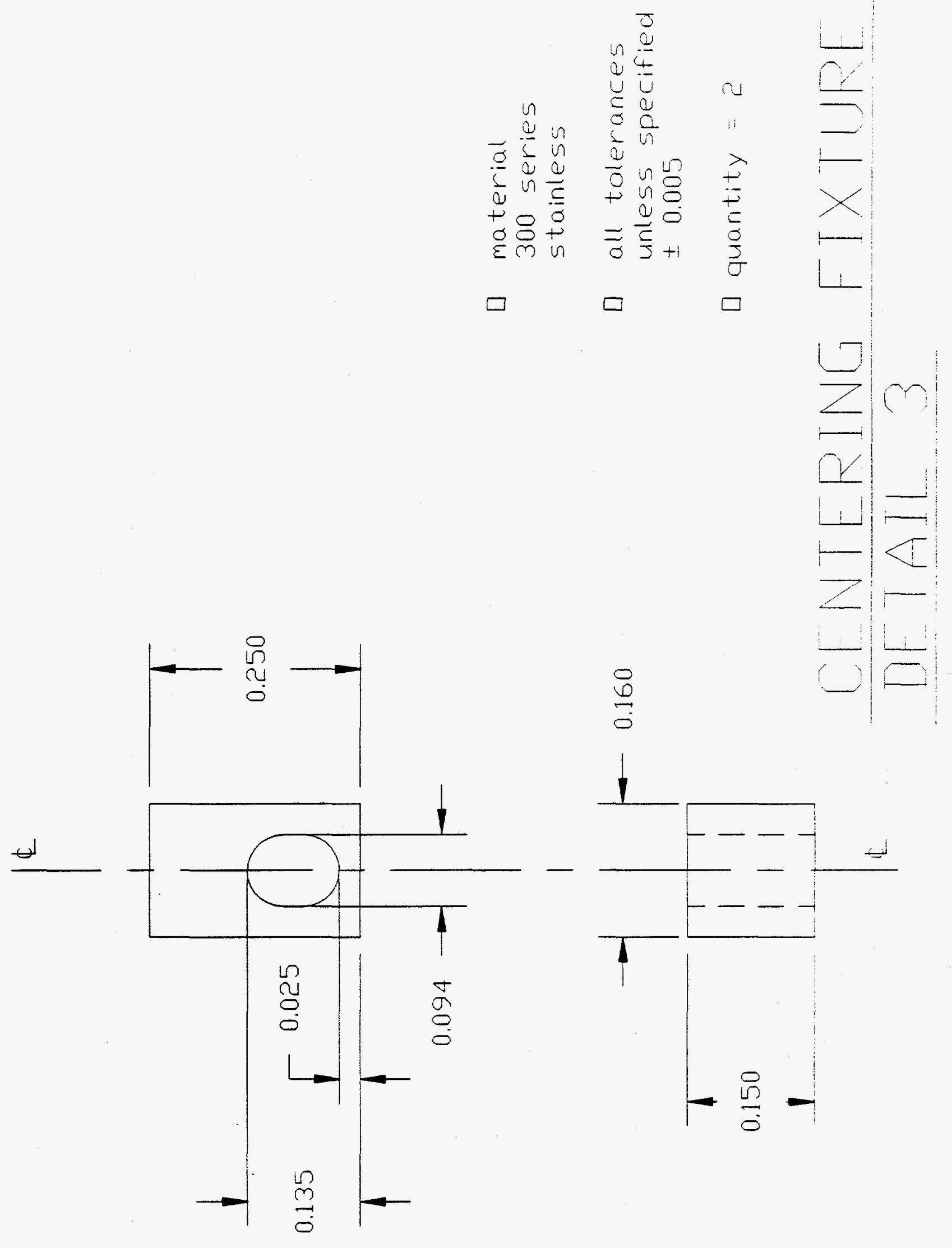




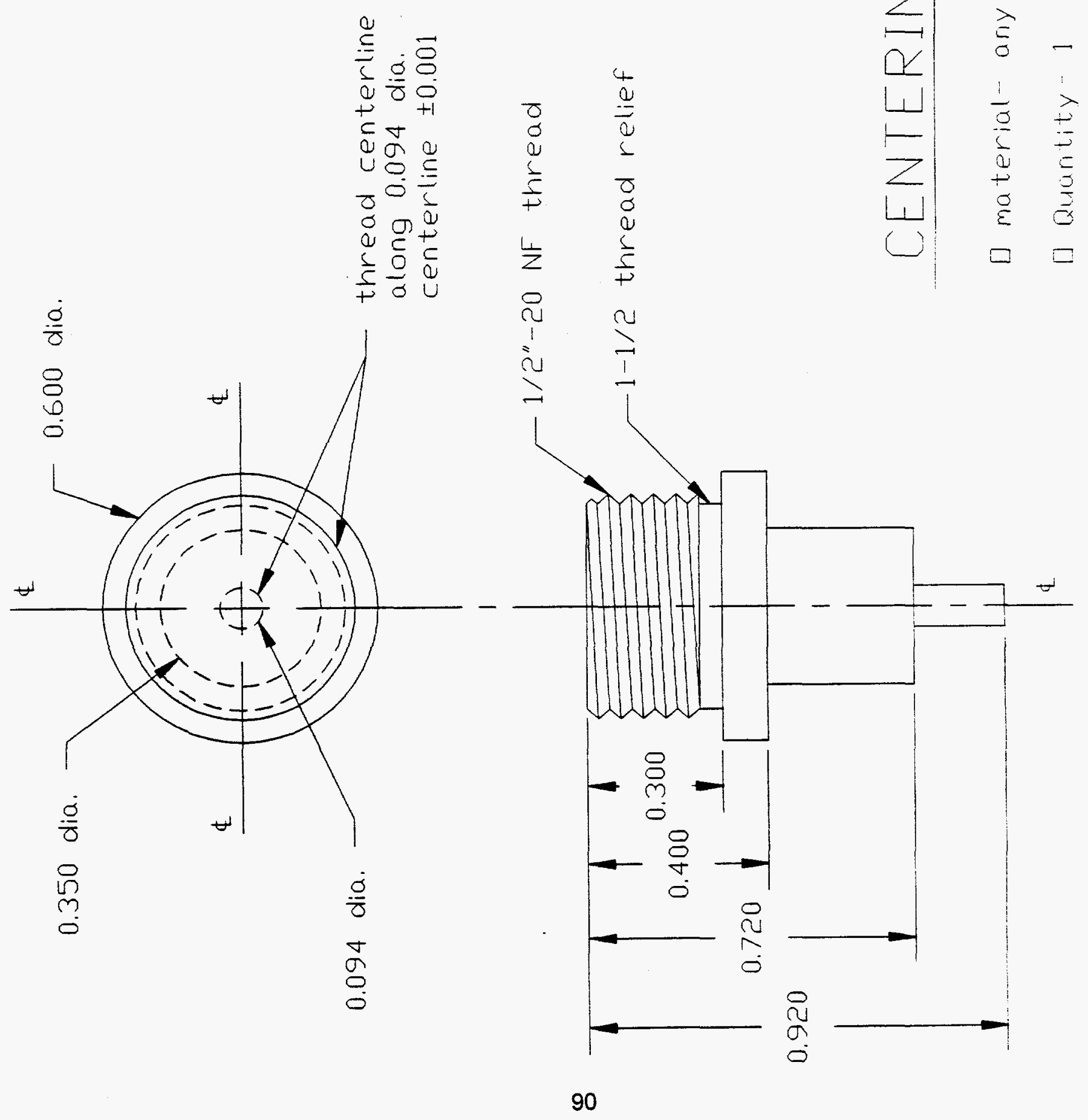




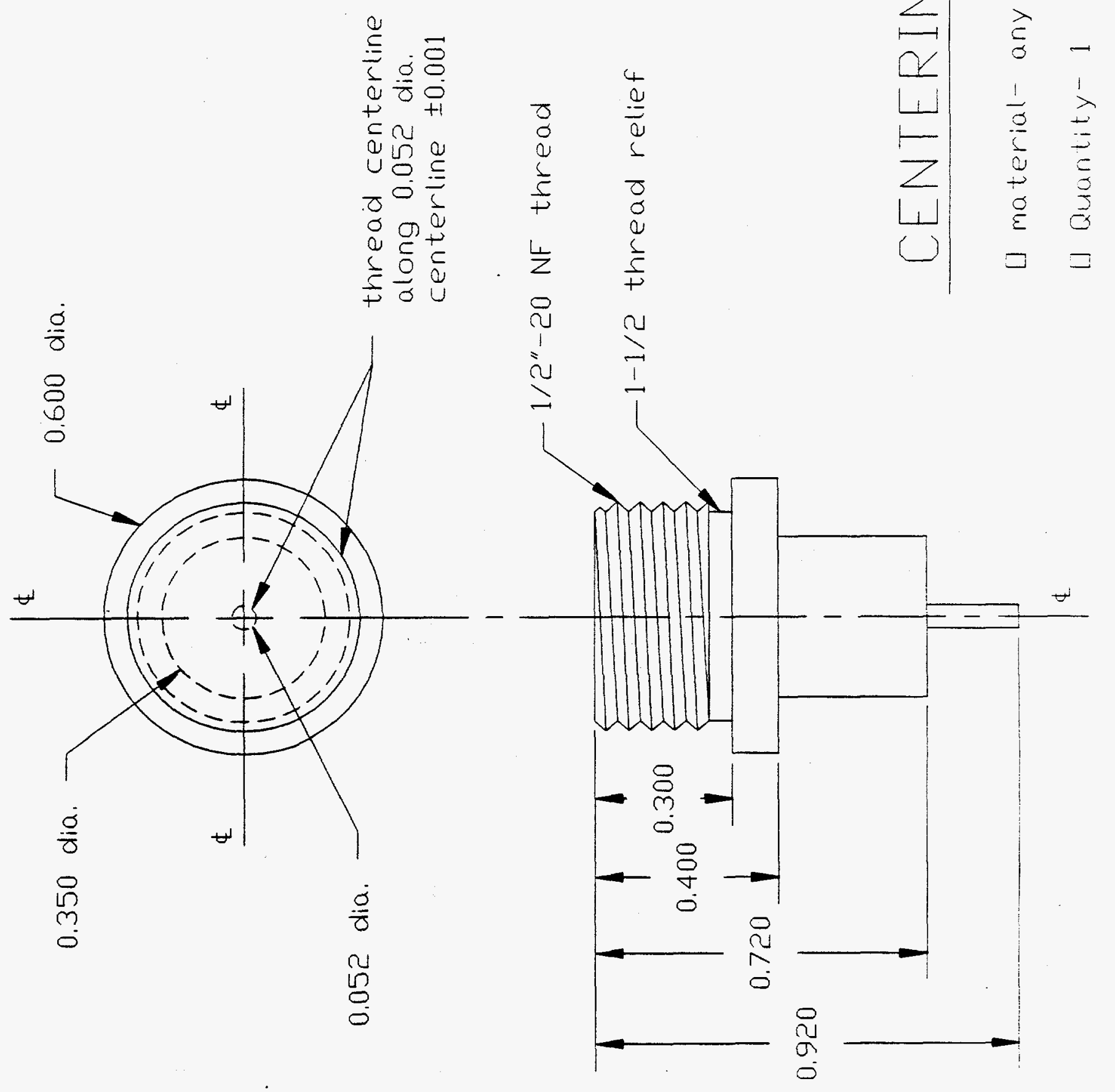




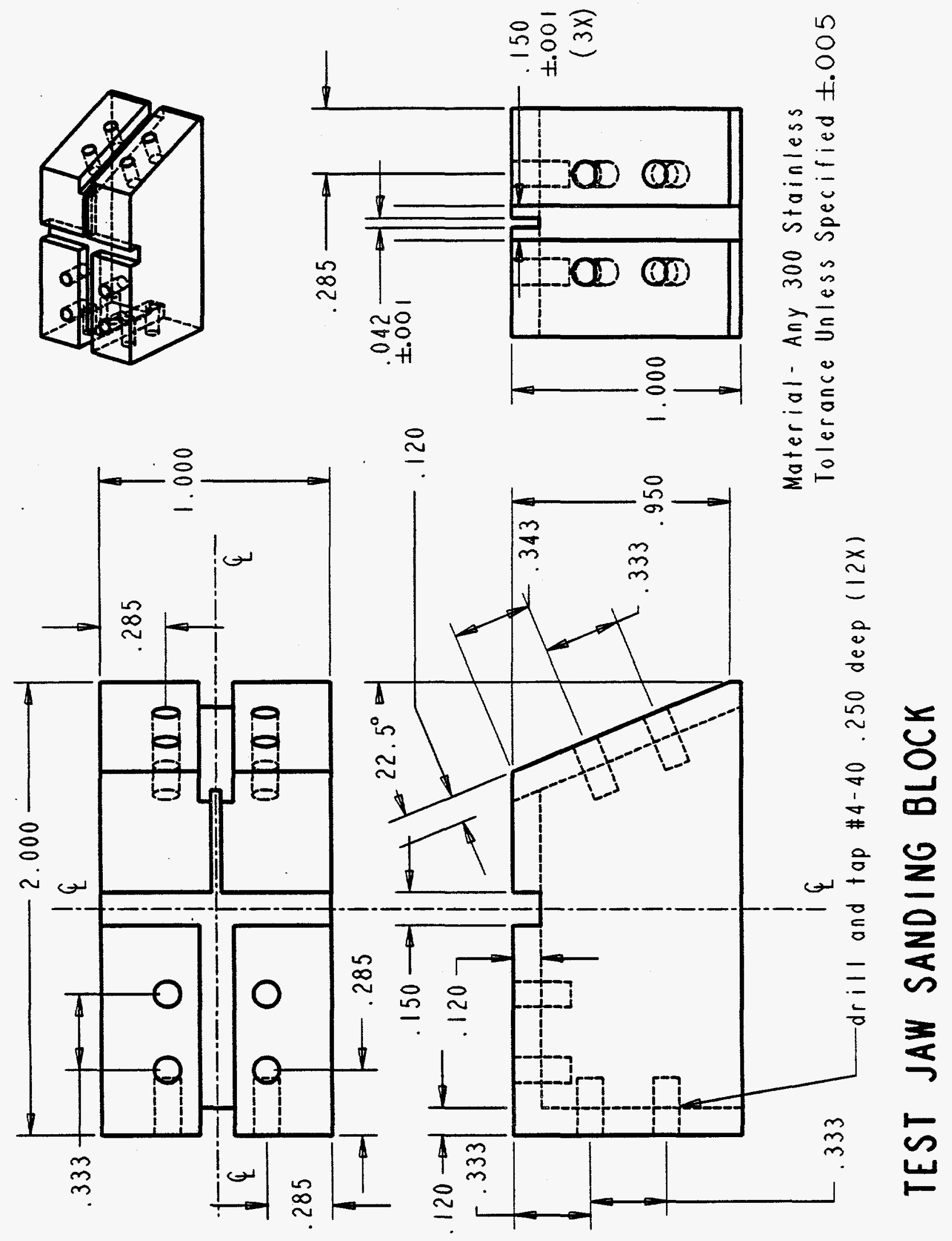




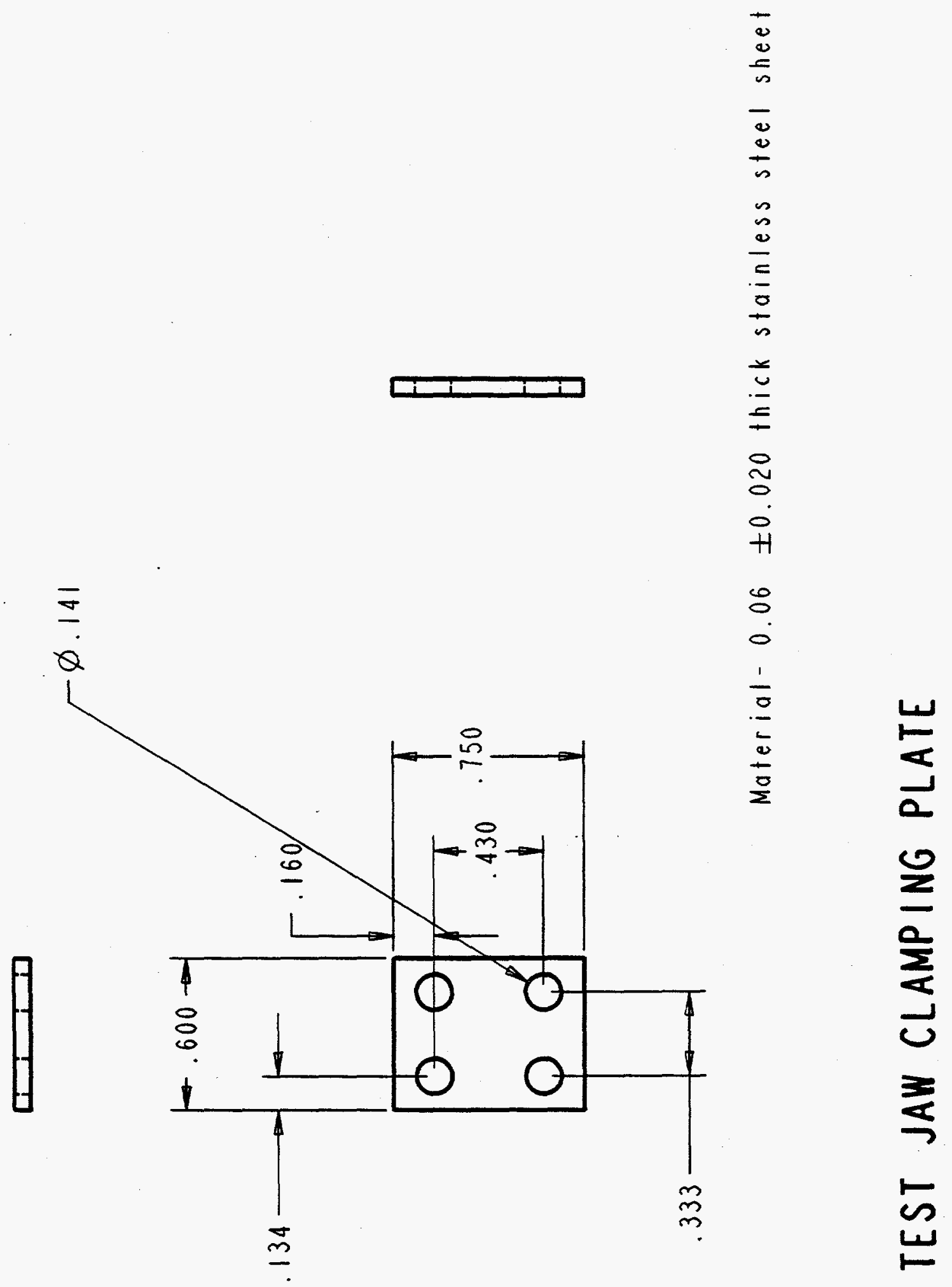

